RESPONSABILIDAD SOCIAL ORIENTADA AL MARKETING GREEN DE MERCADERÍA JUSTO \& BUENO

MARIA ALEJANDRA ACEVEDO RODRÍGUEZ DITSYMAYERLYGUATAQUIRA GUZMÁN

UNIVERSIDAD SANTO TOMAS DE AQUINO FACULTAD DE ADMINISTRACIÓN DE EMPRESAS

LÍNEA DE RESPONSABILIDAD SOCIAL EMPRESARIAL BOGOTÁ 


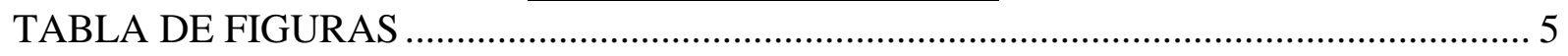

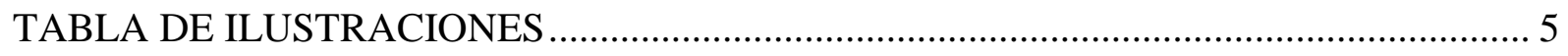

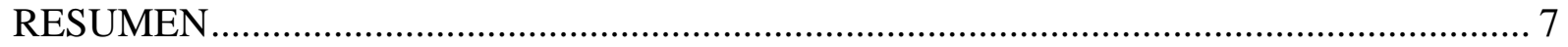

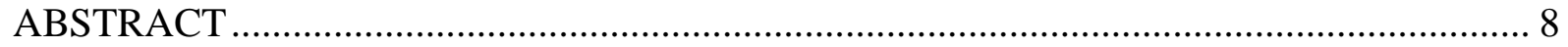

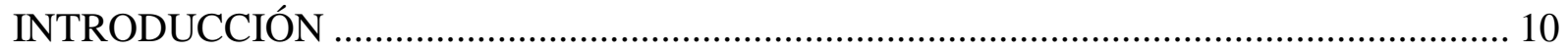

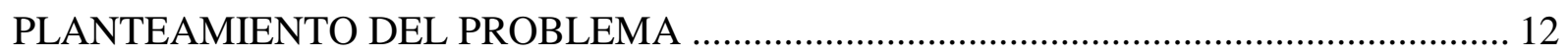

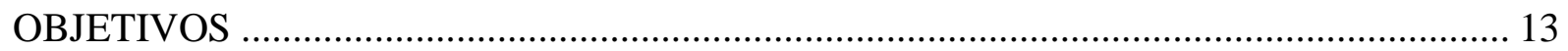

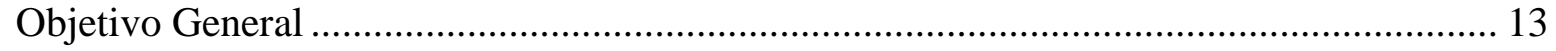

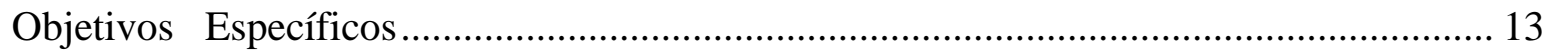

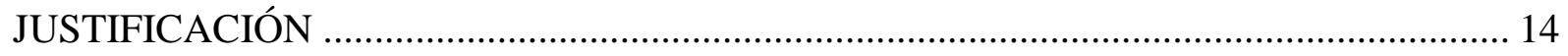

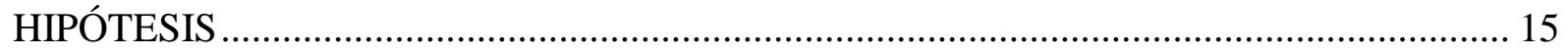

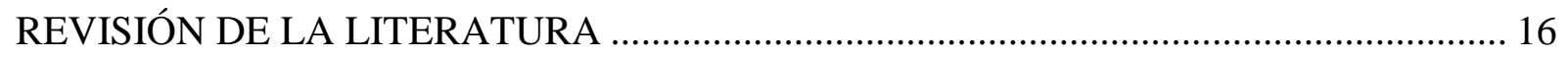

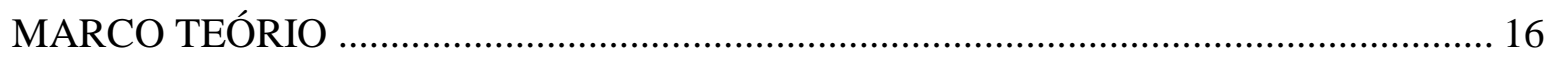

Responsabilidad social desde una visión de cumplimiento ........................................ 17

Responsabilidad social desde una perspectiva de mercadeo: .................................. 18

Responsabilidad social desde una perspectiva corporativa ……………………..... 22

Responsabilidad social desde una perspectiva ética ……........................................ 25

Ética del Consumo

Responsabilidad social desde una perspectiva ambiental ..................................... 28 


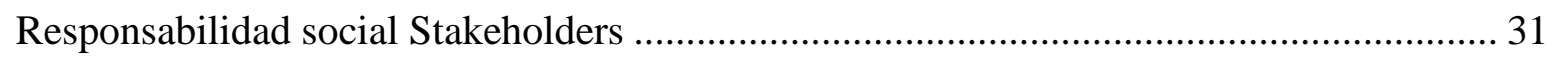

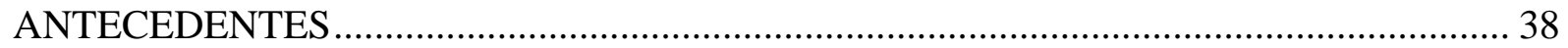

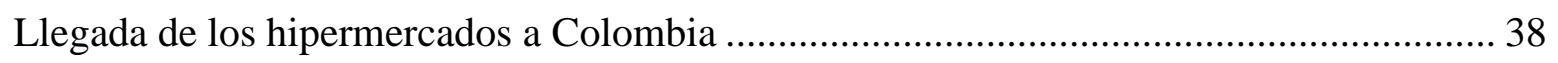

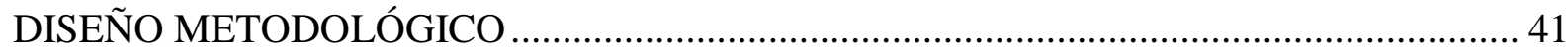

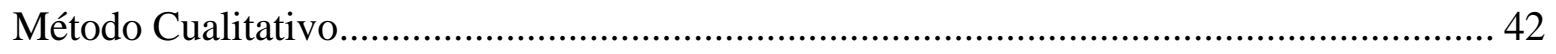

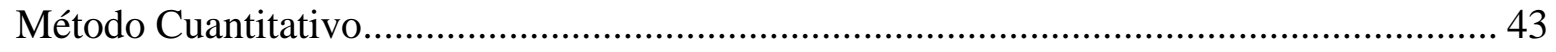

PRIMER INSTRUMENTO: ENTREVISTA DIRIGIDA A ORIENTADOR DE

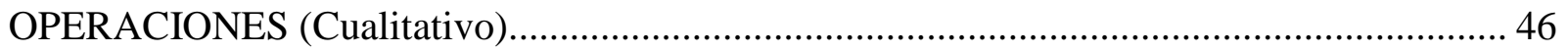

SEGUNDO INTRUMENTOS: ENCUESTA DIRIGIDA A COLABORADORES ............ 47

TERCER INSTRUMENTO: OBSERVACION DIRECTA (método mixto)....................... 47

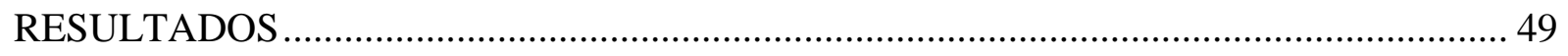

ENCUESTA DIRIGIDA A STAKEHOLDERS (Colaboradores) (Cuantitativo) ................ 49

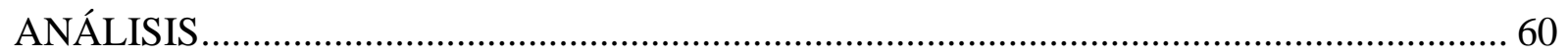

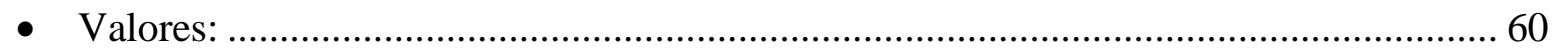

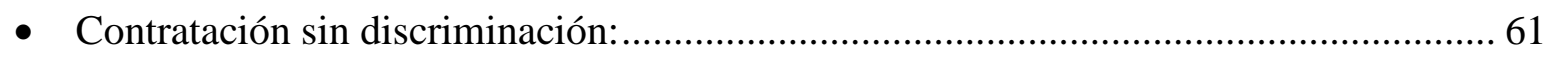

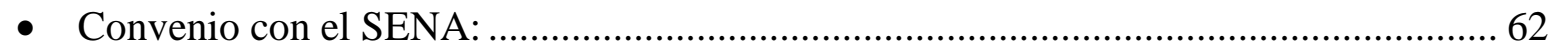

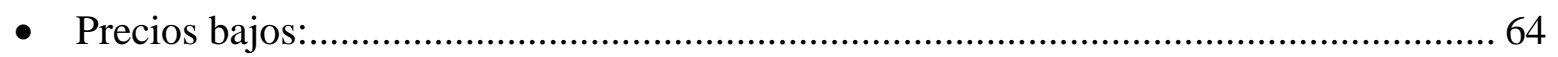

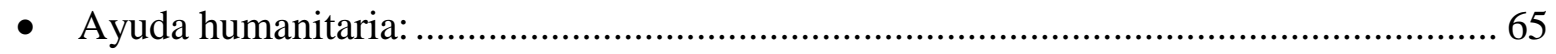

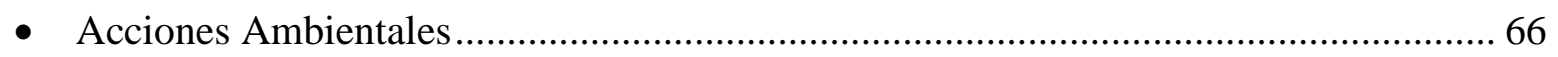




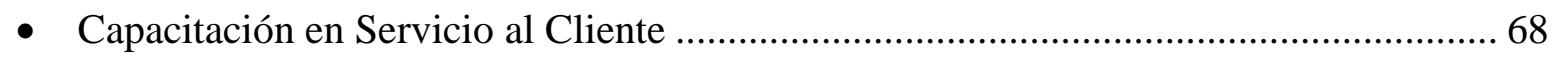

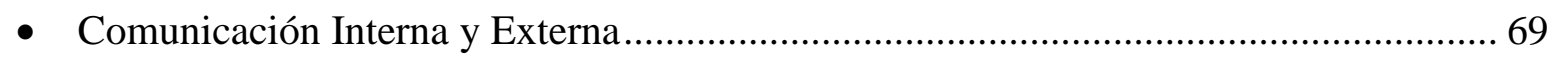

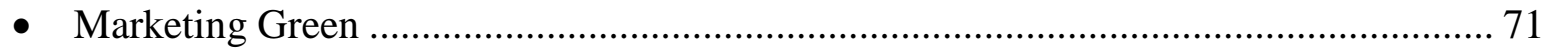

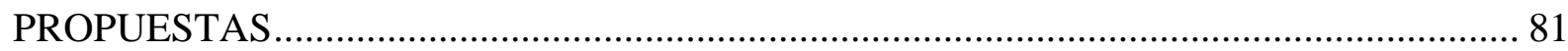

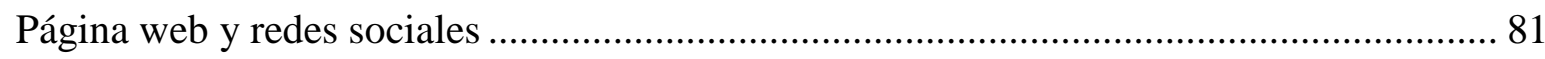

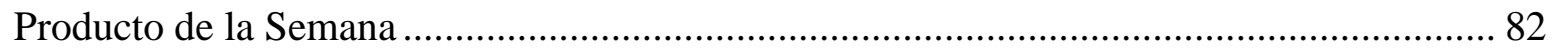

Marketing Sensorial (de acuerdo a las recomendaciones solicitadas por parte de Camilo

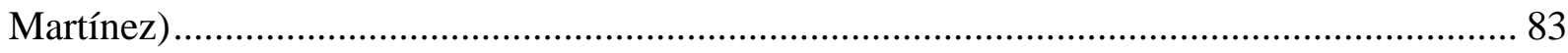

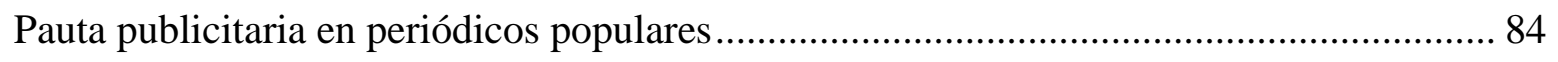

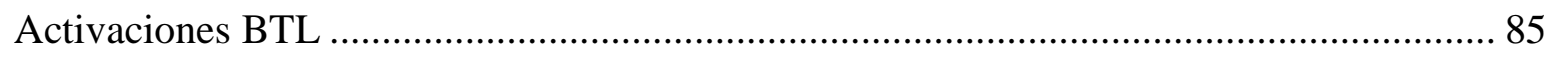

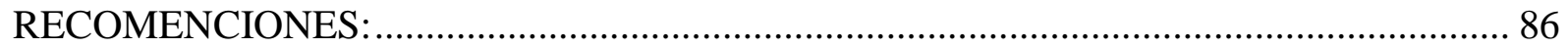

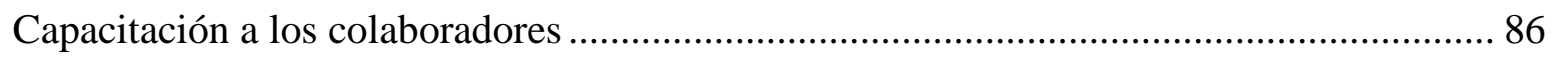

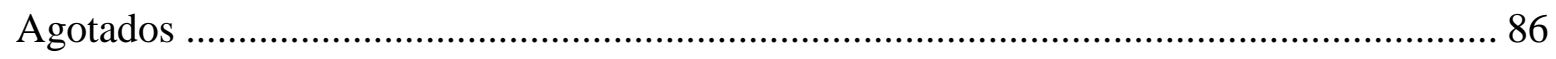

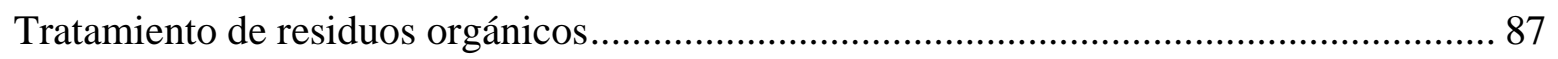

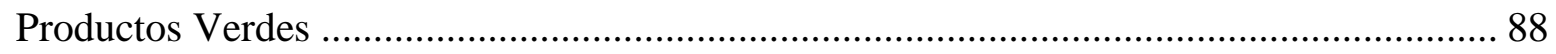

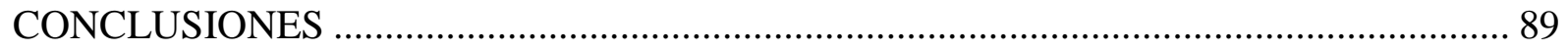

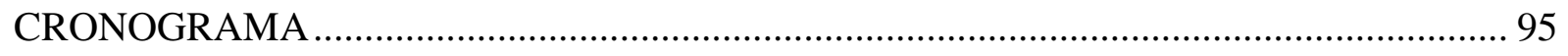

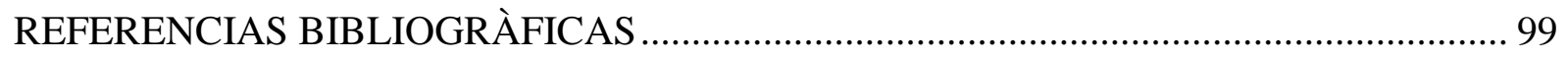

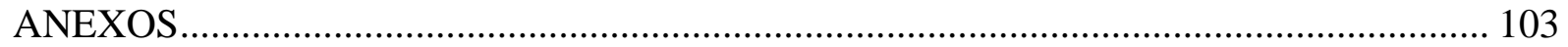




\section{TABLA DE FIGURAS}

TABLA 1PERSPECTIVAS DE RESPONSASIBILIDAD SOCIAL CON RELACIÓN A FUNDAMENTOS TEORICOS 36

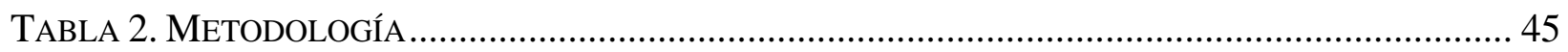

TABLA 3 VALORES REPRESENTATIVOS DE LA EMPRESA SEGÚN COLABORADORES DE ALMACÉN ... 49

TABLA 4CONOCIMIENTO DE LAS ACCIONES SOCIALES POR PARTE DE LOS COLABORADORES DE

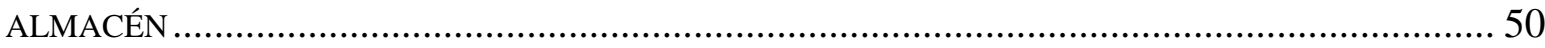

TABLA 5PRINCIPALES ACCIONES SOCIALES SEGÚN COLABORADORES DE ALMACÉN........................ 51

TABLA 6 PERCEPCIÓN DEL COLABORADOR RESPECTO A DIFERENCIA EN EL MERCADO..................... 53

TABLA 7 CANTIDAD DE PRODUCTOS NACIONALES E INTERNACIONALES DE MERCADERÍA JUSTO \&

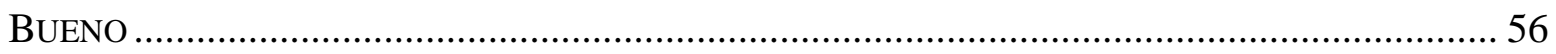

\section{TABLA DE ILUSTRACIONES}

ILUSTRACIÓN 1PIRAMIDE DE RSE SEGÚN CAROLL (1979, PÁG.505) …......................................... 24

ILUSTRACIÓN 2DiAGRAMA DE CONOCIMIENTO DE ACCIONES SOCIALES ......................................... 51

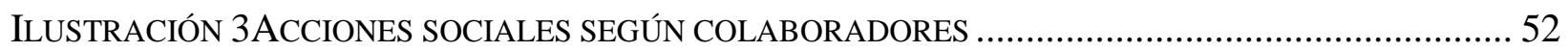

ILUSTRACIÓN 4 CANTIDAD DE PRODUCTOS NACIONALES E INTERNACIONALES EN MERCADERÌA

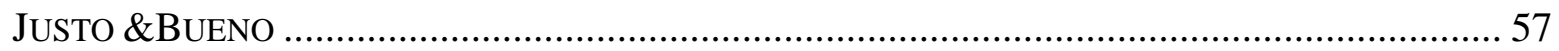

ILUSTRACIÓN 5PORCENTAJE DE PROVEEDORES POR DEPARTAMENTO (COLOMBIA) ........................ 59 


\section{AGRADECIMIENTOS}

Agradecemos a nuestro tutor el Dr. Julián Francisco Figueroa, cuyos aportes fueron fundamentales para el desarrollo de la presente investigación.

Agradecemos a Camilo Martínez y la compañía Justo \& Bueno por su valiosa colaboración y disposición para la construcción de este proyecto.

A la Universidad Santo Tomas de Aquino por brindarnos los cimientos académicos para hacer posible la realización y culminación de este trabajo

A nuestros padres por su formación, dedicación y apoyo.

Esperamos que el presente escrito sea un aporte no solo a nivel empresarial sino académico pues se abre una expectativa investigativa a temas que materializan la teoría enseñada en las aulas de clase a un medio real y palpable. Esperamos sea de agrado del lector y sea una huella para abrirse a un mundo innovador como es el marco de marketing Green. 


\section{RESUMEN}

En este estudio se analizan las acciones sociales y ambientes que realiza la compañía Mercadería Justo \& Bueno, por medio de tres instrumentos los cuales permiten el desarrollo de la presente investigación, el primer instrumento aplicado fue una entrevista semiestructurada dirigida a Camilo Martínez orientador de operaciones de la mini región quince (15) (zona sur), en la cual se indagó acerca de las acciones sociales y ambientales que ejecuta la empresa, con el fin de relacionarlas en orientaciones de responsabilidad social soportadas en distintas perspectivas literarias.

El segundo instrumento empleado en la investigación se basa en una encuesta aplicada a treinta y siete (37) colaboradores en veintidós (22) puntos de venta en la ciudad de Bogotá, en la cual se indagó acerca de los conocimientos corporativos y socio ambientales que efectúa la empresa.

De la misma manera se aplicó una visita de observación a distintos almacenes de la empresa objeto de estudio en la ciudad de Bogotá, con base en los resultados obtenidos se construye una tabla que refleja aspectos como: producto, proveedor, país origen del proveedor, departamento y ciudad, con el fin de corroborar el porcentaje de proveedores nacionales y extranjeros.

Con base en el análisis de resultados, se concluye que la mayoría de acciones sociales y ambientales realizadas por Mercadería Justo \& Bueno se contemplan en un marco legal. Así mismo la empresa apoya industrias nacionales en crecimiento, contribuyendo al mejoramiento de 
la calidad de vida de las personas por medio de precios bajos a productos perecederos y no perecederos que se encuentren al alcance del presupuesto del consumidor.

El objetivo de la presente investigación es establecer propuestas dirigidas a Mercadería Justo $\&$ Bueno desde una perspectiva de responsabilidad social basadas en marketing Green que contribuya al crecimiento de la empresa y al beneficio de la sociedad teniendo en cuenta que el criterio de aplicación de las propuestas sugeridas recae sobre la empresa.

Palabras Clave: Responsabilidad Social, Marketing Green, sostenibilidad, stakeholders, bien común, sociedad.

\section{ABSTRACT}

In this study the social and environmental actions, performed by the company Mercadería Justo \& Bueno are analyzed through three instruments which allow the development of the current research; the first instrument applied was a semistructured survey to Camilo Martinez, operations supervisor of the mini región fifteen (15) (south zone), in which he was asked about the social and environmental actions performed by the company, with the purpose of relate them in orientations of social responsibility supported on different literary perspectives.

The second instrument used in the research is based on a survey applied to thirty-seven collaborators in twenty-two (22) points of sale in the city of Bogota, in which they were asked about the corporative and social environmental knowledge that the company performs.

In the same way it was applied an observation visit to different stores of from the company under study in Bogota, based on the results obtained it is built a table that shows aspects such as: 
product, provider, country of origin of the of the provider, department, and city, with the purpose of corrobotating the percentage of national and foreign providers.

Based on the analysis of results, it is concluded that most of social and environmental actions performed by Mercadería Justo \& Bueno are contemplated on a legal framework, by contributing to the economical development of the country, and so on by supporting growing national industries, and also contributing to the improvement of the quality of life of people through low prices to perishable and non perishable products that within reach of the consumer budget.

The objective of the current research is to establish proposals directed to Mercadería Justo y Bueno from a perspective of social responsibility bases on Green Marketing that consists on contributing to the growing of the company, and to the benefit of the society taking into account that the criteria of application of the suggested proposals fall on the company.

Key words: Social responsibility, Green Marketing, Sustainability, Stakeholders, Common benefit, Society. 


\section{INTRODUCCIÓN}

En Colombia cuando se habla de empresas o microempresas que se encargan de la compra y venta productos de consumo se hace alusión al tema de productividad y rentabilidad, mas no el impacto social del mismo, surgiendo así el interrogante sobre las acciones que se adelantan por parte del sector empresarial para que se materialice la responsabilidad social, lo que motivo el presente estudio.

Para el desarrollo de la investigación se tuvo como sujeto de estudio al almacén Mercadería Justo \& Bueno S.A., almacén minorista perteneciente al sector de negocios denominado retail(en nuestras palabras es una expresión en ingles que hace alusión a la compra de productos al por menor o al detalle) dedicada a la venta de productos perecederos y no perecederos de la canasta familiar colombiana, en el cual se pudo dilucidar elementos necesarios para abordar respuestas propias de la investigación que se dirijan las acciones sociales y ambientales que ofrece la empresa mencionada.

Con la finalidad de analizar las acciones de responsabilidad social y ambiental adelantadas por Mercadería Justo \& Bueno en la ciudad de Bogotá con el fin de relacionarlas con distintas perspectivas literarias de responsabilidad social y ambiental, partiendo de ello se establece un análisis teórico para este trabajo.

A través del análisis que se adelantara en el presente escrito se aporta a mercadería Justo \& Bueno una propuesta en el marco de responsabilidad social,en el cual se contemple los stakeholders como elemento principal para el avance y beneficio organizacional, con el fin de 
obtener una sinergia entre las partes involucradas y un mejoramiento de las acciones establecidas.

Se desarrolla una metodología de carácter mixto compuesta por tres instrumentos, los cuales poseen enfoques cualitativo y cuantitativo. A nivel cuantitativose realizan encuestas las cuales generan resultados que se plasman de forma numérica en los resultados obtenidos y en el análisis cualitativo, se realiza un análisis literario de lo recogido en estos datos para llegar a una propuesta final dirigida a Justo \& Bueno la cual se vería representada en un planteamiento con base en responsabilidad social y Marketing Green. 


\section{PLANTEAMIENTO DEL PROBLEMA}

En la actualidad se han visto reflejados los daños medio ambientales y sociales que el hombre a causado por el egoísmo y falta de interés por el progreso colectivo o también llamado bien común, dejando atrás los principios de sostenibilidad; en consecuencia ahora las empresas han empezado a desarrollar programas o acciones que ayuden a mitigar el impacto medio ambiental y social, con la finalidad de generar un futuro más sostenible y equilibrado a las generaciones venideras. Así mismo las compañías han creado herramientas de negocio que les permite generar no solo beneficios empresariales sino también sociales, beneficiándose mutuamente.

Con base en lo anterior han existido distintas perspectivas de responsabilidad social, implementando en las corporaciones acciones trazadas para facilitar la comercialización de un producto o servicio, con el objetivo de satisfacer las necesidades del consumidor.

Las empresas tienden a confundir las acciones sociales o ambientales con obligaciones legales debido al desconocimiento de estas. En esta investigación se busca analizar las diferentes acciones sociales y ambientales que realiza la empresa objeto de estudio para contrastar en un marco de responsabilidad social, teniendo en cuenta las distintas perspectivas literarias, lo cual nos lleva a la pregunta de investigación:

¿Las acciones que realiza Mercadería Justo \& Bueno en la ciudad de Bogotá se encuentra dentro de un marco de responsabilidad social? 


\section{OBJETIVOS}

\section{Objetivo General}

Analizar las acciones de carácter social y ambiental de Mercadería Justo \& Bueno de acuerdo a distintas perspectivas de responsabilidad social para generar una propuesta a partir del marketing Green enfocado a la empresa Justo \& Bueno en la ciudad de Bogotá.

\section{Objetivos Específicos}

- Identificar las acciones de carácter social y ambiental en Mercaderías Justo y Bueno para tener conocimiento del estado de la compañía.

- Investigar diferentes perspectivasde responsabilidad social para estructurar un diagrama en el cual se relacione las acciones sociales y ambientales que realiza Mercadería Justo \& Bueno.

- Relacionar las acciones sociales y ambientales de la empresa con los diferentes enfoques de RSE vinculado al Green marketing para elaborar una propuesta a Mercadería Justo \& Bueno. 


\section{JUSTIFICACIÓN}

La presente investigación se realiza con base en las acciones sociales y ambientales que ejecutadas por la empresa Mercadería Justo \& Bueno alineándolas en un marco de responsabilidad social orientado al Green marketing (en nuestras palabras entendido como la responsabilidad ambiental de las empresas partiendo del mercadeo de las mismas). Las acciones son factores importantes para cualquier organización; ello lo sustenta (Murray \& Montanari, 1986) puesto que afirman que las acciones de responsabilidad social empresarial sirven como un mecanismo de posicionamiento de marca, siempre y cuando genere un beneficio de imagen, respeto y sentido de pertenencia con la sociedad, es decir que la aplicación de este puede contribuir a un crecimiento de la empresa y un aporte a la sociedad, creando un bien común.

La responsabilidad social empresarial se encuentra relacionada con la gestión de las operaciones que ejecuta la empresa, la cual procura que estas sean sostenibles ${ }^{1}$ en aspectos ambientales y sociales involucrando el interés de los stakeholders ${ }^{2}$ con el fin de contribuir a la preservación medioambiental de las futuras generaciones. Debido a esto la responsabilidad de la sostenibilidad y la conservación de los recursos recaen sobre la sociedad y principalmente las empresas dado a que sobre estas recae el manejo de los recursos, así mismo influye sobre la toma decisión de compra de los consumidores ya sea positiva o negativamente.

\footnotetext{
${ }^{1}$ Sostenible:

Especialmente en ecología y economía, que se puede mantener durante largo tiempo sin agotar los recursos o c ausar grave daño al medio ambiente. (Española, 2017)

${ }^{2}$ Stakeholders: Grupo de personas que tiene un particular interés en nuestra empresa o que se ven afectados por las operaciones que ésta realiza. (Prieto, 2015)
} 
De esta manera el consumo responsable juega un papel importante debido a que los consumidores poseen influencia en la demanda de bienes y servicios; por lo tanto, si se genera una concientización de los recursos por medio de prácticas ambientales y sociales las cuales se vean reflejadas en la decisión de compra del consumidor se generará un beneficio a la empresa, sociedad y al medio ambiente.

\section{HIPÓTESIS}

El proceso investigativo que se plantea en el proyecto implica abordar distintas perspectivas literarias y el análisis de acciones sociales y ambientales de la empresa para crear una propuesta de responsabilidad social enfocada a marketing Green para beneficio de la empresa y la sociedad.

"Mercadería Justo \& Bueno aplica acciones sociales y ambientales dentro de un marco de responsabilidad social que le generan oportunidades de mercado"

"Mercadería Justo \& Bueno implementa estrategias de marketing Green en los productos que ofrece al mercado" 


\section{REVISIÓN DE LA LITERATURA}

\section{MARCO TEÓRIO}

La responsabilidad social y ambiental ha sido un tema de debate a lo largo de los años, debido al surgimiento de una conciencia social con el fin de mitigar el impacto negativo de la actividad empresarial motivo por el cual a continuación, se presentaran las distintas teorías de la RSE (Responsabilidad Social Empresarial) desde diferentes autores y como ha trascendido en la historia, las teorías que se derivan de ella, sus beneficios, como ha revolucionado el sector empresarial convirtiéndola en una ventaja competitiva.

El primer autor que habló del concepto de responsabilidad social fue Clack según Rivera \& Malaver ( 2011)a mediados de 1916 definió la responsabilidad social desde una percepción dirigida a los gerentes con respecto a la sociedad, firmando: "los gerentes debían aceptar sus responsabilidades sociales", (pág. 10), es decir no solo pensar en términos monetarios sino en dejar algún beneficio a la sociedad, ya que los gerentes debían de poseer una mentalidad humanística hacia la comunidad con la finalidad de generar valor y beneficio mutuo.

"Los hombres de negocios tienen la obligación de perseguir líneas de acción que son deseables en términos de objetivos y valores de la sociedad" según (Bowen, 1953, pág. 50), para este autor la responsabilidad social empresarial se basa en la existencia de un contrato social el cual se entiende como un acuerdo implícito entre la sociedad y la empresa donde se adquieren obligaciones tales como: el bienestar de los stakeholders, mitigar las consecuencias negativas del impacto medio ambiental y propiciar el respeto mutuo para garantizar el compromiso del "bien 
común"3 este último término por parte del autor comento resalta que es utilizado por Platón, Aristóteles y Cicerón los cuales hicieron referencia a un marco de relación entre los intereses individuales y de la comunidad, considerado como el bien común, término que para fines de la presente investigación es todo lo material e inmaterial que puede ser utilizado por la comunidad en beneficio de esta, es decir la sociedad siempre busca un bien general sobre el bien particular, que beneficie a todos, contribuyendo al desarrollo humano alcanzando beneficios integrales.

No obstante el bien común no es la suma de los interés particulares ni un equilibrio entre poderes de grupos, un bien es particular cuando lo posee y disfruta una persona con exclusión de los demás ; es común cuando es comunicable a todos o participado por todos, por ejemplo la contribución económica en el pago de impuestos. (Argandoña, La teoria d elos stakeholders y el bien comùn, 1998, págs. 5-7)

En un enfoque organizacional las empresas están obligadas a cooperar con la sociedad y no solo con maximizar el bien económico a los socios debido a que son un ente importante, el cual puede cambiar el futuro de una sociedad brindando oportunidades, valorando capacidades, generando bienes y servicios útiles y sostenibles.

\section{Responsabilidad social desde una visión de cumplimiento}

Según Kenneth (1971) “La responsabilidad social es el interés sensato, el objetivo es el bienestar de la sociedad que restringe el comportamiento individual y empresarial de actividades cuyo fin es destructivo por rentables que sean al principio", para este autor la responsabilidad social empresarial se limita a ser justo con los bienes y servicios que ofrece, pagar impuestos, 
cumplir con obligaciones legales y ser éticamente correctos, factores que deben ser cumplidos por todas las empresas.

Así mismo al respecto Friedman(1973), en su obra "The social responsability of bussiness to increaseitprofits" determina que la RSE no hace parte de una obligación de la organización, ni un beneficio para ella, ya que el único compromiso es maximizar la riqueza para sus socios, debido a que se encuentra dentro de un marco legal, en el cual las partes involucradas establecen acuerdos que deben de cumplirse; las acciones de responsabilidad social las deben ejercer los individuos involucrados en la empresa; además la participación en acciones de responsabilidad social corporativa es una consecuencia de un conflicto interno de la empresa, debido a que estas acciones son un medio de promover agendas sociales, carreras políticas a costa de la organización.

Bajo ese mismo concepto de cumplimiento Wood (2002) plantea un cambio en la mirada de la responsabilidad social de la empresa tratándolo como un ciudadano corporativo, el cual posee derechos y deberes como cualquier individuo de la sociedad. Por tanto la RSE es obligatoria en el sentido del pago de impuestos y aplicación de las leyes.

\section{Responsabilidad social desde una perspectiva de mercadeo:}

Las acciones de responsabilidad social empresarial sirven como un mecanismo de posicionamiento de marca, siempre y cuando genere un beneficio de imagen, respeto y sentido de pertenencia con la sociedad. La aplicación de estas acciones las ejecuta el área de marketing, la cual capta los diversos impactos en el mercado y genera estrategias para la ejecución de estas con el fin de posicionar la empresa en el mercado.(Murray \& Montanari, 1986, pág. 104) 
Además se plantean modelos para la gestión de responsabilidad social en las empresas, estos se clasifican en dos visiones: la primera, hace alusión a actividades aplicadas a la responsabilidad social empresarial y la segunda, se refiere a estrategias orientadas a los procesos y a su ejecución; así mismo las políticas corporativas y el ambiente empresarial en su conjunto son vistas como un producto intangible de la organización, es decir los valores que la compañía inculca a sus colaboradores son reflejados en el producto o servicio que se ofrece, lo que traerá como consecuencia el ascenso o descenso de la reputación de la misma.

En consecuencia a lo anterior, el prestigio de la empresa ayuda a aumentar sus actividades y hace que se incremente el marco de preferencia por parte de sus clientes debido a las acciones de responsabilidad social que la empresa ejerza. Igualmente establecieron un modelo, denominado como "Marketing ApproachtoResponsive Management” (MARM), el cual se establece basándose en generar un valor agregado a largo plazo con acciones sociales desde una perspectiva de marketing.

De lo anterior se observa la influencia de una conciencia social y ambiental del mercado a través del marketing Greenpor medio de estrategias de lo cual se deriva del consumo responsable, este concepto se origina a finales de los años sesenta, por la preocupación de las empresas para crear acciones que contribuyan a la conservación del medio ambiente y la sociedad (Iguarin\& Cavazos, 2015). Siendo este (marketing green) una serie de acciones corporativas, estratégicas y publicitarias que buscan atraer a los consumidores por medio de publicidad alusiva al medio ambiente y la sociedad.

El marketing Green se define como: 
El esfuerzo por una empresa para diseñar, promover, precio y distribución de productos en una de manera que promueve la protección del medio ambiente Además, si un ente económico aplica este concepto maximiza los beneficios, reducen la contaminación del medio ambiente, conservar los recursos naturales, protegen el medio ambiente y obtienen una ventaja competitiva. (Iguarin\& Cavazos, 2015, pág. 35)

El marketing Green sirve como un mecanismo para cuidar el ambiente y que las empresas que son quienes más lo desgastan hagan algo por minimizar este impacto y ayudar a consérvalo, el marketing verde es un fenómeno que le ha gustado a muchas personas y por esta razón interviene en la decisión de compra ya que la mayoría de consumidores prefieren comprar un producto cuya marca o empresa sea amigable con el medio ambiente y la sociedad o que tenga ciertos beneficios para minimizar impactos negativos a la sociedad o el medio ambiente (Pizzinatto\&Giuliani, 2015, pág. 80).

La influencia que el medio ambiente ejerce actualmente es muy fuerte, es por ello que las empresas les interesa ir a la vanguardia y exponer publicidad que contengan frases alusivas al medio ambiente con el fin de influir en la decisión de compra del consumidor aspecto propio de Green Marketing, frente a lo cual se da la existencia del Green Washingsegún Hallama, Montllò, Rofas Tudela, \&Ciutat Vendrell (2011)el cual lo definen de manera textual que señala:

"El uso por parte de un organismo de una ampliación selectiva de la información medioambiental positiva, que produce una imagen distorsionada y tendenciosa a favor de los aspectos "verdes", interpretados como positivos por los consumidores".

Así mismo se hace necesario traer a colación la siguiente definición: "El marketing ecológico ayudará a nuestra sociedad a adaptarse a los límites ecológicos consumiendo productos "más 
respetuosos", o si por el contrario el Green washing asociado mantendrá a la sociedad en una ilusión de un "gran giro verde", sin que en realidad sea asi"”.

De lo anterior, se puede deducir que las empresas actúan de una forma positiva hacia la sociedad al implementar acciones de marketing Green creando un cambio positivo en los consumidores, influyendo así en su voluntad a través de la compra, no obstante este fenómeno debe tener un control debido a que se puede incurrir en publicidad engañosa, sumado a que no se esten generando acciones que minimicen los impactos negativos al ambiente y la sociedad, siendo necesario proteger al consumidor surgiendo con ello la figura de Green washing que identifica cuando se incurre en ello.

Por otra parte se encuentra el Green washing, este fenómeno se presenta cuando las empresas se valen del gusto de los consumidores por productos verdes y crean campañas publicitarias engañando al consumidor y haciéndolo creer que están creando acciones para ayudar a la conservación del ambiente pero no es cierto y solo lo hacen por crear una ventaja competitiva, llamar la atención del consumidor y obtener más ganancias, varias empresas que si tienen estas acciones "verdes" lo hacen saber a los consumidores para crear un valor agregado y cobrar un poco más por esto por lo tanto los clientes deben tener en cuenta los atributos de un producto o servicio que cuenta con responsabilidad social para que no sea comparado con un producto similar pero que no cuente con estos atributos, por eso la publicidad es un factor importante a la hora de diferenciar productos en el mercado ya que informa al consumidor acerca de las características y atributos diferenciadores del producto o servicio, los productos que cuentan con este factor diferenciador tendrán un mayor precio de venta en el mercado. 
Para Kramer \& Porter (2006) generar acciones de responsabilidad social forman parte del posicionamiento estratégico, en el cual la empresa ofrece productos o servicios diferenciadores creando un ventaja competitiva, atendiendo necesidades más específicas de los clientes. (pág. 4)

Existen cuatro argumentos que justifican la RSE:

- La obligación moral, en la cual si la empresa invierte capital y realiza negociaciones con la finalidad de realizar una contribución al desarrollo económico regional.

- Sustentabilidad, las empresas desarrollan actividades a largo plazo que no afecten el bienestar de la sociedad, teniendo en cuenta tres aspectos principales: económico, social y medioambiental.

- Licencia para operar, tener en cuenta las opiniones de los grupos de interés preverá que estos se encuentren en desacuerdo con las decisiones organizaciones.

\section{Responsabilidad social desde una perspectiva corporativa}

Por responsabilidad social corporativa, según De la cuesta (2013) la define como el "reconocimiento e integración en sus operaciones por parte de las empresas, preocupaciones sociales y medioambientales, dando lugar a prácticas corporativas que satisfagan dichas preocupaciones y configuren sus relaciones con sus interlocutores” (pág. 15) Así mismo, indica dos pilares fundamentales en los que se basa la RSC, el primero se integra a partir de los grupos de interés o stakeholders, el segundo tiene como objetivo que la compañía sea generadora de valor para todos los participantes evaluando y analizando aspectos positivos y negativos de esta.

La responsabilidad social corporativa no solo puede llegar a beneficiar a la sociedad sino también a la misma organización, esto lo afirma Bloomstrom(1975) quien considera que: "la responsabilidad social es la responsabilidad gerencial que toma acción para proteger y mejorar 
tanto el bienestar de la sociedad y los intereses de la organización” (pàg.35); ello se ha convertido en una ventaja competitiva definida como la diferenciación que una empresa logra mantener de cara a sus competidores, la cual permite crear o entregar un valor único a sus clientes y que puede generar mayores ingresos (Porter, 2007).

No obstante, Porter \& Kramer (2006) plantean el dilema de las empresas en invertir en responsabilidad social corporativa ya que se encuentran dos visiones: una visión a corto plazo, la cual se refleja como un gasto en los estados financieros, la segunda visión a largo plazo, es una inversión que traería beneficios intangibles a la organización como marca o reputación y beneficios para la sociedad basándose en una filantropía estratégica beneficiándose ambas partes. (pág. 4)

Por consiguiente Caroll (1979) menciona la existencia de una unificación de los conceptos en materia de responsabilidad social el cual lo denomina como modelo de desempeño social, por ende propone tres aspectos: una definición básica de responsabilidad social, enumeración de los asuntos por los cuáles una responsabilidad social existe y una especificación de la filosofía de respuesta.

- Responsabilidades económicas, la empresa debe producir bienes y servicios que la sociedad necesite aumentando las ganancias para la empresa.

- Responsabilidades legales, la empresa debe cumplir con las reglas y normas que la región dispone y lograr sus objetivos económicos.

- Responsabilidades discrecionales, realizar contribuciones sociales que no tengan retribuciones para la empresa y no sean esperadas por la comunidad. 
Este autor Construye a partir de los componentes de la RS, la Pirámide de la Responsabilidad Social Corporativa y el principio sobre el que descansa cada uno de estos componentes. La base de la pirámide es el componente económico.

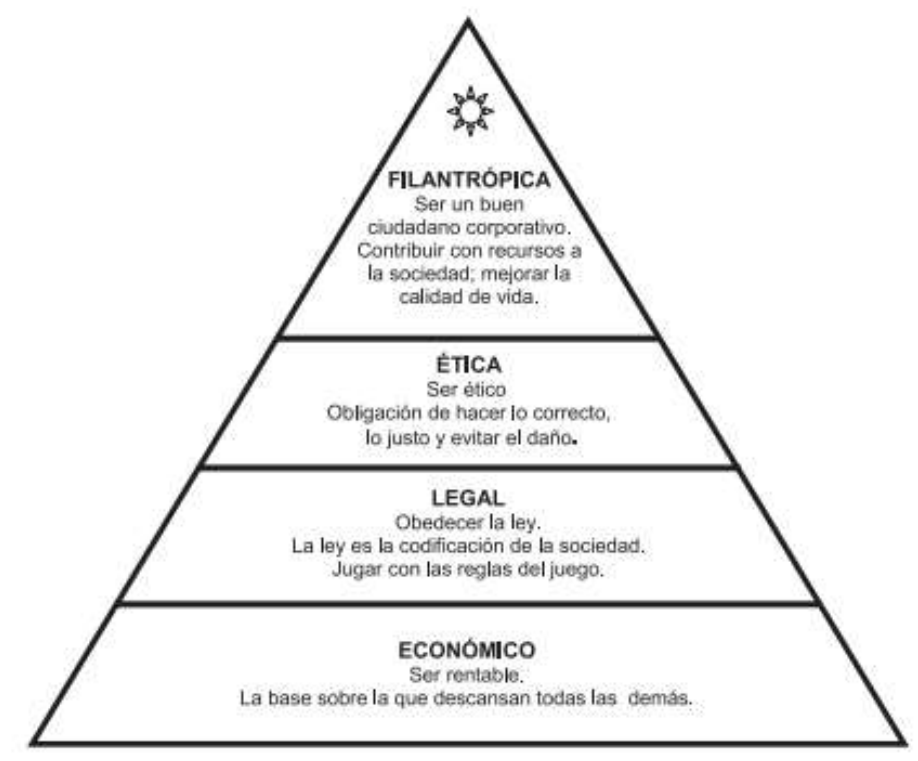

Ilustración 1Piramide de RSE según Caroll (1979, Pág.505)

En la ilustración lel autor menciona a la filantropía (que está ubicada en la parte superior de la gráfica) como las acciones que realiza buen ciudadano para contribuir a la sociedad y generar un "bien común" de manera voluntaria que beneficie y contribuya a la sociedad.

En consecuencia a lo anterior, se hace necesario de manera concreta una breve explicación de cada nivel que compone la pirámide de RSE objeto de análisis conforme a la información que contiene la gráfica objeto de estudio como se señala a continuación: 
Ética:(la cual está ubicada en la parte superior de la gráfica seguida de filantropía) Hace referencia a la solución pacífica de los conflictos, actuando de manera correcta y razonable para obtener como resultado la reducción de daños de los grupos de interés.

Legal: (el cual está ubicado en la parte inferior de la gráfica seguido de ética): Obedece y respeta las normas y acuerdos establecidos, es decir el cumplimiento reglamentario. Por último la base de esta pirámide (ubicado en la parte inferior de la gráfica seguido de legal).

Económico: Se constituye como la producción de bienes y servicios que los consumidores necesitan y desean, en compensación por la entrega de estos bienes la empresa debe tener una ganancia.

Filantrópico: Este se refiere a ser un ciudadano que contribuye con recursos a la sociedad y mejora la calidad de vida, se encuentra en el nivel más alto.

\section{Responsabilidad social desde una perspectiva ética}

(Jones, 1980, pág. 59) plantea que es necesario entablar políticas públicas de responsabilidad social a las empresas, delimitando detalladamente acciones empresariales irresponsables creando compromisos mínimos que beneficien la sociedad, es decir las compañías cumplen con los parámetros mínimos que establece la ley y estas lo consideran como "acciones socialmente responsables", por lo tanto se debe buscar parámetros de incentivos que lleve la empresa a tener más acciones responsables que beneficien a la sociedad.

Del mismo modo, propone un modelo que integra lateoría económica y ética en el cual concluye que las empresas que basan sus negociaciones en la confianza tiene un compromiso de 
conducta ética el cual les brinda una ventaja competitiva y desarrollan relaciones duraderas y productivas.

\section{Ética del Consumo}

Por otra parte según (Cortina, Por una ética de Consumo- la ciudadanía del consumidor en un mundo global, 2002) la autora Adela Cortina propone en su obra por una ética del consumo que “de nuestras formas de consumo depende la sostenibilidad del medio ambiente".

Partiendo de ello realiza un análisis a cerca de la soberanía del consumidor, la dictadura del consumidor, los consumidores constituyen la vanguardia de la historia.

- soberanía del consumidor, Juan Torres (2001) planteada por Adam Smith, la soberanía es establecida en el momento en el cual el consumidor elige un producto teniendo conocimiento de las consecuencias medio ambientales; Cortina determina la ventaja de que los clientes si poseen una cierta libertad de decidir ya que no se encuentran totalmente determinados a elegir un determinado producto, por otra parte esta teoría posee la falencia de que si se enfoca esta soberanía en el capitalismo se encuentra un enfoque diferente, debido a que si un individuo alguna necesidad, la cubre porque tiene el dinero suficiente para autosatisfacerse y quién no tenga esa necesidad entonces no es una necesidad real es una motivación, creencia social o hábito inculcado.

- La dictadura del productor: Galbraith (1958) Son los productores quienes deciden que ofrecer a los consumidores, le crean la "necesidad" a partir dela publicidad crean hábitos de consumo, es decir el cliente depende de lo bienes o servicios que producen el productor. Cortina afirma que el marketing genera publicidad que permite crear una necesidad falsa, con lo cual el 
productor posee cierto poder, a la misma vez critica esta postura argumentando que no se establece un mecanismo de consumo.

-Los consumidores constituimos una vanguardia de la historia: En la obra de Miller ( 1987) propone que los consumidores pueden llevar la iniciativa a cerca de los productos que se comercializa, a causa de que los vendedores informan al departamento de marketing y a los anunciantes de corrientes de demanda con lo cual se define que se produce por lo tanto los productores trataran de responder a la demanda de los consumidores. La autora comenta que los consumidores no forman una clase, se organizan por diversos estilos de vida en consecuencia no se podría llevar a cabo esta transformación de empoderamiento del consumidor al productor.

Por lo tanto Adela Cortina propone que para llevar a cabo una ética del consumidor, debe de existir primeramente una ciudadanía, este concepto entendido como aquel ser humano que es su propio señor junto con sus iguales "aquel que hace su vida con otros, pero es autónomo, no es esclavo o vasallo"

Además plantea que el consumo debe de ser justo, por medio de la creación de nuevos estilos de vida de consumo en los cuales las personas le permitan encontrarse en una manera cómoda que no sea costosa, para ello se debe de plantear un Pacto Global sobre el Consumo para acordar la distribución de los bienes de consumo.

En última instancia sugiere que debe de existir la corresponsabilidad, es decir la existencia de una responsabilidad compartida entre el consumidor y el productor, en la cual el consumidor debe de cambiar los hábitos de consumo y el productor por medio del marketing promocione productos que ayuden a contribuir en la mitigación el impacto medioambiental, informando al consumidor acerca de las consecuencias que conlleve el consumo de ciertos productos. 
Por son siguiente Adela Cortina pronuncia que la felicidad se confunde con el éxito con los bienes de consumo; La felicidad consiste en las relaciones de afecto gratificantes (deportes, música, familia)

\section{Responsabilidad social desde una perspectiva ambiental}

Según Trujillo \& Bedolla (2006) la sociedad en el ámbito mundial ha empezado a ejercer presión a las organizaciones para crear conciencia de las consecuencias ambientales ya que estas repercuten en los intereses de los accionistas y la sociedad creando una preocupación de satisfacer los grupos de interés que se traduce en la incorporación de acciones en las cuales prevalece las necesidades de los grupos de interés.(pág. 25) La preocupación por el medio ambiente y los recursos ha llevado a preguntarse sobre el daño que causan los residuos contaminantes ya que a causa de ello los recursos se ven afectados, por lo tanto las empresas tienen que ser conscientes de que efectos causan y como tratarlos.

${ }^{4}$ Según Nebel \& Wright(1999) el desarrollo sostenible es un sistema o proceso ya que puede continuar indefinidamente sin agotar nada de los recursos materiales o energéticos que necesita para funcionar por lo cual las empresas deben generar actividades sostenibles que no perjudiquen los ecosistemas o el ambiente. (pág. 20)

\footnotetext{
${ }^{4}$ Según (Cabildo, y otros, 2008) residuo es todo material inútil o no deseado, originado por la actividad humana y empresarial en cualquier estado físico que puede ser liberado a la atmósfera, agua o suelo. En países desarrollados se produce basura en gran cantidad y en los países en vía de desarrollo volverían a ser utilizadas o seguirían siendo bienes valiosos, agregando que muchos residuos se pueden reciclar si se dispone de la tecnología y los procesos adecuados, una buena gestión de estos consiste en no perder el valor económico y la utilidad que puedan tener muchos de estos y usarlos en vez descartarlos. Las amenazas al medio ambiente son muchas pero una de las más graves es el aumento desmesurado de los residuos los cuales provocan malos olores, destrucción del paisaje y de los recursos naturales.
} 


\section{Sostenibilidad}

Al hablar de sostenibilidad hace necesario traer a colación el termino conceptual de desarrollo sostenible, trayendo a colación la definición dada por la Comisión Mundial del Medio Ambiente y Desarrollo a través de uno de sus informes señala (Development, 1987):

“El desarrollo sostenible es un desarrollo que satisface las necesidades del presente sin comprometer la capacidad de las generaciones futuras para satisfacer sus propias necesidades".

De lo anterior se puede establecer de manera clara a que a través del desarrollo sostenible se pretende conservar los recursos ambientales con el fin de no perjudicar a futuras generaciones por los escases de los mismos.

Según Marquardt, Marqua Historia de la sostenibilidad. Un concepto medioambiental en la historia de Europa Central(2006)con el surgimiento de la responsabilidad social se origina el concepto de consumo sostenible, el cual surge como una preocupación medio ambiental en el siglo XII en Europa, por el desasosiego de la explotación de bosques y pastizales así mismo en el siglo X Europa se constituía territorialmente en su gran totalidad de zonas boscosas, tres siglos después se convirtió en un paisaje agrícola, debido a la desforestación no controlada en "la pequeña edad de hielo".

Debido a la preliminar situación, se presentó una baja significativa en la temperatura acompañada de una grave crisis ambiental trajo consigo restricciones para la construcción de edificaciones, caza de animales y pastoreo, al mismo tiempo se presentó la peste negra la cual 
trajo como consecuencia la crisis ambiental y la muerte de gran parte de la sociedad Europea, por ello se tomaron medidas de abastecimiento como: el control de la madera, división de pastizales y bosques, regulación de la caza de alimentos, esto respondió a los cinco principios de la sostenibilidad los cuales son:

- La descentralización política en entidades locales

- Anticiparse a la máxima capacidad del sistema local natural,

- Control sistemático cuantitativo del consumo medio ambiental,

- La prioridad del interés de la comunidad frente al interés individual, optimización de la utilidad de la tierra.

Frente a lo anterior Marquardt, Marqua Historia de la sostenibilidad. Un concepto medioambiental en la historia de Europa Central (2006), expresa que:

"Una sociedad no debe usar más recursos de los que renueva, para que la siguiente generación pueda obtener las mismas oportunidades de acceso a estos recursos. El límite de uso de estos últimos para el desarrollo de las actividades de las sociedades y de sus economías depende de la capacidad y reproductividad intergeneracional de sus ecosistemas".

\section{Consumo Responsable: responsabilidad social y consumo responsable}

El consumo responsable según(Murgado, 2016)se remonta a los años sesenta, respondiendo a la preocupación de la sociedad por consumir bienes y servicios que no pongan en riesgo la salud de las personas, que no causen un daños significativo al medio ambiente, que impliquen maltrato de animales, que afecten a otros países y que vengan de empresas honestas y éticamente correctas, (Roberts, 1993) define el consumidor responsable como "Aquel que compra productos y servicios que se percibe tienen un efecto positivo o menos negativo sobre el ambiente, o que favorece a las empresas que intentan generar un cambio social positivo". 
(Gonçalves, 2012)Define al RSE ( Responsabilidad Social Empresarial) del nuevo milenio como "aquel que ve en sus actos de consumo la oportunidad de preservar el medio ambiente y la calidad de vida en sociedad bajo un contexto particular y local", es decir, el consumo responsable recae sobre el consumidor ya que este decide aceptar o rechazar productos o servicios que contribuyan al daño o preservación del medio ambiente y a la sostenibilidad, ello se ve reflejado en la preferencia de compra de los clientes, cuyo factor incide en la producción de los bienes y servicios de las empresas sostenibles.

El consumo responsable según Murgado (2016) cuenta con cuatro dimensiones importantes, la dimensión ética, que hace referencia a las acciones empresariales ética y moralmente correctas siendo transparente en la información que se le expone al consumidor. La dimensión ambiental la cual trata temas como el reciclaje, la reutilización, energías renovables, la optimización de recursos para las generaciones futuras y el maltrato animal. La dimensión social en la cual el producto o servicio no atente contra la salud o bienes de las personas y por último la dimensión económica la cual ayuda al desarrollo sostenible de un país.

\section{Responsabilidad social Stakeholders}

Los stakeholders al conceptualizarlo Freeman (1983) según este autor tiene dos definiciones: La primera en un sentido amplio en la cual el grupo de individuos puede afectar los objetivos de la organización (competidores, gobierno, etc.) Y el segundo un sentido restringido en el cual se encuentran los individuos que interactúan con la empresa (empleados, clientes, proveedores). Así mismo, el autor ordena los stakeholders en dos dimensiones: Los stakeholdersen materia de capital y economía, los stakeholders con poder económico que pueden influir en las decisiones 
de mercado. Del mismo modo la RSE la considera como un instrumento para el incremento de las ganancias de la empresa, con base en la necesidad de los stakeholders.

Según (Avendaño, 2013, pág. 163) se deja de pensar en el Estado como único administrador del gasto social y responsable de la contención de desigualdades y se comienza a defender la idea de que la contribución al bienestar y a la calidad de vida debe ser la meta de todas las instituciones sociales. Con el cambio de perspectiva se le da reconocimiento a diferentes sujetos que pueden verse afectados como resultado de la actividad de las organizaciones stakeholder (Por lo tanto, las organizaciones deben formalizar políticas y sistemas de gestión que promuevan las relaciones con los accionistas, empleados, clientes, proveedores y medioambiente).

(kaku, 2005)Se basa en la filosofía japonesa Kyosei, en la cual las empresas deben de ser responsables con base en la filosofía que este plantea, su principal concepción es "si las empresas gestionan sus negocios con el único objetivo de ganar más dinero, pueden llevar al mundo a la ruina económica, medioambiental y social”, pero, ¿Cómo lograr el equilibrio entre la prosperidad y las ganancias monetarias de la organización? Este autor plantea un modelo denominado como "la filosofía del espíritu de la cooperación”, esta se caracteriza porque las personas y las compañías trabajan de manera conjunta para lograr el bien común, estos establecen una relación armónica con los clientes, proveedores, competidores, gobierno y el medio ambiente, convirtiéndose en un instrumento positivo para un cambio significativo en los distintos ámbitos. Así mismo, expresa que el ente económico tiene en sus manos la decisión de influir en el bienestar de la sociedad o destruirlo a la misma vez, lo principal es unirse en la labor de una paz mundial y la prosperidad. 
(kaku, 2005)Plantea que existen cinco etapas para la construcción del modelo anteriormente mencionado:

- Supervivencia Económica: Las compañías fuertes tienen la responsabilidad de otorgar a la sociedad los bienes y servicios, generando empleos a un número significativo de personas.

- Cooperación con el Trabajo: Este segundo nivel es cuando los directivos y trabajadores empiezan a cooperar entre ellos. Es decir, los empleados adquieren un código de ética intrínseco ya que no se encuentran rivalidades entre las partes.

- Cooperación Fuera de la Compañía: Integra a los grupos externos de la compañía (cliente y proveedores). Los clientes se tratan con respeto y los proveedores buen trato, en materia de competidores se pueden generar alianzas estratégicas, lo que traerá consigo el incremento en las utilidades.

- Activismo Global: Las empresas que se encuentran posicionadas en el extranjero, pueden llegar a invertir en investigación y desarrollo. Entrenando a trabajadores locales en nuevas tecnologías, implicando con ello no solo un avance en la compañía sino a la vez mejorando el nivel de capacitación de sus empleados.

- El Gobierno como un Colaborador Kyosei: Esta última fase es ardua de alcanzar ya que el Gobierno y la compañía trabajan en conjunto para resolver problemas económicos y sociales en el mundo. Además ayudan a reformar las condiciones de vida de las personas y del medio ambiente.

Según Freeman (1983) las acciones que ejerce una empresa se ven afectadas por actores cuyos efectos perjudican unos a otros directa e indirectamente, esta teoría se desarrolló en los años setenta debido a los cambios sociales que se estaban reflejando en la época. 
La responsabilidad social corporativa surge de la presión ejercida por clientes, empleados, algunos accionistas, el gobierno y la sociedad, según el autor "la responsabilidad social es definida como las acciones que parecen favorecer algún bien social, más allá de los intereses de la empresa y de lo que exige la ley”, es decir va más allá de cumplir leyes, por ejemplo el no discriminar es un deber mas no por no discriminar estamos realizando acciones de responsabilidad social es distinto cuando nos involucramos y creamos acciones para esta problemática.

El autor plantea que existen dos fuentes principales de responsabilidad social empresarial: la demanda del consumidor y la demanda de otros grupos de interés los cuales sienten que apoyan una casusa social o ambiental al adquirir productos con atributos amigables con el medio ambiente o la sociedad, estos artículos marcan la diferencia frente al cliente de dos maneras en el servicio que prestan o en el producto ya que el producto puede tener atributos que no dañen el medio ambiente como por ejemplo los alimentos orgánicos y el servicio como por ejemplo brindando alta calidad en los productos y el fuerte empoderamiento de los empleados.

Complementando lo anterior, Litz (1996) plantea que la administración de los recursos dirigido dentro de un marco de responsabilidad social empresarial permite emplear el conocimiento de una forma eficiente, generando sinergia entre la empresa y los grupos de interés para un desarrollo competitivo.

Davis (1960) Indica que a medida que la empresa crece y toma más poder en la sociedad genera empleo, ayuda al desarrollo económico de la región y realiza acciones sociales puede influir de una forma positiva en la sociedad ya que será un ente importante que contribuye a la comunidad, además establece la importancia del papel que juega el gerente, debido a que en este 
recae la responsabilidad en toma de decisiones basados en tres ámbitos: Técnicos, económicos y humanos. Estos tres aspectos reúnen: las necesidades físicas, valores del mercado determinados por el consumidor y las relaciones humanas, todo ello para encontrar una responsabilidad social, cuyo compromiso proviene del poder que los interesados pueden generar.

Por último Wilcox (2005) indica que la responsabilidad social compromete aspectos como la seguridad productiva, la protección al medio ambiente, el buen trato a los empleados de la empresa, la igualdad, satisfacción del cliente y resalta la importancia de la ética en la cadena de suministro con el fin de solucionar problemas sociales, desigualdad y contribuir con los derechos humanos.

De acuerdo a lo planteado hasta el momento se construye el siguiente cuadro resultante de la presente investigación adelantado en el cual se sintetiza las distintas perspectivas literarias anteriormente planteadas. 
Tabla 1PERSPECTIVAS DE RESPONSASIBILIDAD SOCIAL CON RELACIÓN A FUNDAMENTOS TEORICOS

\section{Fuente: Elaboración propia}

\begin{tabular}{|c|c|}
\hline PERSPECTIVA & DESCRIPCIÓN \\
\hline Cumplimiento & $\begin{array}{l}\text { La responsabilidad social se caracteriza por el pleno cumplimiento de la } \\
\text { ley (deberes, pago de impuestos, y lo relacionado con obligaciones } \\
\text { normativas emitidas por la ley, cumplimiento de acuerdos). }\end{array}$ \\
\hline Mercadeo & $\begin{array}{l}\text { La responsabilidad social acompañada de publicidad incrementa el } \\
\text { posicionamiento de marca, reconocimiento y llega a ser una ventaja } \\
\text { competitiva la cual puede generar mayor ingreso a la empresa a esto se le } \\
\text { conoce como marketing Green el cual es aprovechar las acciones sociales } \\
\text { y ambientales de la empresa de forma que retribuya a la empresa, sin } \\
\text { caen en el greenwashing (lavado de marca) en el cual se engaña sobre las } \\
\text { acciones responsables que ejecuta la empresa repercutiendo con daños a } \\
\text { la sociedad o demandas legales por engaño. }\end{array}$ \\
\hline Corporativo & $\begin{array}{l}\text { La responsabilidad social corporativa abarca tanto las actividades } \\
\text { netamente empresariales como el interés de los implicados, es decir el } \\
\text { gobierno, accionistas, etc. El objetivo de esta es integrar todas las } \\
\text { operaciones sociales y medioambientales para generar acciones que } \\
\text { contribuyan a la satisfacción de los interesados. }\end{array}$ \\
\hline Ético & $\begin{array}{l}\text { La responsabilidad social ética se caracteriza porque las acciones sociales } \\
\text { o ambientales ejecutadas por la empresa las realizan sin interés de una } \\
\text { retribución económica ya que su fin es beneficiar a la sociedad ya que } \\
\text { tiene en cuenta que son un ente importante y por ello pueden repercutir } \\
\text { positiva o negativamente a la sociedad. la responsabilidad social ética se } \\
\text { encuentra divida en dos visiones, el enfoque empírico en el cual se } \\
\text { establece las reglas de conducta basado en la observación y normativo el } \\
\text { cual trata de la aplicación de reglas establecidas por ente regulador. }\end{array}$ \\
\hline
\end{tabular}




\begin{tabular}{|c|l|}
\hline Ambiental & $\begin{array}{l}\text { La responsabilidad ambiental nace de la preocupación del impacto } \\
\text { negativo que tiene al medio ambiente las actividades humanas y las } \\
\text { acciones que se deben ejecutar para mitigar este impacto y conservar los } \\
\text { recursos para las futuras generaciones. Algunas de estas acciones más } \\
\text { destacadas son el reciclaje, el tratamiento de residuos y la decisión de } \\
\text { compra del consumidor para adquirir productos que no atenten en contra } \\
\text { de la salud de la sociedad y que no tengan grandes repercusiones al } \\
\text { medio ambiente. }\end{array}$ \\
\hline Stakeholders & $\begin{array}{l}\text { La responsabilidad social con una visión a los stakeholders se fundamenta } \\
\text { en los grupos de interés conformado por inversionistas, proveedores, } \\
\text { clientes, trabajadores y el gobierno los cuales pueden afectar las } \\
\text { actividades de la organización es por esto que debe existir una } \\
\text { cooperación mutua en la cual las personas y la compañía trabajan } \\
\text { conjuntamente para lograr el bien común es decir un valor compartido. }\end{array}$ \\
\hline
\end{tabular}

Por consiguiente, se concluye que las distintas perspectivas de responsabilidad social son: el cumplimiento legal se entiende como el pleno acatamiento de las normas. El marketing Green como estrategia corporativa para generar un beneficio mutuo entre la empresa y la sociedad; La perspectiva de RSE corporativa la cual integra las actividades empresariales y sus grupos de interés; La RSE ética se define como la realización de actividades sin interés alguno. La perspectiva ambiental la cual busca mitigar el impacto al medio ambiente por medio de prácticas empresariales y la RSE de sktakeholders el cual se fundamenta en los intereses de los grupos y cooperación mutua. Se puede concluir que se han desarrollado distintas visiones de responsabilidad social empresarial a lo largo de la historia, proporcionando diferentes aportes los cuales se fundamentan en un solo factor "el bienestar de la sociedad" 


\section{ANTECEDENTES}

Cuando se habla de mercados debemos acudir en primera instancia a plantear un concepto claro sobre retail el cual según

Es una orientación de la dirección del negocio que sostiene que las tareas claves de un minorista son: a) determinar las necesidades y deseos de su mercado objetivo y, b) dirigir la empresa hacia la satisfacción de esas necesidades y deseos, de forma más eficiente que sus competidores. El comercio detallista o minorista es el último eslabón de la distribución comercial, es el intermediario que se dedica a la venta de productos, bienes o servicios a los consumidores o usuarios finales. (Quintero, 2010, pág. 2)

El mismo autor define que "el Retail, debe procurar y planificar la fidelización a través de un proceso de construcción, fortalecimiento, renovación y "apalancamiento" de las marcas del propio Retail, para hacerlas más poderosas." Por esta razón la compañía objeto de estudio pretende crear una experiencia de comodidad a los clientes y recordarles las tiendas de antaño y así mismo promocionar sus marcas compitiendo con precios bajos en el mercado.

\section{Llegada de los hipermercados a Colombia}

Según el estudio económico del sector retail elaborado por la superintendencia de industria y comercio (2012) el retail se desprende del sector de grandes superficies o hipermercados, los cuales ingresaron al país al principio del siglo XXI, grupos internacionales tales como: el Grupo Casino y Grupo Carrefour con el fin de aprovechar las economías de escala generando integración empresarial en el país, contribuyendo con un valor agregado a los usuarios en 
aspectos de precio y calidad para ofrecer facilidades a los consumidores en los medios de compra.

Según Silva (2012) la estrategia de mercadeo de los hipermercados en su inicio era satisfacer amplias capas de la población, ingresando en 1994 la marca Irlandesa Macro, los franceses (1998) Carrefour y Casino a través de almacenes éxito (1999), así continuamente se incorporaron nuevos hipermercados.

Los hipermercados son preferidos por muchos consumidores por su variedad de productos y marcas pero así una de la más fuerte competencia son las tiendas de barrio ya que estas están más en cerca de los hogares de los consumidores y tienen una relación más estrecha con el cliente.

La tienda de barrio posee un formato correspondiente al de un segmento de la población de escasos recursos y que poco a poco se ha ido adaptando a esta necesidad hasta llegar a convertirse en una muralla frente a las multinacionales.(Silva, 2012, pág. 160)

Pero esta segmentación se ha ido expandiendo a distintos estratos socioeconómicos de la sociedad adquiriendo preferencias de compra más cómodas y con mayor facilidad de adquisición.

Mercadería SA ha crecido notablemente en el mercado y ha establecido diferentes puntos en la capital Colombiana. Justo \& Bueno es un modelo de negocio de Retail, una cadena de supermercados minoristas que llegan a los clientes finales, busca satisfacer necesidades y deseos de los consumidores. El cual cumple a cabalidad las características propias de las cadenas de grandes superficies, debido a que son parte importante en la cadena de producción de consumo por lo tanto el fin último es la oferta de productos perecederos y no perecederos 
Según la revista semana 2017 las tiendas de descuento han tenido un surgimiento significativo en el mercado, en Colombia han surgió tiendas como D1, Ara y Mercadería Justo \& Bueno, los cuales registran ventas de 5 billones de pesos, por parte de los consumidores, ha tenido una acogida representativa ya que ofrecen descuentos sustanciales en los precios de productos básicos de la canasta familiar en comparación a los mercados tradicionales. Estos establecimientos no invierten de manera significativa en publicidad ni en el establecimiento de comercio, son sencillos, tienen poco personal y carecen de impulsadores. Justo \& Bueno se caracteriza por comercializar gran variedad de productos de aseo para el hogar, lácteos, embutidos, procesados, granos y cereales que le suministran pymes de diversas regiones del país, los clientes llegan sin gran dificultad a los establecimientos a pesar de que carecen de parqueadero y publicidad.

Según revista dinero 2016 los fundadores de D1 vendieron su idea a Valoren y después crearon Justo \& Bueno una idea de negocio que no pretende hacer competencia a las tiendas de barrio sino que pretende un acercamiento con los consumidores, ofrecer productos de buena calidad y a precios competitivos, está cerca a los hogares de los clientes. Justo \& Bueno busca crear un vínculo afectivo con el consumidor por esto su infraestructura y decoración está inspirado en las tiendas de antaño, arte popular que pretende crear una experiencia en el cliente de comodidad y satisfacción cerca al lugar donde reside valiéndose de un voz a voz y entrega de volantes con información de precios, productos y puntos de venta. 


\section{DISEÑO METODOLÓGICO}

El método científico según Cerda (2006) es entendido como las reglas o normas que dan solución a la pregunta de investigación, se caracteriza por un conjunto de procedimientos que por medio de instrumentos o técnicas examina y da una posible solución a la investigación. Este método está directamente relacionado con la metodología. Este autor se basa en dos perspectivas: la primera, la parte lógica que se ocupa del estudio de los métodos (descripción, explicación y justificación), la segunda metodología es entendida como el conjunto de pasos operativos para generar la investigación.

Basándose en el método científico que han prevalecido históricamente son: "El baconiano: postula (inducción); galileano (experimentación) y Cartesiano (Análisis y síntesis de los problemas). Sin embargo estas teorías se han ido complementando, generando nuevos métodos como: Método Inductivo, deductivo, inductivo-deductivo, hipotético-deductivo, analítico, sintético, método analítico-sintético, histórico- comparativo y método cualitativo- cuantitativo".

El alcance de esta investigación se enfoca en un estudio exploratorio debido a que la problemática de investigación ha sido poco estudiada y no ha sido indagada desde la visión de la responsabilidad Social de los retail (Mercadería Justo \&Bueno) en orientación a Green Marketing.

Para el diseño metodológico de la investigación a realizar, se hace uso del enfoque mixto el cual es definido por (Hernández, 2010) como, "la integración sistemática de los métodos cualitativos y cuantitativos en un solo estudio con el fin de obtener una fotografía más completa del fenómeno". (p.120) Este método permite una perspectiva más amplia y profunda de una 
anomalía, proporciona resultados integrales y holísticos, lo que facilita el proceso de investigación. Este método se basa en estudios cuantitativos y cualitativos, los cuales se aplicarán.

\section{Método Cualitativo}

La investigación cualitativa para LeCompte (1995) es "una categoría de diseños de investigación que extraen descripciones a partir de observaciones que adoptan la forma de entrevistas, narraciones, notas de campo, grabaciones, transcripciones de audio y vídeos cassettes, registros escritos de todo tipo, fotografías o películas y artefactos”. (pág. 2) Con base en la anterior definición, el método cualitativo busca identificar y describir cualidades de eventos, hechos, situaciones o comportamientos.

Por lo tanto, dentro del método cualitativo se emplearán instrumentos como revisión literaria y entrevista. En primera instancia se realizará una revisión literaria para generar un acercamiento a los mercados de mediana superficie, su relación con la responsabilidad social empresarial y con el Green marketing. De la misma manera se realizará una entrevista a un colaborador de la empresa objeto de estudio, con la finalidad de indagar acerca de las acciones sociales y ambientales que ejerce en la compañía.

Con respecto a la entrevistas las preguntas serán claras y comprensibles para las persona, se referirán a un solo aspecto del objetivo de la investigación (acciones sociales y ambientales), evitando preguntas que nieguen el asunto que se interroga, facilitando la interpretación y el análisis de los instrumentos. 


\section{Método Cuantitativo}

Peñuelas(2010) Señala que:

"El método cuantitativo se centra en los hechos o causas del fenómeno social, con escaso interés por los estados subjetivos del individuo. Este método utiliza el cuestionario, inventarios y análisis demográficos que producen números, los cuales pueden ser analizados estadísticamente para verificar, aprobar o rechazar las relaciones entre las variables definidas operacionalmente, además regularmente la presentación de resultados de estudios cuantitativos viene sustentada con tablas estadísticas, gráficas y un análisis numérico". (pág. 25)

Para este método se debe de definir la muestra la cual es definida por (Hernández, 2010) como un subgrupo de la población de interés sobre la cual se recolectan datos; se establecerá el tipo no probabilístico o muestra dirigida, en la cual la selección de la muestra es a definir según las características de la investigación, este tipo de muestra es de gran importancia ya que logran obtener resultados que conciernen a la investigación y ofrecen riqueza para el análisis de datos.

La muestra de este instrumento se fundamentará en un tipo denominado redes o cadenas que según (Murgado2008) una vez contactadas las personas clave (impulsadores de tienda) se les pregunta si conocen a otras personas que puedan proporcionar información; este tipo de red se clasifica en red exponencial en la cual un participante invita a participar a más de dos individuos.

\begin{tabular}{|l|r|c|}
\hline \multicolumn{3}{|c|}{ Muestra no probabilística } \\
\hline \multicolumn{2}{|c|}{ Tiendas encuestadas } \\
\hline \multicolumn{1}{|c|}{ Ítems } & Datos & $\begin{array}{c}\text { Tamaño de } \\
\text { muestra }\end{array}$ \\
\hline Tamaño población & 124 & \multirow{2}{*}{22} \\
\cline { 1 - 2 } Nivel de confianza & 1,43 & \\
\cline { 1 - 2 } Probabilidad de éxito & 0,6 & \\
\hline
\end{tabular}




\begin{tabular}{|l|r|} 
Probabilidad de Fracaso & 0,02 \\
\hline Precisión & 0,03 \\
\hline
\end{tabular}

Fuente: Pérez (2016)

En la anterior tabla se evidencia que en la ciudad de Bogotá existen 124 tiendas, de las cuales se debe de efectuar la visita de mínimo 22 establecimientos ejecutando la entrevista planteada, utilizando el método anteriormente expuesto (redes). Las encuestas dirigidas a los colaboradores de almacén de la organización con el objetivo de analizar el conocimiento que estos poseen acerca de las acciones sociales y ambientales que se realiza dentro y fuera de la empresa, para generar un análisis cuantitativo con respecto a los resultados obtenidos en el instrumento.

El tercer instrumento que se empleará será la observación la cual se catalogará como método mixto debido a que se tomarán datos en visitas (cualitativo) y posteriormente se contabilizará o medirá (cuantitativo) acerca de la cantidad de proveedores nacionales e internacionales que posee Mercaderías Justo \& Bueno, con la finalidad de analizar la contribución al desarrollo económico de las compañías nacionales y donde se encuentran concentradas.

Con base en lo anteriormente descrito en cada uno de los métodos, se realizará una triangulación concurrente (DITRIAC), el cual es denominado el autor (Hernández, 2010)“como un modelo que se utiliza de manera simultánea en la recolección y análisis de la información almacenada en datos cuantitativos y cualitativos aproximadamente al mismo tiempo", es decir se comparan los resultados de las dos partes para que el análisis sea sustancial. Asimismo el autor Pereira (2011) expresa “que la estrategia concurrente de triangulación en un mismo estudio busca confirmar, correlacionar o corroborar, cuyo fin último es la integración”. (pàg.5)

Este método de estudio es conveniente para demostrar las distintas visiones del problema, debido a que permite la interacción y el análisis de los resultados obtenidos de investigación, es 
decir, del producto de los instrumentos aplicados se realizará un análisis de las acciones sociales y ambientales combinando el método cuantitativo y cualitativo. Con base en ello se propondrá una propuesta de responsabilidad social enfocada a marketing Green que beneficie a la empresa y la sociedad soportándonos de distintas visiones literarias.

\section{Tabla 2. Metodología}

\begin{tabular}{|c|c|c|}
\hline ASPECTO & INSTRUMENTO & OBJETIVO \\
\hline $\begin{array}{l}\text { Percepción } \\
\text { Acciones RSE } \\
\text { J\&B }\end{array}$ & \multirow[t]{2}{*}{ Entrevista semiestructurada } & $\begin{array}{l}{ }^{*} \text { Conocer la percepción de RS } \\
\text { que posee los retail } \\
{ }^{*} \text { Conocer las acciones de } \\
\text { responsabilidad social y } \\
\text { ambiental que realiza justo y } \\
\text { bueno. }\end{array}$ \\
\hline Percepción empresa retail & & $\begin{array}{l}\text { Conocer las diferentes } \\
\text { acciones de responsabilidad } \\
\text { social y ambiental de empresas } \\
\text { retail para crear un modelo re } \\
\text { RSC. }\end{array}$ \\
\hline $\begin{array}{c}\text { Percepción de los stakeholders } \\
\text { (colaboradores) }\end{array}$ & $\begin{array}{l}\text { Encuestas a colaboradores : } \\
\text { (valores, acciones sociales, } \\
\text { percepción de la empresa, } \\
\text { acciones ambientales, } \\
\text { capacitación y opiniones de } \\
\text { mejora) }\end{array}$ & $\begin{array}{c}\text { Medir el conocimiento que } \\
\text { tiene los colaboradores de la } \\
\text { empresa y su percepción de las } \\
\text { acciones que realiza }\end{array}$ \\
\hline \multicolumn{3}{|c|}{$\begin{array}{l}\text { Con la informacion adquirida se generara una propuesta de responsabilidad social } \\
\text { enfocada a marketing Green. (DITRITAC) }\end{array}$} \\
\hline
\end{tabular}

Fuente: Elaboración propia. 
El anterior cuadro hace referencia al diseño metodológico, los instrumentos que se utilizaran en la investigación y la finalidad de cada uno.

\section{PRIMER INSTRUMENTO: ENTREVISTA DIRIGIDA A ORIENTADOR DE OPERACIONES (Cualitativo)}

En primer lugar se aplicará una entrevista semiestructurada que se compone de quince (15) preguntas, la cual se realizó al señor Camilo Martínez quien es el orientador de operaciones de Mercadería justo \& bueno de la mini región quince (15) (zona sur de Bogotá), con base en esta entrevista se realiza el siguiente análisis:

El primer instrumento que se utilizará es la entrevista, la cual es una estrategia para hacer que las personas hablen sobre lo que saben, piensan y creen, en la cual el entrevistador obtiene información acerca de lo que desea investigar, de la misma manera (Canales, 2006) explica que es "la comunicación interpersonal establecida entre el investigador y el sujeto de estudio, a fin de obtener respuestas verbales a las interrogantes planteadas sobre el problema propuesto"; Con base en lo anterior, el desarrollo de esta investigación se aplicará a Mercadería Justo \& Bueno, empresa objeto de estudio con la finalidad de generar un primer acercamiento en las acciones de responsabilidad social empresarial que se practican en la empresa.

Existe diferentes clases de entrevista: estructurada, individual, en grupo, mixta y semiestructurada, esta última se usará como instrumento de investigación, la cual se caracteriza por tener un guion de preguntas formuladas con un orden especifico, sin embargo este dialogo no tendrá una estructura definida debido a que será de forma abierta lo cual permitirá sinergia 
entre las partes y así mismo la profundidad de estos sondeando la entrevista con el fin de captar la mayor información posible.

El siguiente estudio fue tipo cualitativo ya que se indagó e investigó por medio de la entrevista el modelo de responsabilidad social empresarial que aplica la empresa mercadería justo y bueno. La cual fue dirigida a Camilo Martínez.

\section{SEGUNDO INTRUMENTOS: ENCUESTA DIRIGIDA A COLABORADORES}

El segundo instrumento que se empleará será una encuesta mixta la cual contiene nueve (9) preguntas abiertas y cerradas a los colaboradores de mercadería justo y bueno, en la cual se seleccionó la muestra de treinta y siete (37) personas que cumplen la función de impulsadores de diferentes zonas geográficas de la ciudad Bogotá, en veintidós (22) tiendas de distintas localidades tales como: Kennedy, Bosa, Antonio Nariño, Barrios Unidos, Puente Aranda, Rafael Uribe, Santa Fe, Ciudad Bolívar, Los Mártires y San Rafael.

La aplicación del instrumento planteado busca indagar acerca del conocimiento de las acciones sociales y ambientales que realiza Mercadería Justo \&Bueno y las percepción de los colaboradores (impulsadores) frente a la compañía con el fin de indagar acerca de su percepción de responsabilidad social que tienen los colaboradores de almacén dentro de la compañía, estas preguntas cumplen las características de ser entendibles y claras.

\section{TERCER INSTRUMENTO: OBSERVACION DIRECTA (método mixto)}

La observación es definida por como "la búsqueda deliberada y controlada de objetos, hechos y fenómenos, bajo ciertas condiciones previamente determinadas, la más importante de las cuales es la intersubjetividad. La objetividad de la ciencia- en el campo empírico - se basa en la posibilidad de que la observación sea realizada por cualquier observador ubicado en una 
situación análoga. Esta exigencia garantiza la eliminación de los factores subjetivos inherentes a un observador, pero, por supuesto, admite las distorsiones comunes a todos ellos. Es evidente que la intersubjetividad es la única posibilidad de evitar el subjetivismo”, por tanto es una herramienta que permite captar información y recopilarla para posteriormente analizarla, con el fin de obtener el mayor número de resultados cuantitativos y cualitativos (método mixto) los cuales se analizaran para validar la veracidad de la información acerca de la cantidad de proveedores nacionales e internacionales. 


\section{RESULTADOS}

A continuación se darán a conocer los resultados cuantitativos de los distintos instrumentos aplicados para el desarrollo de la presente investigación.

\section{ENCUESTA DIRIGIDA A STAKEHOLDERS (Colaboradores) (Cuantitativo)}

Con base a la encuesta realizada a los colaboradores de almacén se dan los siguientes resultados en los cuales se evidencia la percepción de responsabilidad social de los trabajadores, con base a los resultados obtenidos se realizará posteriormente un análisis relacionando la revisión literaria.

Con base en los resultados obtenidos podemos concluir que:

1. ¿Usted conoce los valores de la empresa?

SI $100 \%$

NO $0 \%$

¿Cuáles?

Tabla 3 Valores Representativos de la empresa según colaboradores de almacén

\begin{tabular}{|l|r|}
\hline \multicolumn{2}{|c|}{ Valores de la empresa } \\
\hline Servicio & 7 \\
\hline Responsabilidad & 10 \\
\hline Respeto & 25 \\
\hline Lealtad & 13 \\
\hline Honestidad & 25 \\
\hline Compromiso & 4 \\
\hline Autonomía & 4 \\
\hline Amabilidad & 5 \\
\hline Trabajo en Equipo & 5 \\
\hline
\end{tabular}




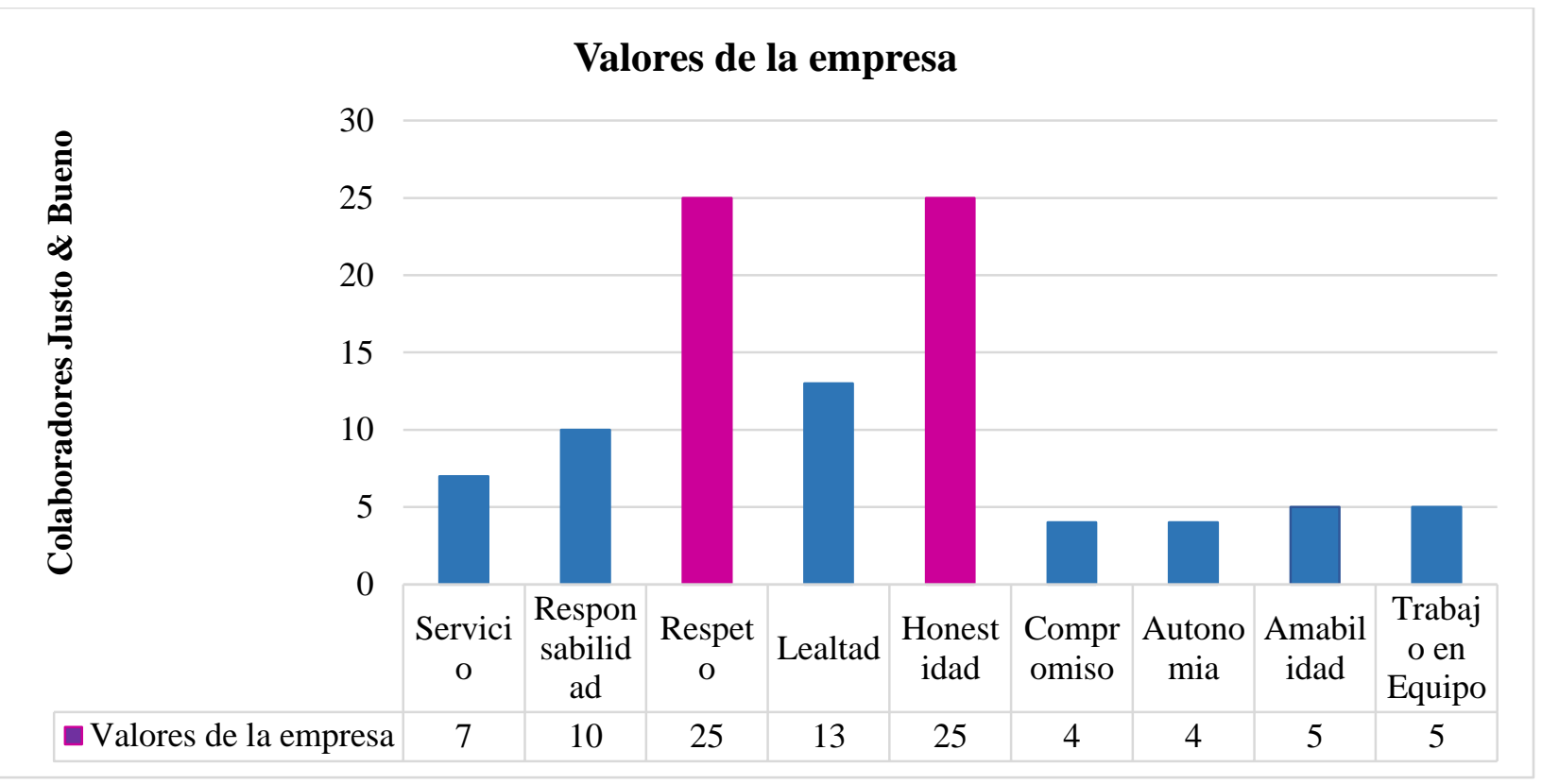

Fuente: Resultados obtenidos encuesta a colaboradores.

En la anterior grafica se evidencia que la mayoría de personas encuestadas es decir 25 de las 37 ven en el respeto y la honestidad como los valores principales que inculca mercadería justo y bueno, seguido de estos se encontró que entre 10 y 13 personas concluyen que la lealtad y la responsabilidad son valores que infunde la empresa, posteriormente el servicio, amabilidad, trabajo en equipo, compromiso y autonomía oscilan entre 4 y 7 colaboradores.

2. ¿Tiene conocimiento acerca de las acciones sociales que realiza la empresa? SI NO

Sabe ¿Cuáles acciones realiza la empresa? (Descríbalas)

Tabla 4Conocimiento de las acciones Sociales por parte de los colaboradores de almacén

\begin{tabular}{|l|r|}
\hline \multicolumn{2}{|c|}{$\begin{array}{c}\text { Conocimiento Acciones } \\
\text { Sociales }\end{array}$} \\
\hline NO & 5 \\
\hline SI & 32 \\
\hline
\end{tabular}




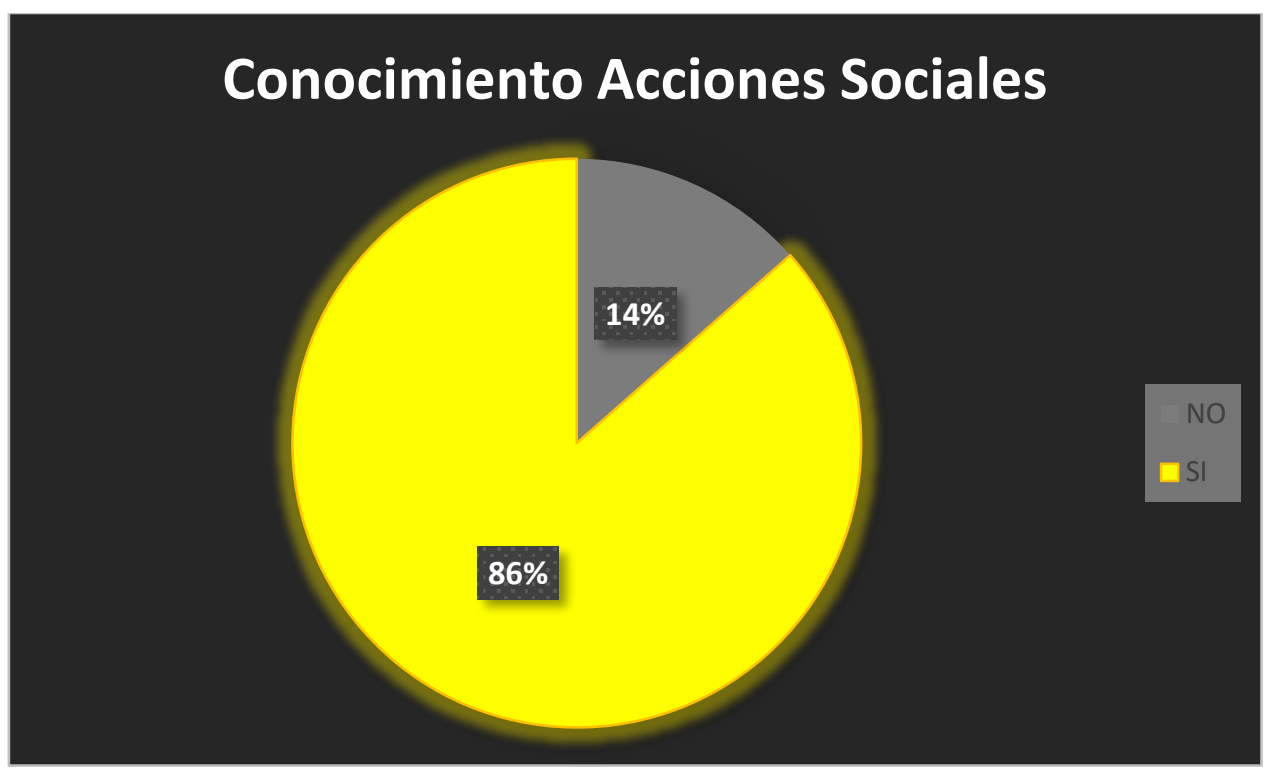

Ilustración 2Diagrama de Conocimiento de Acciones Sociales

El anterior diagrama demuestra que el $86 \%$ (32 colaboradores), si poseen conocimiento acerca de las acciones sociales que realiza la compañía; En contraste el 14\% (5 colaboradores) desconocen las acciones sociales.

A continuación se muestra las principales acciones sociales que describieron los colaboradores en la pregunta realizada.

Tabla 5Principales Acciones sociales según colaboradores de almacén

\begin{tabular}{|l|c|}
\hline Precios Bajos & 9 \\
\hline $\begin{array}{l}\text { Contratación de personal sin } \\
\text { discriminación }\end{array}$ & 29 \\
\hline Convenio con el Sena & 1 \\
\hline Ayuda Humanitaria & 7 \\
\hline
\end{tabular}




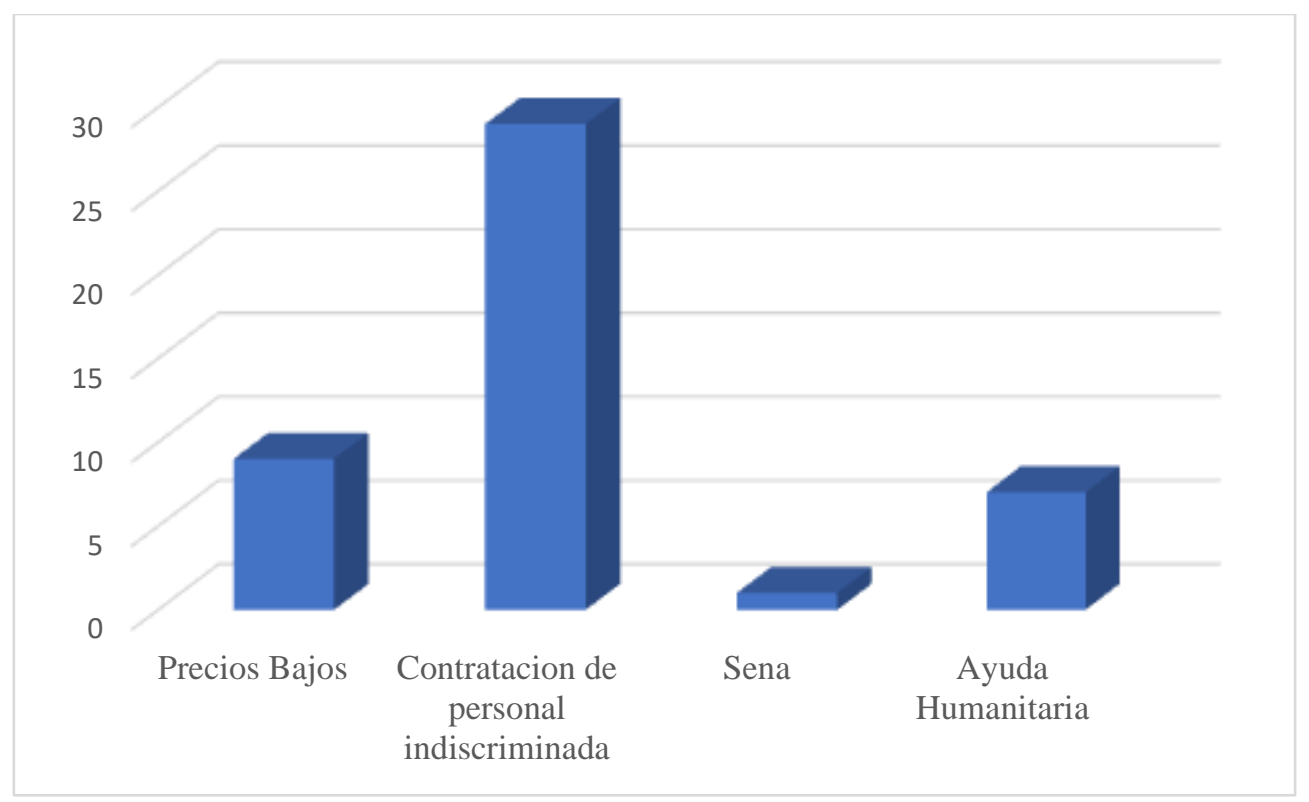

Ilustración 3Acciones sociales según colaboradores

Algunos colaboradores respondieron de cero a cuatro aspectos los cuales en su mayoría

contestaron que la acción social más destacada fue la contratación a personal sin discriminación (29), seguida de precios bajos (13), ayuda humanitaria (7) y convenio con el Sena (1).

3. ¿Cree que la empresa con estas acciones sociales beneficia a la sociedad? SI 33

NO SABE/ NO RESPONDE 4

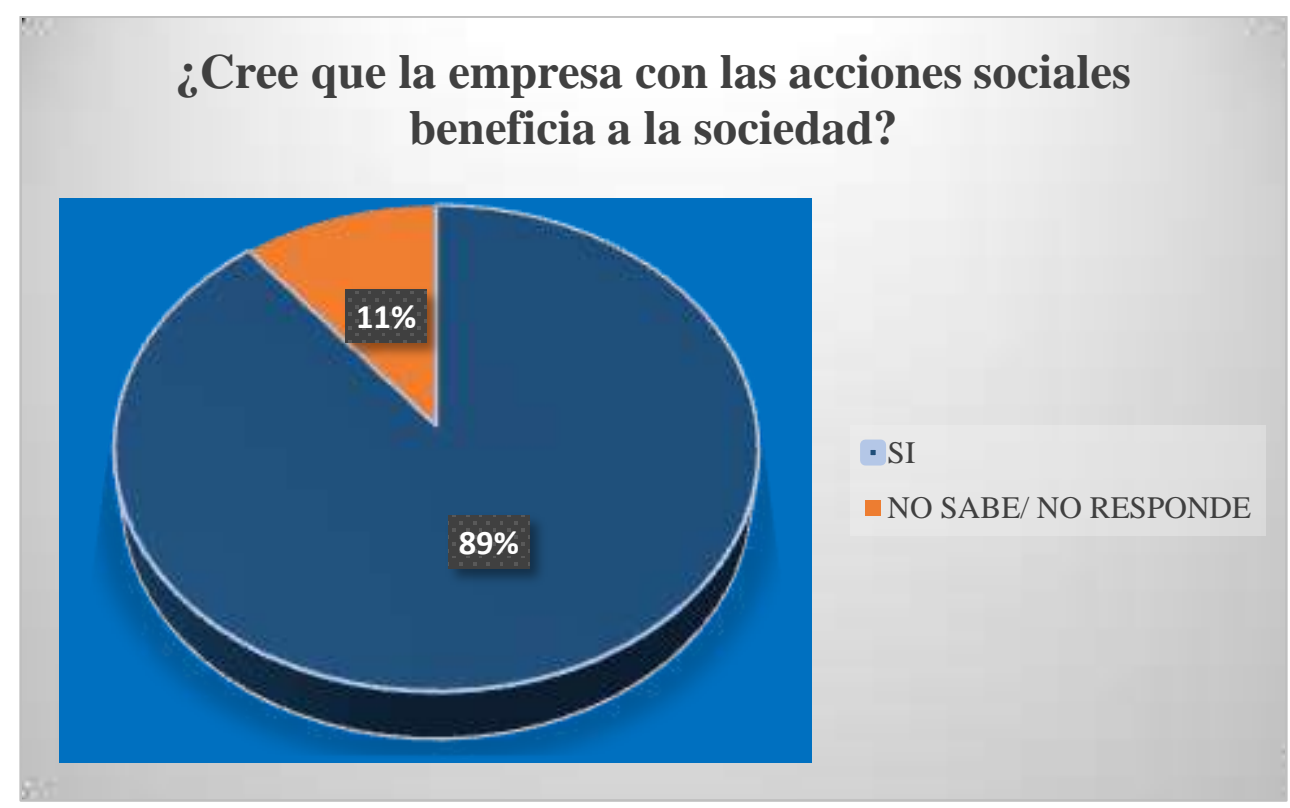


El anterior diagrama demuestra que el 89\% (33 colaboradores), creen que la empresa beneficia a la sociedad con las acciones sociales que ejecuta. En contraste el 11\% (4 colaboradores) desconocen que las acciones sociales que realiza la empresa benefician a la sociedad.

4. Cree usted que justo y bueno es diferente que otras instituciones. Por:
a. Precio
b. Por calidad en el producto
c. Por servicio al cliente
d. Por conocimiento en el merado

Tabla 6 Percepción del colaborador respecto a diferencia en el mercado

\begin{tabular}{|l|r|}
\hline \multicolumn{2}{|c|}{ Justo\& Bueno es diferente por: } \\
\hline Precio & 20 \\
\hline Calidad en el producto & 21 \\
\hline Servicio al cliente & 21 \\
\hline Reconocimiento en el mercado & 9 \\
\hline Acciones Sociales & 6 \\
\hline
\end{tabular}

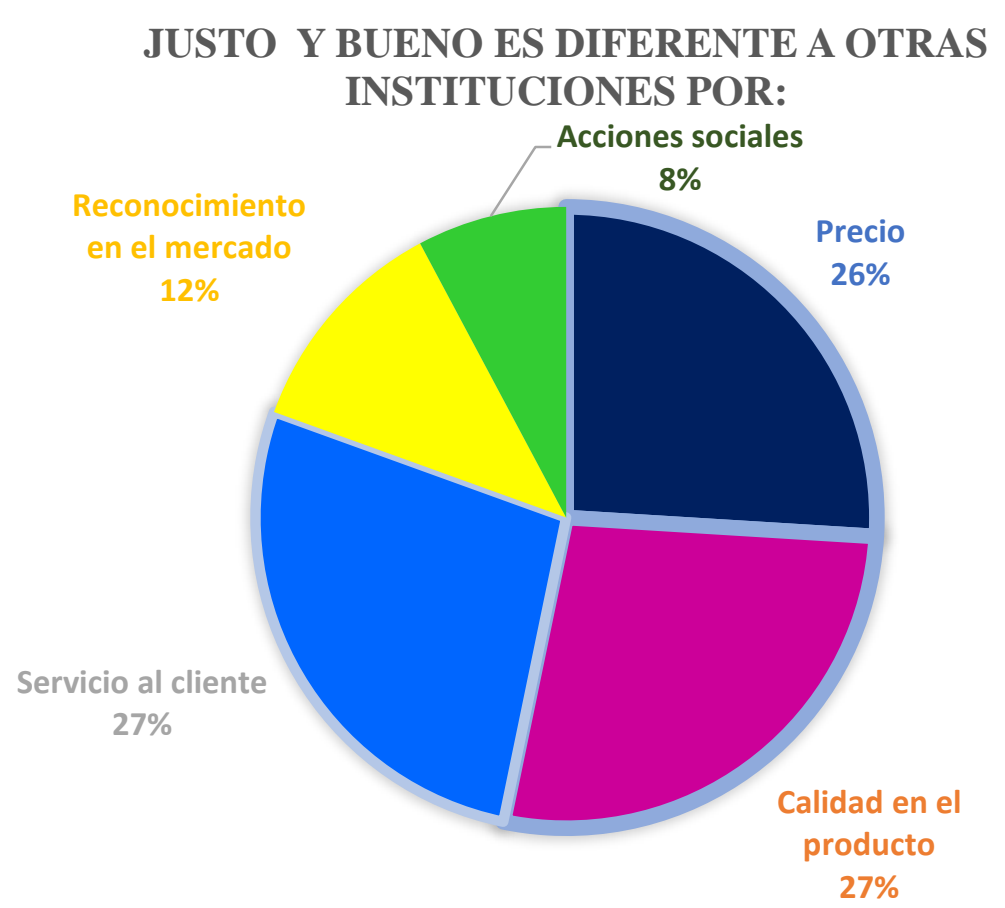


En la figura se muestra que la mayoría de colaboradores consideran que los factores diferenciadores de la empresa con $27 \%$ servicio al cliente y con el mismo porcentaje calidad en el producto, seguido de precio con un $26 \%$. Posteriormente reconocimiento en el mercado con un $12 \%$ y acciones sociales con un $8 \%$. Los resultados numéricos obtenidos se analizarán posteriormente en el trabajo (Pág. 51)

5. ¿Se siente acorde con los valores de la empresa?

SI

NO

\begin{tabular}{|l|c|}
\hline \multicolumn{2}{|c|}{ Se siente acorde con los valores de la empresa. } \\
\hline SI & 34 \\
\hline NO SABE/ NO RESPONDE & 3 \\
\hline
\end{tabular}

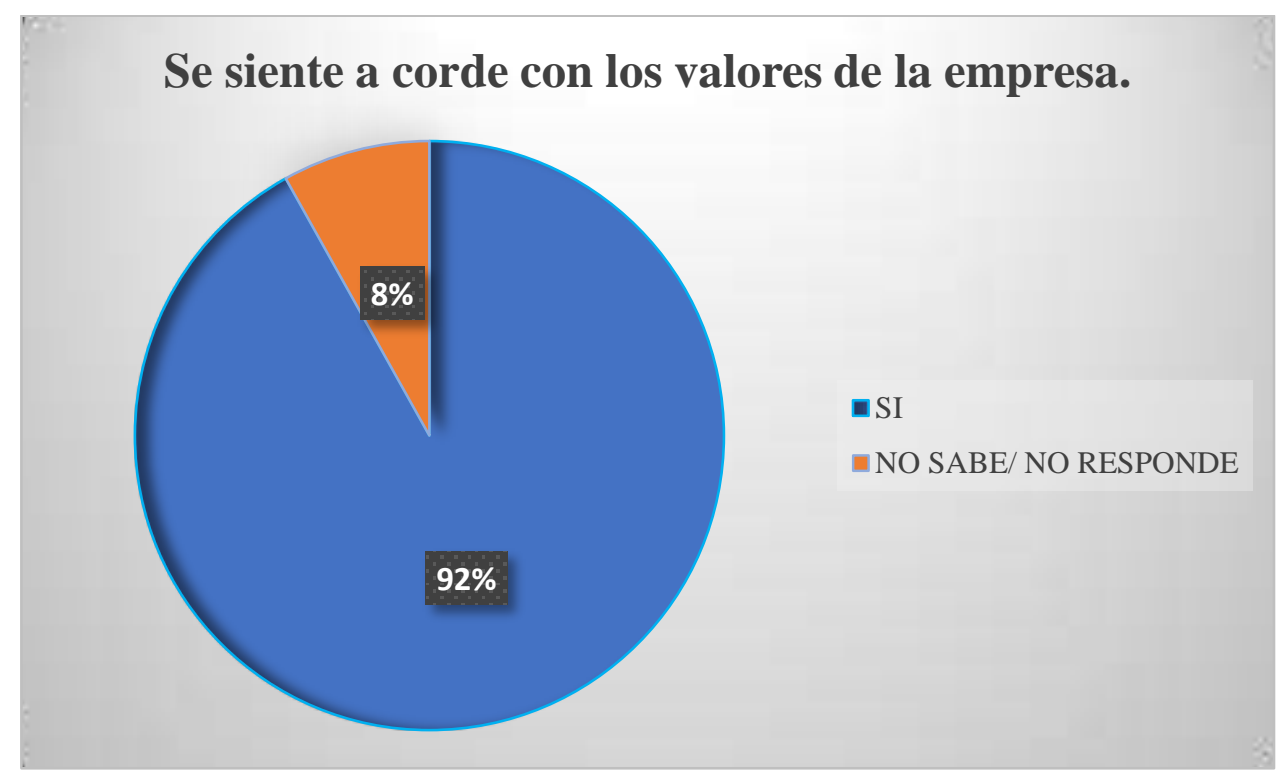

El anterior diagrama demuestra que el 92\% (34 colaboradores se sienten acordes con los valores corporativos de la empresa. Encontraste el 8\% (3 colaboradores) no se sienten acordes con los valores corporativos de la empresa.

6. ¿Usted cree que la empresa realiza alguna acción ambiental? 
La mayoría de las personas encuestadas respondieron que las acciones que ejecutaba la empresa a nivel ambiental son el reciclaje y la destrucción de residuos y productos vencidos, explicando que se separa el plástico y el cartón, lo almacenan y lo envían centro de distribución para ser vendido, también explican que la destrucción de residuos y productos vencidos se realiza de forma masiva. Los colaboradores argumentan que venden bolsas plásticas y que con esto ayudan a disminuir el uso de estas contribuyendo a mitigar el impacto al ambiente.

7. ¿Existen programas de capacitación en la empresa? ¿Cuáles? ¿Cada cuánto?

La mayor parte de las personas encuestadas respondieron que las capacitaciones que genera Mercadería Justo y Bueno son enfocadas en su gran mayoría en servicio al cliente y salud ocupacional. Simultáneamente se encuentra la capacitación en seguridad, agotados y manipulación de alimentos, por último el aspecto ambiental.

8. ¿Qué opina de la comunicación interna y externa de la empresa? ¿Qué canales de comunicación utilizan?

Los colaboradores describieron que el canal interno que utiliza mercaderías Justo \&Bueno es WhatsApp y la página oficial denominada Mercapost.

Por otra parte, el aspecto externo se destaca el volanteo, voz a voz y degustación.

9. ¿Cree usted que la empresa puede fortalecer en algún aspecto?

La mayoría de los colaboradores expresan que a Mercadería Justo\& Bueno puede fortalecer aspectos como:

- Seguridad.

- Motivación al trabajador (plan carrera) 
- Capacitación en programas ambientales

Tabla 7 Cantidad de productos nacionales e internacionales de Mercadería Justo \& Bueno

\begin{tabular}{|cc|}
\hline PAIS & $\begin{array}{c}\text { CANTIDAD POR } \\
\text { PRODUCTO }\end{array}$ \\
\hline Alemania & 1 \\
\hline Argentina & 1 \\
\hline Brasil & 3 \\
\hline China & 2 \\
\hline China & 1 \\
\hline Colombia & 149 \\
\hline Ecuador & 1 \\
\hline Escocia & 1 \\
\hline España & 1 \\
\hline Italia & 1 \\
\hline México & 1 \\
\hline Panamá & 1 \\
\hline Perú & 1 \\
\hline TOTAL & $\mathbf{1 6 4}$ \\
\hline
\end{tabular}




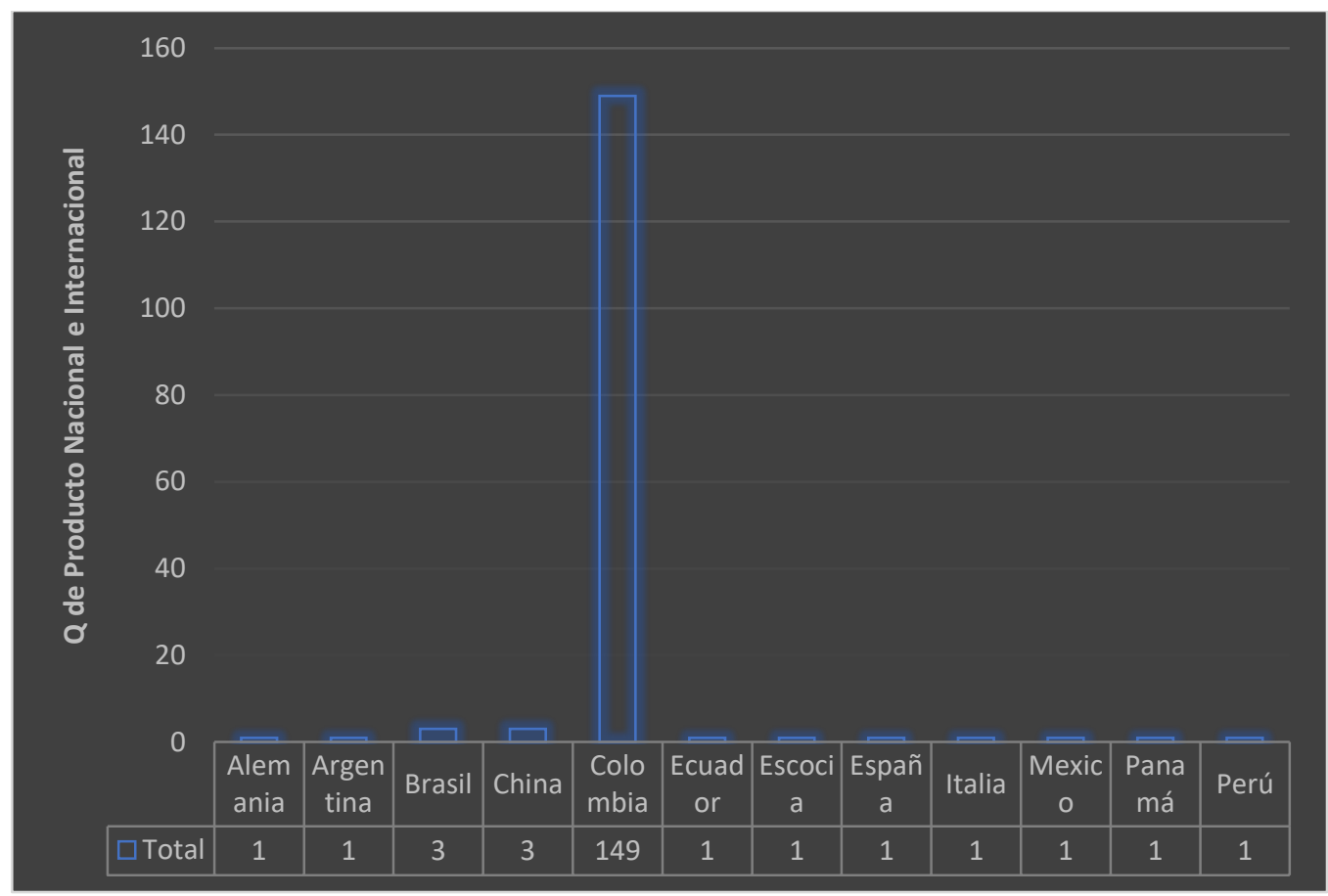

Ilustración 4 Cantidad de productos nacionales e internacionales en Mercadería Justo \&Bueno

En la presente gráfica se puede identificar de manera clara cada uno de los países que

abastecen Mercadería Justo \&Bueno, en el cual se puede establecer el número de productos que proveen a la empresa en comento; al realizar un análisis de los resultados tabulados se refleja que la mayoría de proveedores son colombianos (149), amplia diferencia frente a los productos que provee países extranjeros (Brasil, Argentina, España, China, Escocia, Alemania, Italia, México, Panamá, Perú), que en números equivale a un total de catorce (14) productos que estos proveen, aproximadamente al sujeto objeto de análisis de la presente investigación. 


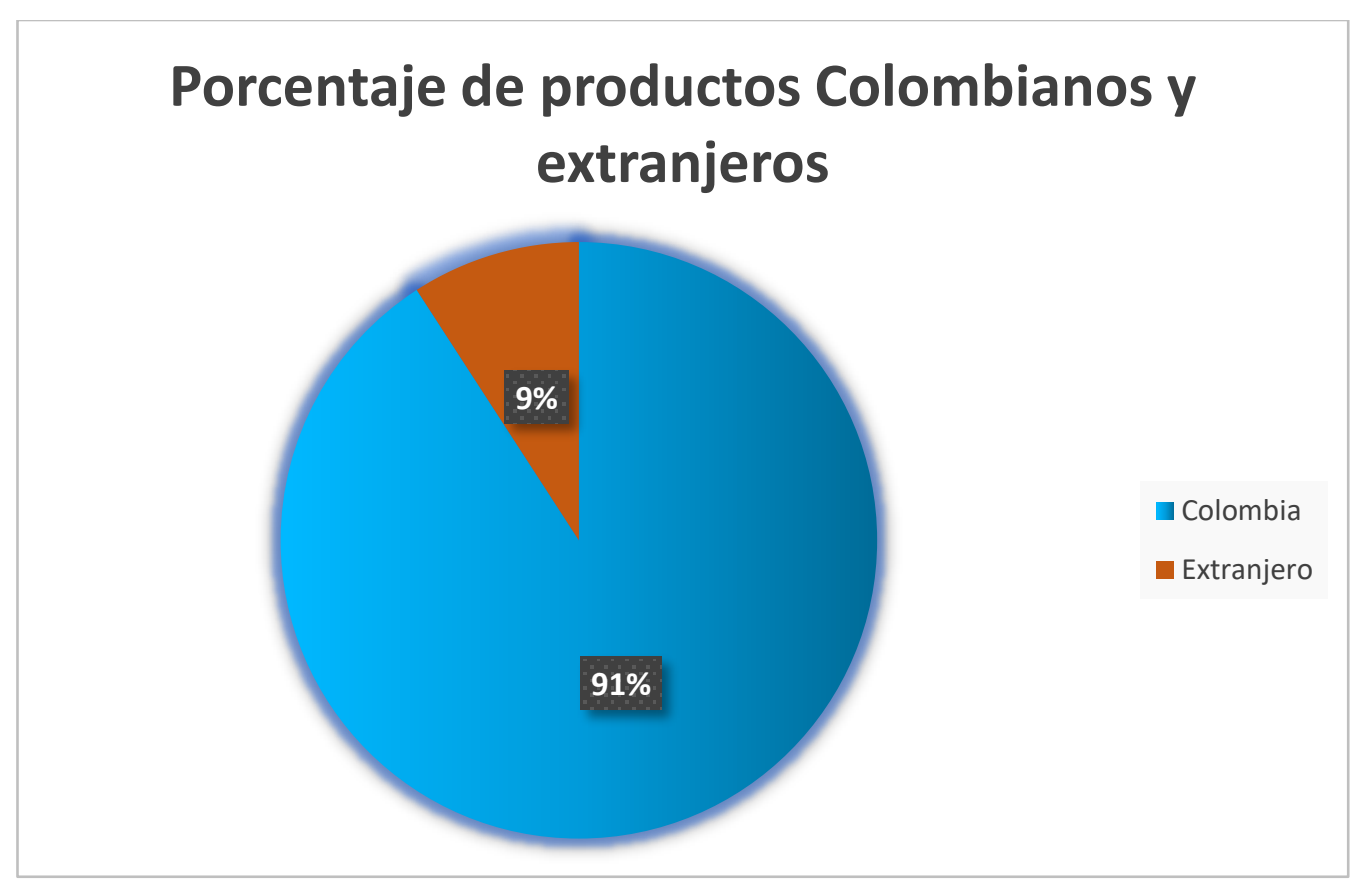

Con base en los resultados obtenidos de la presente investigación, se evidencia una representatividad del $91 \%$ de proveedores Nacionales y un $9 \%$ de proveedores Internacionales aproximadamente. 


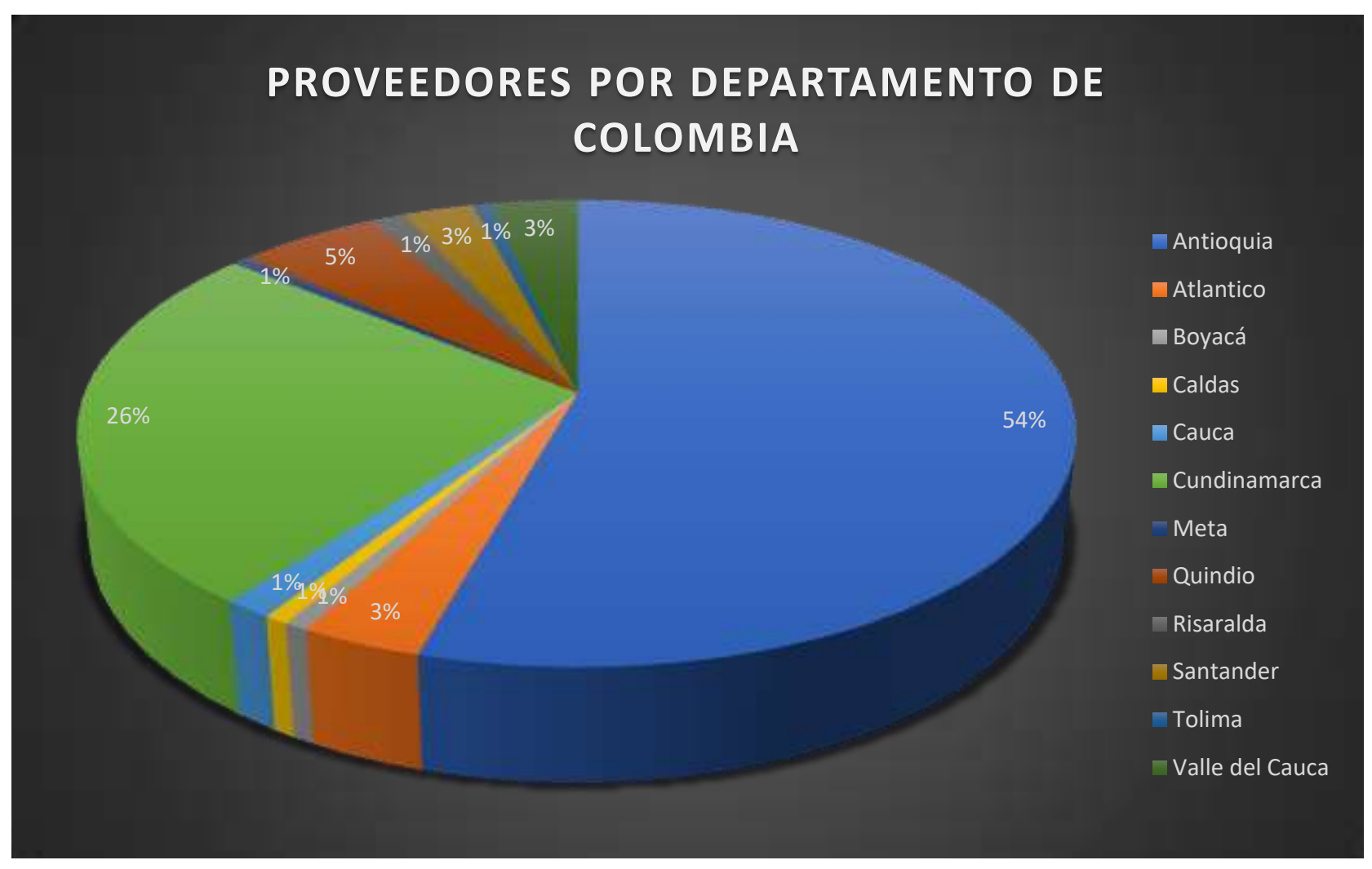

Ilustración 5Porcentaje de proveedores por Departamento (Colombia)

En este diagrama se expone el porcentaje de proveedores a nivel nacional departamental de Mercadería Justo \& Bueno donde se evidencia que el mayor porcentaje de proveedores nacionales se encuentran en el departamento de Antioquia con un 54\%, seguido del departamento de Cundinamarca con un 26\%. Los departamentos con menos proveedores de la compañía son: Atlántico, Boyacá, Caldas, Cauca, Meta, Quindío, Risaralda, Santander, Tolima y Valle del Cauca. 


\section{ANÁLISIS}

Una vez estudiada esta investigación, es procedente realizar un análisis del caso objeto de estudio a fin de plasmar los distintos enfoques doctrinarios contenidos en el marco teórico versus la información recaudada a través de entrevista, encuestas y observación de lo cual se pudo establecer:

\section{- Valores:}

Según los valores manifestados por Camilo Martínez (Orientador operativo) de Mercadería Justo \& Bueno son: autogestión, justicia, colaboración, respeto e integridad, con base en esta respuesta, se compararon con los resultados de la encuesta aplicada a los colaboradores de almacén para ellos los dos valores (respeto y autogestión/autonomía).

Conforme al planteamiento anterior, se trae a colación un pronunciamiento literario de Murray \& Montanari (1986), en el que están de acuerdo con ello pues manifiestan que los valores que inculca la compañía a los colaboradores son reflejados en el producto o servicio generando un valor agregado a la empresa.

Partiendo de ello se puede establecer que los stakeholders (colaboradores de almacén) no poseen un conocimiento claro delos valores de la compañía, lo cual puede generar falta de sentido de pertenencia o imagen errada de la empresa sumado a que los valores de la compañía no son aplicados por los colaboradores en la prestación del servicio, aspecto que se hace evidente mediante el uso de redes sociales como Twitter y Facebook en las cuales se presentan quejas por parte de los usuarios acerca del servicio que se presta, de acuerdo a anexos 2 y 3 , lo cual refleja que existen problemas de sentido de pertenencia por parte de los trabajadores hacia la 
empresa, debido a que no prestan el servicio con los valores de la empresa, trayendo como consecuencia una imagen errada de la compañía.

Acciones sociales y Ambientales:

De acuerdo a la información suministrada por los colaboradores de Mercaderías Justo \& Bueno se pudo establecer los siguientes aspectos:

- Contratación sin discriminación: La mayoría de colaboradores encuestados y entrevistados consideran de manera subjetiva, que este aspecto como una acción social argumentando que en el proceso de contratación es irrelevante la edad, el nivel de estudios, experiencia, condición social, discapacidades, religión o preferencia sexual, argumentando que para la vinculación laboral sólo se requiere tener disposición y actitud para el puesto de trabajo.

Según Fernandez (1999) señala que la RSE se configura cuando se adelantan actuaciones que van más allá del cumplimiento de las obligaciones jurídicas por parte de la empresa, motivo por el cual este enuncia actuaciones empresariales como: una mejor relación interpersonal, más capital humano y respeto al medio ambiente aspectos que en el sentir del autor plasman valores que son de gran influencia de supervivencia de la empresa en un medio "cambiante, globalizado y competitivo como el que nos toca vivir.

En el caso objeto de análisis, es claro que si bien es cierto la empresa vincula laboralmente a personas sin distingo de raza, sexo o edad bajo la perspectiva de este autor se hace claro que no es una acción social en vista que se está dando el mero cumplimiento de obligaciones jurídicas al vincular personal sin distinción alguna (artículo 13 de la Constitución Política), para el desarrollo de actividades propias del 
objeto de la empresa, sin mediar una actuación en valores que va más allá de sus obligaciones jurídicas.

\section{ARTICULO 13 DE LA CONSTITUCION POLITICA DE COLOMBIA.}

Artículo 13 “Todas las personas nacen libres e iguales ante la ley, recibirán la misma protección y trato de las autoridades y gozarán de los mismos derechos, libertades y oportunidades sin ninguna discriminación por razones de sexo, raza, origen nacional o familiar, lengua, religión, opinión política o filosófica. El Estado promoverá las condiciones para que la igualdad sea real y efectiva y adoptará medidas en favor de grupos discriminados o marginados. El Estado protegerá especialmente a aquellas personas que, por su condición económica, física o mental, se encuentren en circunstancia de debilidad manifiesta y sancionará los abusos o maltratos que contra ellas se cometan".

- Convenio con el SENA: para los colaboradores de la empresa investigada, consideran como acción social la vinculación laboral que esta adelanta mediante contrato de aprendizaje con los estudiantes del SENA, a fin de realizar sus prácticas laborales, ello bajo el argumento que beneficia a un grupo de personas para obtener su título como técnico o tecnólogo al adelantar sus prácticas de manera remunerada.

Frente a lo anterior, acudimos a la normatividad que regula este tema como lo es la contenida en: 
El artículo 32 de la ley 789 de 2002 que reza:

\section{“ARTÍCULO 32 Empresas obligadas a la vinculación de aprendices. Las empresas}

privadas, desarrolladas por personas naturales o jurídicas, que realicen cualquier tipo

de actividad económica diferente de la construcción, que ocupen un número de

trabajadores no inferior a quince (15), se encuentran obligadas a vincular aprendices

para los oficios u ocupaciones que requieran formación académica o profesional

metódica y completa en la actividad económica que desempeñan."

El artículo 189 de la ley 115 de 1994, señala:

“Deducción por programas de aprendices. Los empleadores podrán deducir anualmente

de su renta gravable, hasta el $\mathbf{1 3 0 \%}$ de los gastos por salarios y prestaciones sociales de los trabajadores contratados como aprendices, adicionales a los previstos legalmente, en programas de formación profesional previamente aprobados por el Servicio Nacional de Aprendizaje SENA”.

Una vez observado la consideración de los colaboradores al considerar la vinculación de estudiantes del SENA con la empresa, al ser considerada una acción social, se trae a colación a (Friedman, 1973) que al respecto en su obra "The social responsability of bussiness to increpase it profits" determina que la RSE no hace parte de una obligación de la organización, ni un beneficio para ella, ya que el único compromiso es maximizar la riqueza para sus socios, en el caso que nos ocupa se observa que al aplicar esta normativa, a cambio las empresas adquieren descuentos de la renta gravable, aspecto que al momento de deducirlo a cifras implican un amplio beneficio económico al empleador 
toda vez que adquiere un descuento en una suma de dinero real por el solo hechos de adelantar este tipo de vinculaciones mediante contrato de aprendizaje.

En materia normativa, la empresa objeto de estudio aplica las leyes que se han establecido, lo cual para (Carroll, 1979) es una de las responsabilidades básicas empresariales “operar la normatividad legal”. Cabe resaltar que la normatividad es un principio básico para la creación y funcionamiento de toda empresa, no obstante el no cumplimiento de la norma traerá como consecuencia sanciones monetarias o la pérdida del beneficio económico en la renta gravable, por lo tanto Mercadería Justo \& Bueno aplica el beneficio económico y evita inmiscuirse en problemáticas legales.

- $\quad$ Precios bajos: Los colaboradores entrevistados consideran que los precios bajos establecidos por la empresa es una acción social que contribuye un beneficio a la sociedad ya que esta facilita la adquisición de productos de la canasta familiar a menor precio en comparación al mercado. Según Caroll (1979) “la responsabilidad económica se constituye como la producción de bienes y servicios que los consumidores necesitan y desean, en compensación por la entrega de estos bienes, la empresa debe tener una ganancia", si bien es cierto las empresas deben de generar ganancias para el sostenimiento de la misma, pero para el objeto de este trabajo no se puede considerar como una acción social (contribución voluntaria de las empresas) sino como una estrategia de mercado debido a que el ente aplica la maximización por ventas que le genera ganancias de esta.

Además en el estudio de campo se observó que Mercaderías Justo \& Bueno ofrece productos de "marcas blancas o propias" (productos con el nombre del autoservicio

\footnotetext{
5 "Las marcas propias se pueden definir como cualquier producto con el nombre del autoservicio, y se clasifican de la siguiente forma: Marcas blancas. Son productos que se comercializan en el autoservicio y se caracterizan por
} 
(Consuegra, 2003, pág. 53)) característica que según(Duque, 1999) implica un precio bajo debido a que el empresario no invierte en promocionarlo pues estos se rotulan con el nombre de Justo \& Bueno fijando los precios en el que ya está inmerso un margen de beneficio por venta, en consecuencia se hace claro que contrario a lo expuesto por los colaboradores, los precios bajos no se consideran un acción social pues la empresa en comento ya tiene prevista la ganancia o rentabilidad con la venta de este tipo de productos con "marca blanca."

- Ayuda humanitaria: Los trabajadores argumentan que esta acción social se llevó a cabo en el momento del desastre natural de Mocoa ocurrido (31 de marzo de 2017) y Manizales (19 de abril de 2017), debido a que se donaron productos de la canasta familiar a los damnificados. Cuya acción se cataloga según(Abrisketa \& Perez , 2006) como diferentes acciones de ayuda a las víctimas de desastres desencadenados por catástrofes naturales o conflictos armados, por lo tanto esta labor se relaciona cómo beneficio a la sociedad en la cual se ayuda a las personas damnificadas contribuyendo en un situación crítica del país.

Respecto a esta acción Caroll (1979) afirma que "estas acciones incluyen el involucramiento activo de las corporaciones en actividades o programas que promueven el bienestar social y mejoren la calidad de vida de la población" (pág. 4), por lo tanto podemos afirmar que esta actividad la podemos catalogar como acción social porque Mercadería Justo \& Bueno realizó esta acción de manera voluntaria ejerciendo una filantropía según lo establecido por el autor.

llevar el nombre del autoservicio. Marcas privadas: Son productos que se comercializan en el autoservicio y se caracterizan por llevar un nombre diferente al del autoservicio, pero son manejadas como marcas nacionales." (Consuegra, 2003, pág. 53) 


\section{- Acciones Ambientales}

Antes de empezar a desglosar este ítem es necesario traer a colación que los residuos( se denominan como " material que pierde utilidad tras haber cumplido con su misión o servido para realizar un determinado trabajo" (eduteka, 2017) ) se clasifican en orgánicos e inorgánicos

${ }^{6}$.En Mercaderías Justo \& Bueno, de acuerdo a la información suministrada por sus colaboradores señalaron como acciones ambientales: la clasificación de residuos inorgánico( cartón y el plástico), la venta de bolsas plásticas y la destrucción de residuos orgánicos (alimentos vencidos).

De la clasificación de los residuos inorgánicos, los empleados explican que dentro del procedimiento de manipulación de materiales inorgánicos proceden a separar el plástico del cartón y posteriormente es enviado al centro de distribución para ser vendido siendo considerado este actuar por sus empleados como acción ambiental.

Según(Ecologia, 23) señala la importancia de los actores de la sociedad para adelantar acciones para el correcto uso de los residuos a fin de equilibrar el medio ambiente, en el caso objeto de estudio Mercaderías Justo \& Bueno aporta al equilibrio ambiental al momento que clasifica los

\footnotetext{
${ }^{6}$ Según(eduteka, 2017)la palabra residuo (con origen en el latín residium) describe al material que pierde utilidad tras haber cumplido con su misión o servido para realizar un determinado trabajo. El concepto se emplea como sinónimo de basura por hacer referencia a los desechosque el hombre ha producido.

Para generalizar, podemos decir que los residuos domiciliarios se dividen en orgánicos y no-orgánicos o inorgánicos.

Residuos orgánicos: son biodegradables (se descomponen naturalmente). Son aquellos que tienen la característica de poder desintegrarse o degradarse rápidamente, transformándose en otro tipo de materia orgánica. Ejemplo: los restos de comida, frutas y verduras, sus cáscaras, carne, huevos.

Residuos inorgánicos: son los que por sus características químicas sufren una descomposición natural muy lenta. Muchos de ellos son de origen natural pero no son biodegradables, por ejemplo, los envases de plástico. Generalmente se reciclan a través de métodos artificiales y mecánicos, como las latas, vidrios, plásticos, gomas. En muchos casos es imposible su transformación o reciclaje; esto ocurre con el talgo por, que seguirá presente en el planeta dentro de 500 años. Otros, como las pilas, son peligrosos y contaminantes.
} 
productos inorgánicos pues una vez adelanta esta actuación es vendido con la finalidad de darle una utilidad a estos residuos de tipo inorgánico frente a lo cual estamos de acuerdo con los colaboradores al señalar que esta es una acción ambiental en vista que ayuda mitigar el impacto medio ambiental

De los residuos orgánicos e inorgánico, ello se da por la expiración de la fecha de vencimiento de los mismos, que de acuerdo a lo informado verbalmente por Camilo Martínez (orientador operativo de Mercadería Justo \& Bueno) afirma que le sacan foto al producto que van a desechar y remiten esta información a la intranet denominada merca post, y proceden a arrojar a la basura los productos ya mencionados, con la observación que en caso que allá un detergente vencido dentro los mismos lo esparcen este sobre los residuos vencidos ( con el fin que no sea apto para el consumo humano).

Según (blogvillapinzon, 2012) la manera correcta o incorrecta de la manipulación de los "residuos sólidos y en proceso de reciclaje" incide en la generación de problemáticas de medio ambiente en el caso que nos ocupa se observa que no se da el uso adecuado de los residuos orgánicos o inorgánicos al momento de arrojar a la basura sin un procedimiento adecuado para el manejo de estos productos sino proceden a arrojarlos aspecto que en los términos de este autor implica una incidencia de problemas ambientales, aspecto con el cual estamos de acuerdo.

De la venta de Bolsas Plásticas de acuerdo a lo observado se da en Mercaderías Justo \& Bueno la venta de bolsas plásticas, en el que sus colaboradores señalan que esta es una acción ambiental toda vez que contribuyen a disminuir su uso, ayudando a mitigar el impacto ambiental. 
En Colombia la Resolución 668 de 2016 emitida por el Ministerio de Medio Ambiente y Desarrollo Sostenible reglamenta el uso racional de bolsas en el que divulga el cobro mínimo de la bolsa plástica en el mercado ( artículo 11 literal a de Resolución 668 de 2016) Con lo anteriormente dicho podemos inferir que la empresa actualmente realiza procesos ambientales obligatorios de lo cual se infiere que adelanta acciones ambientales en cumplimiento a un marco legal, frente a lo cual estamos totalmente de acuerdo en vista de lo observado en la presente investigación en el que se observa actualmente el cabal cumplimiento.

\section{- Capacitación en Servicio al Cliente}

Así mismo se indagó sobre los programas de capacitación que realiza la empresa a sus trabajadores en el que la mayor parte de las personas encuestadas manifestaron que estas son enfocadas en su gran mayoría en servicio al cliente, afianzadas a sus funciones en el almacén.

Partiendo de lo anterior, se puede deducir que la compañía visualiza a los almacenes como una pequeña empresa, a causa de ello suscita capacitaciones para potencializar las habilidades de sus trabajadores en materia de servicio al cliente, no obstante esto en virtud a las entrevistas adelantadas a sus colaboradores estos no tenían pleno conocimiento de los valores de la compañía sumado a que en redes sociales se presentaron quejas por indebida atención al

cliente, es de aclarar que esta afirmación se basa en la información suministrada aspecto que ya fue objeto de pronunciamiento en el ítem de valores del presente acápite. 


\section{- Comunicación Interna y Externa}

De la Comunicación Interna, en Mercaderías Justo \& Bueno de acuerdo a las encuestas adelantadas con el personal se identificó como medios de comunicación interno: el WhatsApp y la intranet "Mercapost".

Del WhatsApp, este es un grupo que está integrado por los números de teléfono de los denominados “ lideres u orientador" de cada tienda ( supervisor ) la cual corresponden a una zona específica de acuerdo a la ubicación geográfica la cual denominan como "mini región” ( anexo 5). De la intranet, se observó en el estudio de campo la existencia de la plataforma nombrada como "Mercapost" plataforma que permite la facilidad y rapidez de comunicación entre las mini regiones.

De los dos aspectos enunciados hace referencia a medios de comunicación entre la denominadas "mini regiones" aspecto que es positivo ya que fortalece la comunicación entre los líderes de cada una de la tiendas para un mejor funcionamiento, no obstante en cuanto a la comunicación entre el líder y los colaboradores ( subalternos) del almacén fue informada falencias debido a que los primeros realizan la respectiva supervisión de la tiendas unos días específicos en cuya visita algunos de ellos no están prestos a escuchar las sugerencias o requerimientos del personal del lugar solo se limitan a hacer los requerimientos del productos (de acuerdo a lo expuesto por los colaboradores) siendo la comunicación entre líderes (jefes) y los colaboradores deficiente, lo anteriormente mencionado. Por su parte Caroll (1979) afirma que la responsabilidad ética se refieren a "la obligación de hacer lo correcto, justo y razonable, así como de evitar o minimizar el daño a los grupos con los que se relaciona la empresa” (pág. 4), en este caso stakeholders (la relación entre líder y colaborador), la empresa en comento no 
realiza una responsabilidad ética ya que no evita o minimiza el daño a los grupos en este caso la comunicación interna de la tienda.

Según (kaku, 2005) plantea una filosofía empresarial basada en (kaku, 2005) "la filosofía del espíritu de la cooperación" (Pág. 3) en la cual las empresas deben de ser responsables con base en la filosofía que este plantea, su principal concepción es que si el fin principal es solo ganar dinero llevarían a futuro a una quiebra económica cuya solución es que las personas y las compañías trabajan de manera conjunta para lograr el bien común, estos establecen una relación armónica con los clientes, proveedores, competidores, gobierno y el medio ambiente, convirtiéndose en un instrumento positivo para un cambio significativo en los distintos ámbitos.

De acuerdo a lo expuesto, por el autor este plantea un nivel de cooperativismo mutuo entre los miembros de la organización en el caso de Mercaderías Justo y Bueno se materializa parcialmente esta filosofía ya que no hay una buena comunicación entre los líderes y los colaboradores aspecto que afecta a la tienda toda vez que en la medida que no se coloca en conocimiento las falencias del funcionamiento de la misma a la sede administrativa de la empresa afectando el normal funcionamiento de la tienda que en el caso que nos ocupa es el bien común de las partes que intervienen.

De la Comunicación Externa, esta se practica mediante volanteo, voz a voz y degustación, canales tradicionales que permiten dar información al cliente y atraerlo. Cabe resaltar que la comunicación externa puede mejorar adicionando otras estrategias de comunicación y el mejoramiento de la página web de la empresa ya que se evidencia poca información y contacto con el cliente en ella. (Anexo 4). 
También evidencia presencia en redes sociales como Facebook, Instagram y Twitter, pero falta promocionar sus redes sociales en los almacenes incentivando al cliente a participar en ellas debido a que en la sociedad actual las redes sociales son un canal influyente al consumidor en su decisión de compra, en algunas de estas redes sociales se responde algunas quejas de usuarios virtualmente, así mismo la empresa establece un formato de quejas y reclamos el cual se puede diligenciar de manera escrita en el almacén y tendrá un tiempo de respuesta de 24 horas, este tipo de comunicación externa materializa un nivel de cooperación entre las partes tal como lo predica (kaku, 2005) al momento en que los clientes colocan en conocimientos sus requerimientos.

\section{- Marketing Green}

Con respecto al marketing Green se evidenció que Mercadería Justo \& Bueno no practican este mercadeo ecológico debido a que se define como:

El esfuerzo por una empresa para diseñar, promover, precio y distribución de productos en una de manera que promueve la protección del medio ambiente Además, si un ente económico aplica este concepto maximiza los beneficios, reducen la contaminación del medio ambiente, conservar los recursos naturales, protegen el medio ambiente y obtienen una ventaja competitiva”. (Iguarin\& Cavazos, 2015, pág. 35)

Además Pizzinatto\&Giuliani, (2015) afirma que el Green marketing sirve como un mecanismo para cuidar el ambiente y que las empresas quienes más las desgastan hagan lo posible por minimizar el impacto medioambiental, este fenómeno también interviene en la decisión de compra, debido a que gran parte de las personas prefieren adquirir productos cuya marca o empresa contribuyan al medio ambiente. 
La protección del medio ambiente es uno de los factores claves del marketing Green, este factor se puede configura como un bien común debido a que el ambiente es un factor común de la sociedad, es decir el medio ambiente es un bien que se advoca como común porque es de todos, en consecuencia Adela Cortina propone la creación de redes de consumidores que tengan como objetivo construir un ciudadano autónomo y dejar a un lado al vasallo de los bienes de consumo.

Con base en lo anteriormente mencionado, se puede dilucidar que ninguno de sus productos o promociones poseen el factor de marketing Green la afirmación se realiza por el instrumento aplicado de observación ya que no se conservan los recursos naturales

En materia de la decisión de compra del consumidor se puede traer a colación a la ética del consumo planteada por Adela Cortina, la cual pronuncia que para que el ser humano sea un ciudadano autónomo en la decisión, el productor en este caso el intermediario (Mercadería Justo \&Bueno) debe de informar acerca de las consecuencias (positivas y negativas) medioambientales que acarrea el consumo de productos, además debe promover la creación de otros hábitos, estilos de vida que permitan la sostenibilidad ambiental por medio del marketing, dejando a un lado las falsas creencias sociales en el que el éxito es tener bienes de consumo

\section{Aspectos a Mejorar}

Así mismo se preguntó a los colaboradores sobre los aspectos en que puede mejorar la empresa para lo que los colaboradores respondieron seguridad, motivación al trabajador y capacitación en programas ambientales, la gran mayoría de las personas encuestadas coincidieron en seguridad debido a que no cuentan con un vigilante en el almacén para la eventualidad de robo y agresiones a colaboradores y clientes. 


\section{Proveedores}

El tercer instrumento que inicialmente estaba propuesto como una entrevista dirigida al área de compras de Mercadería Justo \& Bueno con el fin de indagar acerca de los proveedores nacionales e internacionales de la compañía y aspectos corporativos, lo cual no fue posible llevar a cabo por motivos de confidencialidad de la información.

Por lo tanto, se propuso una aplicación de visita de observación a distintos almacenes de Mercadería Justo \& Bueno en la ciudad de Bogotá; Con base en lo observado se realizó la creación de la siguiente tabla en la cual se refleja aspectos como: producto, proveedor, país origen del proveedor, departamento y Ciudad. Cabe resaltar que la información que contiene la figura es aproximada debido a que no se encuentra todos los productos que ofrece Mercadería Justo \& Bueno.

\begin{tabular}{|c|c|c|c|c|}
\hline PRODUCTO & PROVEEDOR & PAIS & DEPARTAMENTO & CIUDAD \\
\hline \multicolumn{5}{|c|}{ VARIOS } \\
\hline Browne Chocolate & $\begin{array}{c}\text { Pastel delpan La } \\
\text { enviada de Buenos } \\
\text { Aires }\end{array}$ & Colombia & Antioquia & Medellín \\
\hline $\begin{array}{l}\text { Chusquitas } \\
\text { (Galletas) }\end{array}$ & Grupo Bimbo & Colombia & Cundinamarca & Bogotá \\
\hline Pan de Yuca & $\begin{array}{c}\text { Productos Ponque } \\
\text { Rico S.A.S }\end{array}$ & Colombia & Antioquia & Medellín \\
\hline $\begin{array}{c}\text { Pan de Arroz } \\
\text { (Roscas de arroz) }\end{array}$ & $\begin{array}{c}\text { Comestibles El } \\
\text { Galvan S.AS }\end{array}$ & Colombia & Meta & Villavicencio \\
\hline Pastel de Guayaba & $\begin{array}{c}\text { Productos } \\
\text { Alimenticios Pan } \\
\text { Arabe S.A.S }\end{array}$ & Colombia & Antioquia & Medellín \\
\hline $\begin{array}{c}\text { Arroz Integral con } \\
\text { Quinua }\end{array}$ & Kanvansay & Colombia & Cundinamarca & Bogotá \\
\hline DeliziaPasapalos & Famsas S.A.S & Colombia & Antioquia & Rionegro \\
\hline Palitroques & Famsas S.A.S & Colombia & Antioquia & Rionegro \\
\hline DeliziaPasapalos & Famsas S.A.S & Colombia & Antioquia & Rionegro \\
\hline $\begin{array}{c}\text { Steba (Tostadas con } \\
\text { Maiz) }\end{array}$ & Seba S.A.S & Colombia & Antioquia & Itagüí \\
\hline
\end{tabular}




\begin{tabular}{|c|c|c|c|c|}
\hline Delizia Miga de Pan & Famsas S.A.S & Colombia & Antioquia & Rionegro \\
\hline Pan de Leche & $\begin{array}{c}\text { Panificadora Produpan } \\
\text { S.A.S }\end{array}$ & Colombia & Antioquia & Medellín \\
\hline Pan Caiman & $\begin{array}{c}\text { Panificadora Produpan } \\
\text { S.A.S }\end{array}$ & Colombia & Antioquia & Envigado \\
\hline Mogolla Blanca & $\begin{array}{c}\text { Productos } \\
\text { Alimenticios Pan } \\
\text { Arabe S.A.S } \\
\end{array}$ & Colombia & Antioquia & Medellín \\
\hline $\begin{array}{l}\text { Las Caseritas } \\
\text { (Galleta con } \\
\text { Mantequilla) } \\
\end{array}$ & $\begin{array}{c}\text { Productos } \\
\text { Alimenticios las } \\
\text { Caseritas S.A }\end{array}$ & Colombia & Antioquia & Sabaneta \\
\hline Galletas Cucas & $\begin{array}{c}\text { Productos } \\
\text { Alimenticios Pan } \\
\text { Arabe S.A.S } \\
\end{array}$ & Colombia & Antioquia & Medellín \\
\hline Produpan & $\begin{array}{c}\text { Panificadora Produpan } \\
\text { S.A.S } \\
\end{array}$ & Colombia & Antioquia & Envigado \\
\hline $\begin{array}{c}\text { Las Caseritas } \\
\text { (Galletas Sutidas) }\end{array}$ & $\begin{array}{c}\text { Productos } \\
\text { Alimenticios las } \\
\text { Caseritas S.A } \\
\end{array}$ & Colombia & Antioquia & Sabaneta \\
\hline $\begin{array}{l}\text { Delizia Mini } \\
\text { Tostada }\end{array}$ & Famsas S.A.S & Colombia & Antioquia & Rionegro \\
\hline $\begin{array}{c}\text { Seba Mini } \\
\text { Bizcochitos }\end{array}$ & Seba S.A.S & Colombia & Antioquia & Itagüí \\
\hline Mantequilla & Harinera del Vale S.A & Colombia & Valle del Cauca & Yumbo \\
\hline Salsa Tartara & $\begin{array}{c}\text { Frigorifico de la costa } \\
\text { SAS } \\
\end{array}$ & Colombia & Atlantico & Barranquilla \\
\hline Salsa de piña & Ascender SA & Colombia & Antioquia & La estrella \\
\hline Vinagreta & Frugal SA & Colombia & Antioquia & Sabaneta \\
\hline Salsa negra & $\begin{array}{c}\text { Frigorifico de la costa } \\
\text { SAS } \\
\end{array}$ & Colombia & Atlantico & Barranquilla \\
\hline Mermalada de piña & Frugal SA & Colombia & Antioquia & Sabaneta \\
\hline Miel de abejas & $\begin{array}{c}\text { Productos el dorado } \\
\text { SA } \\
\end{array}$ & Colombia & Cundinamarca & Bogotá \\
\hline Mayonesa & Frugal SA & Colombia & Antioquia & Sabaneta \\
\hline Mayonesa & Frugal SA & Colombia & Antioquia & Sabaneta \\
\hline Adobo & Delika & Colombia & Bogotá & Bogotá \\
\hline Sopa de fideos & $\begin{array}{c}\text { Compañía industrial } \\
\text { de cereales }\end{array}$ & Colombia & Bogotá & Bogotá \\
\hline Agua & RTD SAS & Colombia & Antioquia & Bello \\
\hline Crema de cebolla & $\begin{array}{c}\text { Compañía industrial } \\
\text { de cereales }\end{array}$ & Colombia & Bogotá & Bogotá \\
\hline Sopa instantanea & Sunlife & Colombia & Cauca & Timbo \\
\hline Sal rosada & Himalaya & Colombia & & \\
\hline Tamal Tolimense & Incolar SA & Colombia & Bogotá & Bogotá \\
\hline
\end{tabular}




\begin{tabular}{|c|c|c|c|c|}
\hline Salchicha enlatada & Incolar SA & Colombia & Bogotá & Bogotá \\
\hline Color & Badiaspices & Colombia & Antioquia & La estrella \\
\hline Cabello de ángel & Incoharinas & Colombia & Santander & Bucaramanga \\
\hline Semillas de chía & $\begin{array}{l}\text { Packing and } \\
\text { distributed }\end{array}$ & Colombia & Cundinamarca & Bogotá \\
\hline Manzanilla en polvo & $\begin{array}{c}\text { Cadenas centrales } \\
\text { LTDA }\end{array}$ & Colombia & Risaralda & \begin{tabular}{|c} 
Dosquebrada \\
s
\end{tabular} \\
\hline Canela en polvo & Badiaspices & Colombia & Antioquia & La estrella \\
\hline Compota & Babyfruit & Colombia & Bogotá & Bogotá \\
\hline Colada & Gironés & Colombia & Santander & Bucaramanga \\
\hline Granola & $\begin{array}{c}\text { Compañía de cereales } \\
\text { SA }\end{array}$ & Colombia & Antioquia & La estrella \\
\hline Granola & Antardico & Colombia & Bogotá & Bogotá \\
\hline Cereal de chocolate & Congrupo SA & Colombia & Cundinamarca & Cota \\
\hline Avena & $\begin{array}{c}\text { Compañía de cereales } \\
\text { SA }\end{array}$ & Colombia & Antioquia & La estrella \\
\hline $\begin{array}{l}\text { leche en polvo de } \\
\text { chocolate }\end{array}$ & $\begin{array}{c}\text { Elite Max nutrition } \\
\text { SAS }\end{array}$ & Colombia & Antioquia & Itagüí \\
\hline Mezcla de torta & Frugal SA & Colombia & Antioquia & Sabaneta \\
\hline Brownie & Frugal SA & Colombia & Antioquia & Sabaneta \\
\hline Arroz integral & $\begin{array}{c}\text { Biodistribuciones } \\
\text { Terra SA }\end{array}$ & Colombia & Cundinamarca & Bogotá \\
\hline Agua arómatica & Congrupo SA & Colombia & Cundinamarca & Cota \\
\hline Endulzante natural & Funat SA & Colombia & Antioquia & Medellín \\
\hline Panela orgánica & La alsacia & Colombia & Valle del Cauca & San Pedro \\
\hline Ciruelas & $\begin{array}{c}\text { Frigorifico de la costa } \\
\text { SAS }\end{array}$ & Colombia & Atlantico & Barranquilla \\
\hline Té en polvo & Frugal SA & Colombia & Antioquia & Sabaneta \\
\hline $\begin{array}{l}\text { Panela en polvo con } \\
\text { limón }\end{array}$ & $\begin{array}{c}\text { Multingeniosmakariza } \\
\text { SA }\end{array}$ & Colombia & Bucaramanga & Barbosa \\
\hline $\begin{array}{c}\text { Bolsa arómaticas de } \\
\text { panela }\end{array}$ & Doña panela LTDA & Colombia & Boyacá & Tintaraque \\
\hline Café instantáneo & Descafeinado SA & Colombia & Caldas & Manizales \\
\hline Chocolate & Girones & Colombia & Santander & Floridablanca \\
\hline Galletas & Comestibles integrales & Colombia & Risaralda & \begin{tabular}{|c} 
Dosquebrada \\
s
\end{tabular} \\
\hline Gelatina de pata & $\begin{array}{c}\text { Distribuidora locuras } \\
\text { del sabor }\end{array}$ & Colombia & Antioquia & Medellín \\
\hline Dulce de coco & $\begin{array}{l}\text { Cardona londoño y } \\
\text { compañias SA }\end{array}$ & Colombia & Antioquia & Guame \\
\hline Bocadillos & Monar SA & Colombia & Antioquia & Guame \\
\hline Dulce de coco & Dulces conchita & Colombia & Antioquia & Envigado \\
\hline $\begin{array}{c}\text { Panelas de arequipe } \\
\text { y coco }\end{array}$ & productos yupi SA & Colombia & Antioquia & Medellín \\
\hline
\end{tabular}




\begin{tabular}{|c|c|c|c|c|}
\hline Chicharrones & Croc SAS & Colombia & Cundinamarca & Bogotá \\
\hline Mani & megamarket SAS & Colombia & Antioquia & Medellín \\
\hline $\begin{array}{c}\text { ubas pasas con } \\
\text { sabor a chocolate }\end{array}$ & Quinoa & Colombia & Valle del Cauca & Palmira \\
\hline Galleta de coco & $\begin{array}{c}\text { Compañía nacional de } \\
\text { pasabocas piquitos } \\
\text { LTDA }\end{array}$ & Colombia & Cundinamarca & Madrid \\
\hline Nachos & Un solo proveedor SA & Colombia & Antioquia & Itagüí \\
\hline $\begin{array}{l}\text { Mezcla para } \\
\text { empanadas }\end{array}$ & Bellini SA & Colombia & Cundinamarca & Madrid \\
\hline Harina de trigo & Soberanas SA & Colombia & Antioquia & Itagüí \\
\hline Frijol & $\begin{array}{c}\text { Granos y alimentos de } \\
\text { colombia SA }\end{array}$ & Colombia & Atlantico & Barranquilla \\
\hline Aceite & CJ Yumbo SA & Colombia & Valle del Cauca & Yumbo \\
\hline Tortilla integral & Un solo proveedor SA & Colombia & Antioquia & Itagüí \\
\hline carne enlatada & Un solo proveedor SA & Colombia & Antioquia & Itagüí \\
\hline Natilla & $\begin{array}{c}\text { Compañía de cereales } \\
\text { SA }\end{array}$ & Colombia & Antioquia & La estrella \\
\hline Jalapeño & $\begin{array}{c}\text { Conservas gran union } \\
\text { LTDA }\end{array}$ & Colombia & Cundinamarca & Bogotá \\
\hline Huevos de codorniz & La hojarasca & Colombia & Cundinamarca & Bogotá \\
\hline Huevos & Avicola & Colombia & Tolima & Ibagué \\
\hline \multicolumn{5}{|c|}{ BEBIDAS } \\
\hline Jugo de limon & JannaFoods SAS & Colombia & Atlantico & Baranoa \\
\hline Te liquido & RTD SAS & Colombia & Antioquia & Bello \\
\hline Gaseosa cola negra & RTD SAS & Colombia & Antioquia & Bello \\
\hline Jugo de mandarina & RTD SAS & Colombia & Antioquia & Bello \\
\hline agua carbonatada & RTD SAS & Colombia & Antioquia & Bello \\
\hline \multicolumn{5}{|c|}{ LACTEOS } \\
\hline Bolsa de Leche & $\begin{array}{l}\text { Productos Lácteos } \\
\text { Colfrance }\end{array}$ & Colombia & Cundinamarca & Fúquene \\
\hline Yogurt Griego & $\begin{array}{l}\text { Productos Lácteos } \\
\text { Colfrance }\end{array}$ & Colombia & Cundinamarca & Fúquene \\
\hline $\begin{array}{l}\text { Bebida Lactea de } \\
\text { Yogurt }\end{array}$ & $\begin{array}{l}\text { Productos Lácteos } \\
\text { Colfrance }\end{array}$ & Colombia & Cundinamarca & Fúquene \\
\hline Leche Entera & $\begin{array}{l}\text { Productos Lácteos } \\
\text { Colfrance }\end{array}$ & Colombia & Cundinamarca & Fúquene \\
\hline Leche Deslactosada & $\begin{array}{l}\text { Productos Lácteos } \\
\text { Colfrance }\end{array}$ & Colombia & Cundinamarca & Fúquene \\
\hline $\begin{array}{c}\text { Queso Mozarella } \\
\text { Bloque }\end{array}$ & $\begin{array}{l}\text { Productos Lácteos } \\
\text { Colfrance }\end{array}$ & Colombia & Cundinamarca & Fúquene \\
\hline $\begin{array}{l}\text { Queso Holandes } \\
\text { Tajado } \\
\end{array}$ & $\begin{array}{l}\text { Productos Lácteos } \\
\text { Colfrance }\end{array}$ & Colombia & Cundinamarca & Fúquene \\
\hline Queso Rallado & Productos Lácteos & Colombia & Cundinamarca & Fúquene \\
\hline
\end{tabular}




\begin{tabular}{|c|c|c|c|c|}
\hline Parmesano & Colfrance & & & \\
\hline Queso Pera & $\begin{array}{l}\text { Productos Lácteos } \\
\text { Colfrance }\end{array}$ & Colombia & Cundinamarca & Fúquene \\
\hline $\begin{array}{l}\text { Queso Mozarella } \\
\text { Tajado }\end{array}$ & $\begin{array}{l}\text { Productos Lácteos } \\
\text { Colfrance }\end{array}$ & Colombia & Cundinamarca & Fúquene \\
\hline Suero Costeño & $\begin{array}{l}\text { Productos Lácteos } \\
\text { Colfrance }\end{array}$ & Colombia & Cundinamarca & Fúquene \\
\hline $\begin{array}{l}\text { Becasine (queso } \\
\text { para untar) }\end{array}$ & Desplechin S.A.S & Colombia & Cundinamarca & Bogotá \\
\hline \multicolumn{5}{|c|}{ REFRIGERANTES } \\
\hline $\begin{array}{c}\text { Arepa de Maiz } \\
\text { Blanca }\end{array}$ & $\begin{array}{c}\text { Productos } \\
\text { Alimenticios de la } \\
\text { Finca } \\
\end{array}$ & Colombia & Antioquia & Bello \\
\hline $\begin{array}{l}\text { Arepa Minitela } \\
\text { Blanca }\end{array}$ & $\begin{array}{c}\text { Productos } \\
\text { Alimenticios de la } \\
\text { Finca } \\
\end{array}$ & Colombia & Antioquia & Bello \\
\hline Salchicha Parrilla & CCB S.A & Colombia & Antioquia & Medellín \\
\hline Jamón Premium & CCB S.A & Colombia & Antioquia & Medellín \\
\hline $\begin{array}{c}\text { Mortadela } \\
\text { Tradicional } \\
\end{array}$ & CCB S.A & Colombia & Antioquia & Medellín \\
\hline $\begin{array}{c}\text { Salchicha } \\
\text { Tradicional }\end{array}$ & CCB S.A & Colombia & Antioquia & Medellín \\
\hline Salchicha Big Dog & CCB S.A & Colombia & Antioquia & Medellín \\
\hline $\begin{array}{c}\text { Chorizo Coctel } \\
\text { Tradicional }\end{array}$ & CCB S.A & Colombia & Antioquia & Medellín \\
\hline Carnelly & Carnes Casablanca & Colombia & Antioquia & Medellín \\
\hline \multicolumn{5}{|c|}{ FRUTAS } \\
\hline Mango & Inversfruit S.AS & Colombia & Antioquia & Medellín \\
\hline Naranja & Inversfruit S.AS & Colombia & Antioquia & Medellín \\
\hline Cebollas & Inversfruit S.AS & Colombia & Antioquia & Medellín \\
\hline Ajo & SuperGarlic & China & & \\
\hline Aguacate & Inversfruit S.AS & Colombia & Antioquia & Medellín \\
\hline Lulo & Inversfruit S.AS & Colombia & Antioquia & Medellín \\
\hline Platano & Linea Verde & Colombia & Antioquia & Medellín \\
\hline Papas & Línea Verde & Colombia & Antioquia & Medellín \\
\hline Tomates & Línea Verde & Colombia & Antioquia & Medellín \\
\hline \multicolumn{5}{|c|}{ ASEO } \\
\hline Sanko (shampoo) & VelclaCosmeticos & Colombia & Antioquia & Medellín \\
\hline Gel Antibacterial & VelclaCosmeticos & Colombia & Quindio & Tebaida \\
\hline Jabón Liquido & LatinProducts & Colombia & Valle del Cauca & Yumbo \\
\hline $\begin{array}{l}\text { Hechicera (limpia } \\
\text { Muebles) }\end{array}$ & VelclaCosmeticos & Colombia & Antioquia & Medellín \\
\hline Guante de Limpieza & Plus Solutions S.A.S & China & & \\
\hline
\end{tabular}




\begin{tabular}{|c|c|c|c|c|}
\hline Bolsa Resellable & Sellopack & Colombia & Cundinamarca & Mosquera \\
\hline Plástico Adeherente & Aluminio Nacional & Colombia & Cundinamarca & Bogotá \\
\hline Papel higienico & PDCS SA & Colombia & Cauca & Puerto Tejada \\
\hline Detergente liquido & $\begin{array}{c}\text { Berhlan de colombia } \\
\text { SA }\end{array}$ & Colombia & Quindío & La Tebaida \\
\hline Suavizante de ropa & $\begin{array}{c}\text { Berhlan de colombia } \\
\text { SA }\end{array}$ & Colombia & Quindío & La Tebaida \\
\hline Suflan & $\begin{array}{l}\text { Berhlan de colombia } \\
\text { SA }\end{array}$ & Colombia & Quindío & La Tebaida \\
\hline Suflan & Fepromel SAS & Colombia & Antioquia & Medellín \\
\hline Detergente liquido & Fepromel SAS & Colombia & Antioquia & Medellín \\
\hline Detergente en polvo & $\begin{array}{c}\text { Industriales la victoria } \\
\text { SA }\end{array}$ & Colombia & Bogotá & Bogotá \\
\hline $\begin{array}{c}\text { Jabón pasa losa } \\
\text { liquido }\end{array}$ & $\begin{array}{c}\text { Berhlan de colombia } \\
\text { SA } \\
\end{array}$ & Colombia & Quindío & La Tebaida \\
\hline $\begin{array}{c}\text { Jabón para losa en } \\
\text { barra }\end{array}$ & Brinza SA & Colombia & Cundinamarca & Cajicá \\
\hline $\begin{array}{c}\text { Jabón para losa en } \\
\text { barra }\end{array}$ & $\begin{array}{c}\text { Berhlan de colombia } \\
\text { SA }\end{array}$ & Colombia & Quindío & La Tebaida \\
\hline $\begin{array}{c}\text { Crema dental para } \\
\text { niños }\end{array}$ & Proquident SA & Colombia & Antioquia & Envigado \\
\hline Enjuague bulcal & Proquident SA & Colombia & Antioquia & Envigado \\
\hline Talcos & Prebel SA & Colombia & Antioquia & Medellín \\
\hline Rodajas de algodón & LHX SAS & Colombia & Antioquia & Itagüí \\
\hline $\begin{array}{c}\text { Bolsas } \\
\text { biodegradables }\end{array}$ & $\begin{array}{c}\text { Logus } \\
\text { representaciones SAS }\end{array}$ & Colombia & Antioquia & Medellín \\
\hline Desechables & Vemesa & Colombia & Antioquia & La estrella \\
\hline \multicolumn{5}{|c|}{ LICORES } \\
\hline Vino & Orfila & Argentina & & \\
\hline Wisky & $\begin{array}{c}\text { Licores del Quindío } \\
\text { Coloma LTDA }\end{array}$ & Colombia & Quindío & Armenia \\
\hline Wisky & Bledenscotch Whisky & Escocia & & \\
\hline Coctel & $\begin{array}{l}\text { Licores del Quindío } \\
\text { Coloma LTDA }\end{array}$ & Colombia & Quindío & Armenia \\
\hline Coctel & Joron SAS & Colombia & Bogotá & Bogotá \\
\hline Cerveza & GettingerBrauerei & Alemania & & \\
\hline \multicolumn{5}{|c|}{ PRODUCTO PARA MASCOTAS } \\
\hline $\begin{array}{c}\text { Shampoo original } \\
\text { para perro }\end{array}$ & Laboratorio Saenz S.A & Colombia & Antioquia & Medellín \\
\hline $\begin{array}{c}\text { Concentrado para } \\
\text { perros }\end{array}$ & Hercosul Alimentos & Brasil & & \\
\hline $\begin{array}{c}\text { Sabor y Vida para } \\
\text { gatos }\end{array}$ & Manufactured & Brasil & & \\
\hline Juguete comestible & Logus & Colombia & Antioquia & Medellín \\
\hline
\end{tabular}




\begin{tabular}{|c|c|c|c|c|} 
para gatos & representaciones S.A.S & & Medellín \\
\hline $\begin{array}{c}\text { Huesos de Carnaza } \\
\text { para perro }\end{array}$ & $\begin{array}{c}\text { Logus } \\
\text { representaciones S.A.S } \\
\text { Comercializadora } \\
\text { Colombiana S.A.S }\end{array}$ & Colombia & Antioquia & Bogotá \\
\hline $\begin{array}{c}\text { Goncentras para perro } \\
\text { perros }\end{array}$ & $\begin{array}{c}\text { Compañía Industrial } \\
\text { de productos } \\
\text { Agropecuarios }\end{array}$ & Colombia & Antioquia & Bello \\
\hline Arena para gatos & $\begin{array}{c}\text { Compañía Industrial } \\
\text { de productos } \\
\text { Agropecuarios }\end{array}$ & Colombia & Antioquia & Bello \\
\hline $\begin{array}{c}\text { Alimento para } \\
\text { canarios }\end{array}$ & Vitagrano & Colombia & Antioquia & Itagüí \\
\hline Comida para gatos & Contegral S.A & Colombia & Antioquia & Itagüí \\
\hline
\end{tabular}

De la observación realizada en los distintos puntos de venta de Mercadería Justo \& Bueno, se puede afirmar que según lo expuesto en la entrevista (primer instrumento) a Camilo Martínez (Orientador Operativo) el cual expresó “el $80 \%$ de nuestros productos son nacionales”, es verídico ya que según la investigación realizada el 91\% (149 proveedores aproximadamente) son Colombianos y el 9\% (14 proveedores aproximadamente) son extranjeros, con lo cual podemos concluir que Mercadería justo \& Bueno efectivamente contribuye al crecimiento de producto nacional debido que apoya la comercialización de este.

Del mismo modo se realizó un análisis de los proveedores a nivel nacional departamental de la compañía objeto de estudio en la cual se constata que la mayoría de proveedores pertenecen al departamento de Antioquia (Medellín, Itagüí, Envigado, Bello, Guame, Sabaneta, Rio negro y La Estrella), seguido del departamento de Cundinamarca (Bogotá, Madrid, Mosquera, Fúquene, Cajicá y Cota).Con lo anteriormente mencionado se pude concluir que la centralización de proveedores para Mercadería Justo \& Bueno se encuentra en el departamento de Antioquia y Cundinamarca, apoyando industrias con alto volumen de producción las cuales no cuentan con un alto reconocimiento en el mercado, pero se encuentran en pleno desarrollo empresarial; De 
esta manera podemos concluir que Mercadería Justo \& Bueno apoya el crecimiento del producto nacional. 


\section{PROPUESTAS}

En el año en curso se adelantó un estudio acerca de las acciones sociales y ambientales dentro de un marco RSE de Mercaderías Justo \& Bueno, con la finalidad de generar una propuesta de responsabilidad social a partir del marketing Green.; así mismo con base en el análisis previamente realizado se evaluó aspectos tanto internos como externos hallando falencias y posibles mejoras que contribuyan al crecimiento de la empresa, por lo tanto a continuación se generaran distintas propuestas. Cabe resaltar que la decisión de aplicación de las propuestas y mejoras recae sobre Mercadería Justo \& Bueno:

\section{Página web y redes sociales}

Se evidencia que la página web no es atractiva visualmente al público por lo tanto no contribuye un beneficio a la compañía, en consecuencia proponemos su restructuración en la cual contenga las tonalidades propias de Mercadería Justo \& Bueno haciéndola visualmente atractiva a las personas que visiten el sitio web, además se sugiere que incluya información corporativa de la empresa como:

- Misión, visión, valores e historia a fin de suministrar información de los valores de la compañía.

- Información de los productos orgánicos e inorgánicos que se ofrece con la finalidad que el consumidor tenga el conocimiento de las consecuencias que se acarrea al momento decidir la compra del producto, aplicando un consumo ético.

- Acciones Sociales y ambientales: apoyo al arte Colombiano, ayuda humanitaria en momentos difíciles para el país y alianza con proveedores nacionales. 
- Quejas y reclamos: Establecer un banner en la parte inferior de la página dedicada a proveedores que permita la comunicación directa y rápida con estos. Igualmente un banner destinado a las quejas y reclamos de los clientes el cual contenga: nombre, numero de cedula del cliente, ciudad, dirección del establecimiento en el que ocurrió el inconveniente y el argumento de la queja. Finalizado el proceso de diligenciamiento se informará al cliente el tiempo estipulado de respuesta a la queja o reclamo.

Con esta herramienta se pueden generar indicadores en los cuales se pueda medir la frecuencia de visita a la página, analizar en la satisfacción del cliente y generar un indicador de quejas y reclamos. Con base en esto se podrá construir informes mensualmente que facilitaran la generación de estrategias empresariales que permitirán la satisfacción del cliente y con esto la fidelización de los consumidores.

\section{Producto de la Semana}

Dentro del análisis adelantado se observó cómo se procedía a la destrucción de los productos orgánicos por parte de los colaboradores de la tienda en vista del vencimiento de los mismos cuya causa observada era su baja venta debido a que al desconocimiento de la existencia del producto por parte de los clientes.

Frente a lo anterior, se propone implementar mecanismos de publicidad de dicho producto inorgánico, al colocar un letrero en una pizarra con tiza en el que será informado a los clientes el producto inorgánico de baja venta para época, este se colocara de manera estratégica junto a “ la sección de degustación" ( lugar donde colocan al público de manera gratuita la degustación de productos comestible) en dicho letrero será informado el valor y características de "el 
producto de la semana" de tal forma que se aborda la falencia de falla de información a través de esta estrategia de promoción siendo esta una estrategia de captación al cliente y la decisión ética del consumo.

Del producto de la semana, también se pondrá en conocimiento a los clientes por medio de redes sociales con hashtag \#productodelasemana, en la página web de la empresa, flyers y la implementación de una pizarra en los puntos de venta de todas las ciudades, en la cual se pueda diligenciar por escrito el producto de la semana este insumo será de acuerdo a las necesidades de la regional del país en un lapso de tiempo (una semana), con el propósito de posicionar el producto y el consumo de este en el mercado.

\section{Marketing Sensorial (de acuerdo a las recomendaciones solicitadas por parte de Camilo}

\section{Martínez)}

Debido a la necesidad de captar y fidelizar clientes sugerimos implementar estrategias sensoriales a los puntos de venta tales como:

- Auditivo: Adaptar música suave tradicional (bambuco, corridos, boleros, cumbia, porros, pasillos, guabinas, joropo, etc.), es decir melodías autóctonas de Colombia.

- Visual: Organizar los productos en recipientes autóctonos de la región como por ejemplo: huacales, canastos, etc., característicos de las tiendas de antaño ya que permiten un mejor aspecto visual, con lo cual permite mejorar la percepción del orden se los insumos que se ofrece.

- Olfato: Recomendar un aroma que represente a la mercadería en lo sensorial. 
Implementar un aroma para causar una experiencia sensorial en el consumidor, cuya fragancia le recuerde a Mercadería Justo \& Bueno, debido a que este olor es característico en el campo y en las tiendas de la época antigua.

Todos los aspectos nombrados anteriormente se proponen con la finalidad de generar una experiencia en el consumidor, logrando recordación en el cliente. Además aprovechando este marketing sensorial se podría incentivar al consumo de productos que no contaminen al medio ambiente o perjudique al ser humano ello con la finalidad de integral el marketing Green con el marketing sensorial.

\section{Pauta publicitaria en periódicos populares}

En consecuencia de la necesidad de generar estrategias publicitarias que vayan acorde con la razón social de la empresa y su tradicionalismo, se propone realizar una pauta publicitaria en periódicos populares como por ejemplo ADN y Polímetro con el objetivo de dar a conocer información de los productos a los consumidores, las acciones ambientales y sociales que realicen, la promoción del producto de la semana y de los nuevos procesos o productos verdes, de esta manera se implementa un marketing Green que contribuya a la imagen de la empresa incrementando su reconocimiento en el mercado.

Esta pauta se adquiere fácilmente y no suma un gasto significativo para la empresa ya que según las tarifas del diario El Gráfico del grupo empresarial Polímetro el costo de la pauta publicitaria del tamaño de un cuarto de página par es de $\$ 1^{\prime} 516.064$, aunque se tiene que implementar un gasto 


\section{Activaciones BTL}

Con la finalidad de captar más clientes y así mismo ocasionar un top of main en los consumidores se plantea realizar activaciones $\mathrm{BTL}^{7}$ previo a un estudio de mercado en zonas concurridas de la zona geográfica. Se sugiere realizar inauguraciones a nuevos establecimientos en los que se genere un ambiente familiar, hogareño y tradicional por medio de la integración de juegos tradicionales de Colombia (tejo, rana, billar) acompañado de música tradicional de la región. De la misma manera se sugiere realizar en el cumpleaños de la empresa actividades que involucren al cliente y promociones de productos con baja rotación, empleando productos nacionales.

\footnotetext{
${ }^{7}$ Activación BTL: "Son acciones de Marketing Directo, Patrocinios, Relaciones Publicas, Activaciones, Producto Placement, y varias medios no convencionales que se dan en los sitios de compra y consumo."Fuente especificada no válida.
} 


\section{RECOMENCIONES:}

\section{Capacitación a los colaboradores}

Se propone a Mercadería Justo \& bueno fortalecer y controlar el proceso de capacitación en planeación estratégica, lo cual comprende misión, visión, valores, acciones que realiza la empresa (sociales, ambientales, publicitarias, corporativas) debido a que según el estudio realizado en la presente investigación se evidencia una carencia en los temas anteriormente mencionados, en consecuencia de esto los colaboradores se alinearán a los objetivos corporativos de la empresa y así mismo se incrementara el sentido de pertenecía que algunos manifestaron.

Complementando lo anterior se recomienda la implementar la publicación física en cada uno de sus almacenes, con la finalidad que los colaboradores afiancen más los valores de la compañía a la cual se encuentran laborando.

Por último, se sugiere la implementación de educación ambiental para generar una cultura ciudadana que concientice al buen manejo de los recursos y los colaboradores sepan por qué y el para qué de las acciones ambientales abordando con esta actuación un nivel de implementación de marketing Green.

\section{Agotados}

Según el análisis realizado la comunicación entre líderes y subalternos no es efectiva debido a que se manifestó la inconformidad en este aspecto, por esta razón se recomienda inculcar al orientador un grado de compromiso, lealtad, trabajo y comunicación de la tienda en las cuales se encuentra como responsable para lograr una sinergia entre el almacén y el centro de distribución, lo anteriormente mencionado se argumenta debido a que los productos se agotan rápidamente y 
no son suplidos rápidamente lo que ocasiona pérdida de clientes y mala imagen ya que los clientes perciben que los productos no se encuentran en las tiendas.

Así mismo se recomienda establecer un formato en el que los colaboradores coloquen en conocimiento a la sede administrativa las consideraciones o recomendaciones que consideran relevantes y así halla pleno conocimiento delas falencias de la tienda y quien sea la sede administrativa quien defina el nivel de importancia para abordar la queja y no una visión subjetiva del supervisor de la tienda.

Por último se recomienda establecer un indicador de productos de alta rotación, para determinar las fechas de estos pedidos a los proveedores, con la finalidad que los insumos más rotados no se agoten en un breve periodo de tiempo en los almacenes y cause pérdida de clientes.

\section{Tratamiento de residuos orgánicos}

Realizar una alianza con empresas que brinden alternativas orgánicas y botánicas utilizando la estrategia de compostaje la cual según(InfoAgro, 2016)la define como "el proceso biológico aeróbico mediante, el cual los microorganismos actúan sobre la materia rápidamente biodegradable (Restos de cosecha, excrementos y residuos urbanos) permitiendo obtener el compost, abono excelente para la agricultura". Puesto que el estudio realizado arrojo una falencia en la destrucción de los residuos orgánicos que se encontraban en mal estado o vencidos.

Lo anteriormente expuesto se enlaza con la temática de marketing Green en el momento que a través del mecanismo de compostaje se reducen aquellos residuos orgánicos que iban a la basura para reutilizarlos como abono para la tierra, de tal forma que beneficia el medio ambiente, en el 
que se da una alianza estratégica entre empresas para mitigar el impacto ambiental con la debida manipulación de los residuos inorgánicos.

\section{Productos Verdes}

Incrementar la comercialización de productos verdes para influir en la decisión de compra del consumidor generando una concientización positiva de los recursos hacia el cuidado del medio ambiente, esta implementación puede llevarse a cabo desde el embalaje hasta el proceso del producto ofrecido a la sociedad empleando así estrategias de marketing Green.

\section{Seguridad}

En cuanto a seguridad se recomienda que de acuerdo a la ubicación geográfica de la tienda que corresponda a zonas donde los índices de hurto son altos o se evidencia que hala una alta frecuencia de este tipo de actividades delictivas, se solicite la colaboración de la policía nacional a fin de que se genere un acompañamiento por parte de los policías de la zona, a fin de brindar seguridad a los colaboradores y clientes de la tienda. 


\section{CONCLUSIONES}

El presente trabajo tuvo como objetivo la generación de propuestas empresariales de responsabilidad social enfocadas en marketing Green de la empresa Mercadería Justo \& Bueno con el fin de beneficiar a la empresa y a la sociedad.

\section{Conclusiones Objetivo 1}

Se puede concluir que Mercaderías Justo \& Bueno adelanta pocas acciones sociales ${ }^{8}$ toda vez que las supuestas actuaciones adelantadas por el almacén de orden social (de acuerdo a lo manifestado por los colaboradores), eran dadas a cambio de un beneficio económico como se observó con los descuentos en el impuesto de renta por vincular estudiantes SENA, al igual que la estipulación de precios bajos en cuyo valor se encontraba inmersa la ganancia de la empresa.

No obstante lo anterior, la empresa si adelanto como acción social la donación de productos a las personas damnificadas de la avalancha surtida en Mocoa.

En cuanto a las acciones ambientales se identificó la venta de las bolsas de basura en cumplimiento a la resolución 668 de 2016 emitida por el ministerio de medio ambiente y desarrollo sostenible.

El almacén adelanta de manera errada la manipulación de residuos orgánicos e inorgánicos al momento de no darles un tratamiento previo a los mismos sino simplemente, una vez se cumpla

\footnotetext{
${ }^{8}$ Acción social que puede "ser vista como colaboración, ayuda voluntaria y un comportamiento socialmente responsable, es por esto que la acción social se considera una de las iniciativas de las políticas de Responsabilidad Social Empresarial por lo que no necesariamente se utilice en todas las empresas, que una empresa desarrolle acciones sociales no implica que la misma sea socialmente responsable"(Marrugo, 2013)
} 
la fecha de expiración del producto proceden arrojarlo a la basura. Con ello se puede establecer en este sentido dicha acción es debido a el desconocimiento del tratamiento adecuado de los residuos.

Conclusiones Objetivo 2

Según la revisión literaria podemos concluir que la responsabilidad social empresarial son aquellas acciones sociales y ambientales que realiza una organización para beneficiar a la sociedad y al grupo de interesados la cual va más allá del cumplimiento legal para la construcción de un bien común ya anteriormente definido. La RSE contiene distintas perspectivas, las cuales se clasifican:

1. Cumplimento: Se caracteriza por la aplicación de la normatividad según lo establecido en cada país.

2. Mercadeo: La RSE alineada junto con la publicidad puede aumentar el posicionamiento de marca, reconocimiento y generar una ventaja competitiva en el mercado, cuya acción se denomina como marketing Green.

3. Corporativo: Este enfoque comprende no solo actividades netamente empresariales, sino que involucra responsabilidad social gubernamental.

4. Ético: Se caracteriza por la realización de acciones sociales o ambientales sin un interés retributivo debido a que se fundamenta en contribuir positivamente a la sociedad.

5. Ambiental: Este enfoque contiene las acciones empresariales en pro del bienestar del medio ambiente y contribuir a la conservación de los recursos para las futuras generaciones. 
6. Stakeholders: Se caracteriza por incluir grupos de interés como inversionistas, proveedores, clientes, trabajadores y el gobierno, por lo tanto, realiza acciones que no afecten el bienestar de los interesados con el fin de lograr una cooperación mutua reflejada en la sociedad.

\section{Conclusiones Objetivo 3}

Por lo tanto, se establece una serie de propuestas y recomendaciones enfocadas a marketing Green con la finalidad de contribuir al crecimiento de la empresa en aspectos internos (capacitaciones, agotados) y externos (publicidad y mercadeo).

Las acciones sociales y ambientales con las distintas percepciones de responsabilidad social empresarial no se encuentran plasmadas dentro de un marketing Green debido a que las acciones investigadas no posee una relación directa con esta temática, tal como se observó en los productos ofertados por parte de mercadería Justo \& Bueno en el que, en la mayoría de ellos no poseen un embalaje que contribuya al medio ambiente.

Se puede concluir que se hace necesaria la implementación de propuestas y recomendaciones debido a que se observan falencias en materia de acciones sociales y ambientales.

Dentro del marco ambiental con un enfoque de Marketing Green se destaca:

- La implementación del "producto de la semana" (promoción de productos de baja rotación a través de redes sociales y publicidad visual a través de un letrero en la zona de degustación).

- Implementar mecanismos de mejor manipulación de residuos orgánicos e inorgánicos a fin de evitar que los mismos sean depositados en la basura sin un tratamiento. 
- Promoción de productos verdes que implica generar información al consumidor acerca de los insumos que va adquirir, determinando si es una contribución medioambiental o un daño para sí mismo y la sociedad, lo cual implicaría oportunidades de mercado para la tienda.

Dentro del marco social se destaca el brindar mejores condiciones de seguridad a los colaboradores de la tienda debido a que en el lugar no se brinda seguridad privada, motivo por el cual se recomienda apoyarse en la policía nacional para brindar garantías de seguridad a empleados y clientes, a fin de materializar un actuar dentro del marco de responsabilidad social empresarial.

En cuanto a la pregunta problema que se planteó en la investigación, se puede establecer que mercadería Justo \& Bueno realiza acciones en su mayoría dentro del cumplimiento de un marco legal tales como: la contratación laboral sin discriminación, practicantes del SENA y la venta de bolsas, si bien es cierto es implícita una actuación social no se considera que esta corresponda a un nivel de responsabilidad social bajo el entendido que esta figura se implementa con el fin de adelantar buenas obras en beneficio de la sociedad sin mediar una orden legal. Así por ejemplo se identificó como una única acción con responsabilidad social fue las donaciones a los damnificados del desastre de Mocoa

De la misma forma se puede concluir que basado en la revisión literaria realizada en la presente investigación, la Responsabilidad social empresarial no se limita al mero cumplimiento de la normatividad legal, pues se encuentra implícita el avance empresarial partiendo de la importancia de los stakeholders sin dejar atrás la importancia de la conservación ambiental y la sostenibilidad de generaciones futuras, ahora bien al momento de materializar dicho concepto a 
la investigación realizada, en Mercadería Justo \&Bueno, sus colaboradores tienen una percepción de RSE basada en acciones sociales y ambientales en el que tienen un concepto errado de la responsabilidad social empresarial pues ellos enuncian acciones como: precios bajos, vinculación SENA, etc. aspectos que bajo el concepto enunciado anteriormente no corresponden a una RSE debido a que estas actividades en nuestro concepto no genera la mitigación ambiental ni la sostenibilidad de generaciones futuras, ya que dichos aspectos de una parte implican el cumplimiento de una acción legal y de otra por el modelo implementado de marcas blancas ya el precio establecido implica una ganancia para la empresa.

\section{Conclusión Hipótesis}

Se observó cómo acción ambiental en un marco RS la clasificación de los residuos orgánicos como es al momento de separar el cartón y el plástico; en materia social se observó donativos a los damnificados; acciones que en su conjunto no generan oportunidades de mercado en consecuencia se hace necesario implementar propuestas y recomendaciones para el mejoramiento del almacén objeto de investigación, al igual que el beneficio de la sociedad dentro de un marco de RS, es decir ambas partes tanto el intermediario como el cliente se verían beneficiados.

En consecuencia a lo anterior se puede concluir que para mercadería Justo \&Bueno se generaría oportunidades de mercado al momento de implementar las propuestas de Marketing Green ya enunciados en el presente ítem de conclusiones, bajo un concepto de acción ambiental.

Mercadería Justo \& Bueno no implementa estrategias de marketing Green en sus productos, esta premisa se basa en que los productos de marcas blancas que son etiquetados con el nombre 
de la misma empresa, dentro de su empaque no brindan información necesaria al consumidor, pues no establece sus beneficios o contraindicaciones que afecten al comprador y al medio ambiente, por lo tanto Justo \& Bueno pierde una ventaja competitiva en posicionamiento de marca, imagen y reconocimiento ya que en muchas ocasiones este decide su compra porque la marca o producto ayuden a la mitigación del impacto medioambiental (Iguarin\& Cavazos, 2015).

Por lo tanto no se hace un aporte real al medio ambiente ni se da una aplicación de la ética del consumo (Cortina, Por una ética de Consumo- la ciudadanía del consumidor en un mundo global, 2002) 
CRONOGRAMA

\begin{tabular}{|c|c|c|c|c|c|c|c|c|c|c|c|c|c|c|c|c|c|c|c|c|}
\hline \multirow{2}{*}{$\begin{array}{l}\text { ACTIVIDADES } \\
\text { / TIEMPO } \\
\end{array}$} & \multicolumn{4}{|c|}{ MARZO } & \multicolumn{4}{|c|}{ ABRIL } & \multicolumn{4}{|c|}{ MAYO } & \multicolumn{4}{|c|}{ JUNIO } & \multicolumn{3}{|c|}{ JULIO } & \multirow[t]{2}{*}{ RESPONSABLE } \\
\hline & 1 & 2 & 3 & 4 & 1 & 2 & 3 & 4 & 1 & 2 & 3 & 4 & 1 & 2 & $\mathbf{3}$ & 4 & 1 & 2 & 3 & \\
\hline $\begin{array}{l}\text { Selección del } \\
\text { tema de } \\
\text { investigación }\end{array}$ & & & & & & & & & & & & & & & & & & & & $\begin{array}{c}\text { María Alejandra } \\
\text { Acevedo. } \\
\text { Mayerly } \\
\text { Guataquira }\end{array}$ \\
\hline $\begin{array}{c}\text { Delimitación del } \\
\text { tema }\end{array}$ & & & & & & & & & & & & & & & & & & & & $\begin{array}{c}\text { Maria Alejandra } \\
\text { Acevedo. } \\
\text { Mayerly } \\
\text { Guataquira }\end{array}$ \\
\hline $\begin{array}{l}\text { Definición de } \\
\text { herramientas de } \\
\text { Investigación }\end{array}$ & & & & & & & & & & & & & & & & & & & & $\begin{array}{c}\text { Maria Alejandra } \\
\text { Acevedo. } \\
\text { Mayerly } \\
\text { Guataquira } \\
\end{array}$ \\
\hline $\begin{array}{l}\text { REVISION } \\
\text { LITERARIA }\end{array}$ & & & & & & & & & & & & & & & & & & & & \\
\hline
\end{tabular}




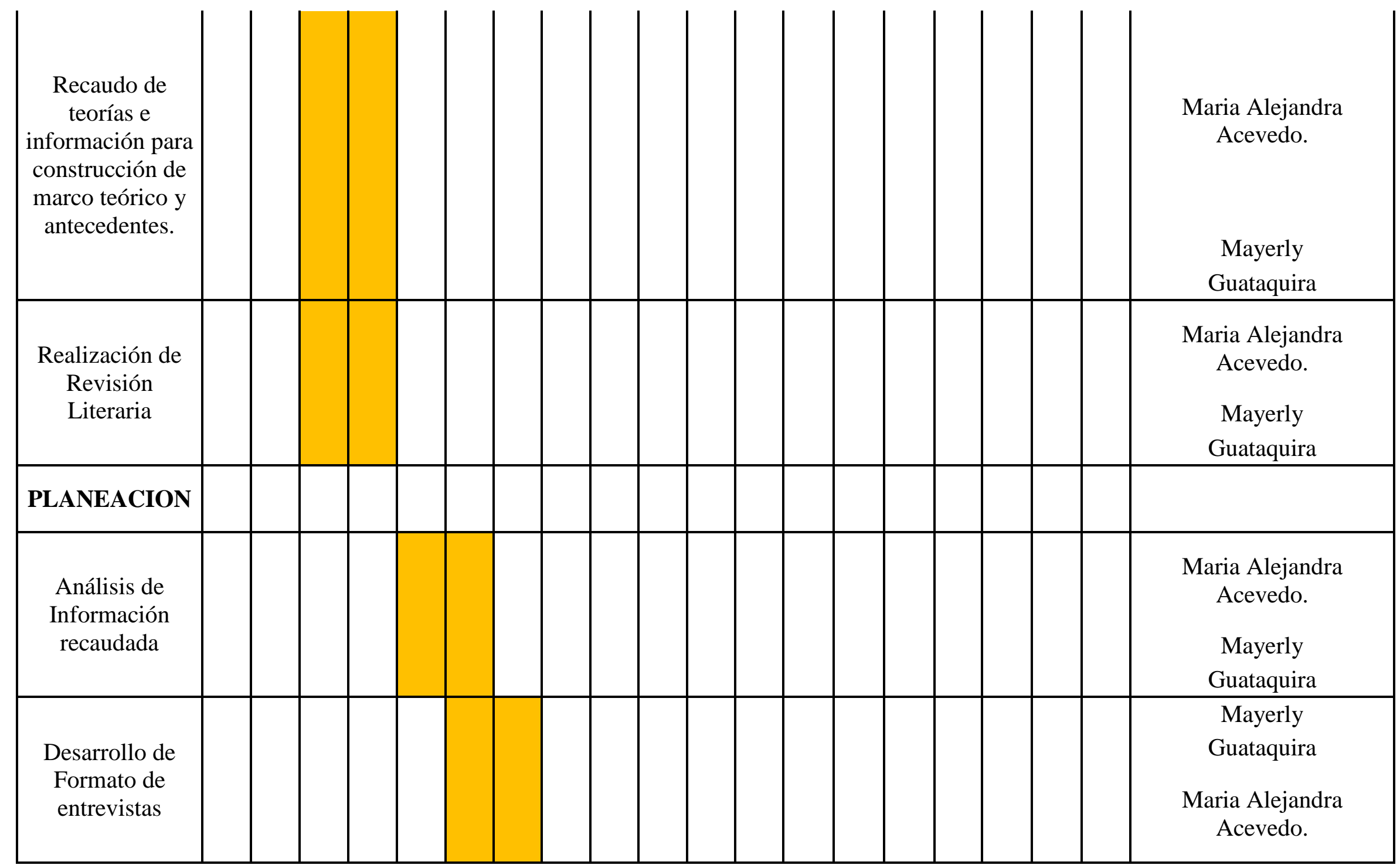




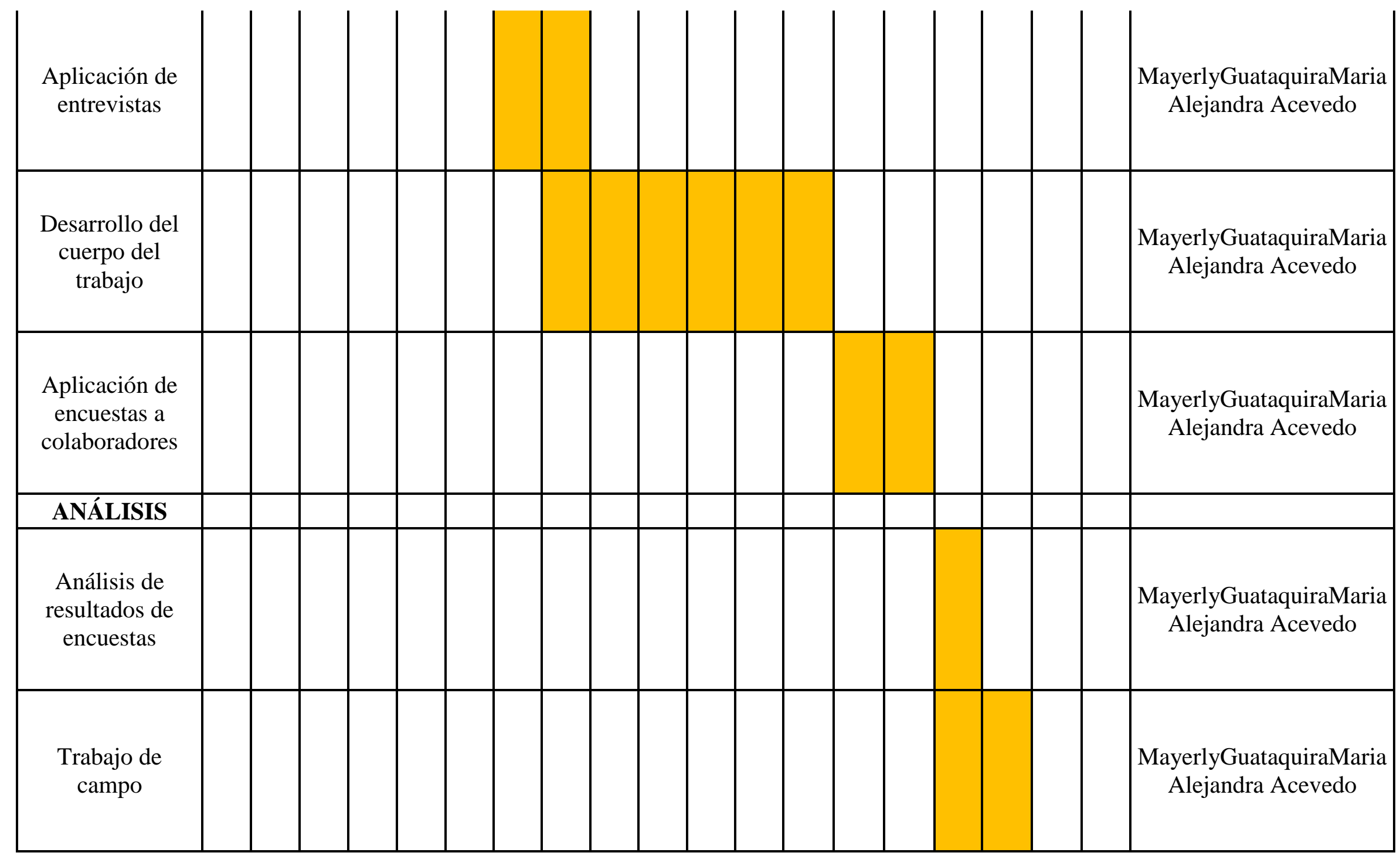




\begin{tabular}{|c|l|l|l|l|l|l|l|l|l|l|l|l|l|l|l|l|}
$\begin{array}{c}\text { Finalización del } \\
\text { trabajo del } \\
\text { trabajo } \\
\text { Entrega del } \\
\text { trabajo }\end{array}$ \\
\hline
\end{tabular}




\section{REFERENCIAS BIBLIOGRÀFICAS}

Abrisketa , J., \& Perez , K. (2006). Diccionario de acción humanitario y coperación al desarrollo. Obtenido de Diccionario de acción humanitario y coperación al desarrollo: http://www.dicc.hegoa.ehu.es/listar/mostrar/1

Maslow, A. (1943). Una teoría sobre la motivación humana

Argandoña, A. (Julio de 2011). El Bien Común (IESE). Obtenido de El Bien Común (IESE): http://www.iese.edu/research/pdfs/di-0937.pdf

Avendaño, W. (2013). Responsabilidad social (RS) y responsabilidad social corporativa (RSC): Una perspectiva para las empresas . Revista lasallista de investigación , 163.

Batalla comercial entre D1 y Justo \&Bueno.(2016). RevstaDinero.

Bloomstrom, D. (1975). Business and Society: Enviroment and responsability. New York: McGraw-Hill.

Bowen, H. R. (1953). Social responsabilitis of the businessman. New York: Harper.

Cabildo , M., Claramunt, R., Cornago, M., Ecolastico , C., Esteban, S., Farrán, M., ... Sanz, D. (2008). Reciclado y tramaiento de residuos . Madrid : Universidad Nacional de eduacación a distancia .

Canales, C. (2006). Matodologias de la Investigaciòn Social. En C. Canales, Metodologias de la Investigaciòn Social (pág. 208). Santiago: LOM Ediciones.

Cancino del Castillo, C., \& Morales Parragué, M. (2008). Reponsabilidad social empresarial. Economía y negocios , 58.

Carroll, A. (1979). The three-dimensional conceptual model of corporate performance. Academy of management review, 505. 
Cerda, H. (2006). Metodologia de Investigacion para administracion y economía. México: Pearson.

Cruz, I. (2013). Importancia de la calidad del servicio al cliente, un pilar en la gestión empresarial . El buzón de Pacioli, 7.

Davis, K. (1960). Can business afford to ignore corporate social responsibilites. California maangement review, 76.

De la cuesta , M. (2013). Responsabilidad social de la empresa, medición desarrollo en España . Boletín ICE económico, 19.

Development, W. C. (1987). Report of the World Commissionon Environment and Development:. Oxford University .

Donaldson, T., \& Duntee, T. (1994). Toward a Unified Conseption of business ethics:Integrative Social Contracts Theory. Academy of Management Review, 284.

Guias empresariales en las delagaciones federales de la seguridad de la secretaria de economía y centros regionales de competitividad. (s.f.). Obtenido de Guias empresariales en las delagaciones federales de la seguridad de la secretaria de economía y centros regionales de competitividad:

http://segob.guanajuato.gob.mx/sil/docs/capacitacion/guiasEmpresariales/GuiaCalidad.pdf

Española, D. d. (2017). Diccionario de la Real Acádemia Española. Obtenido de http://dle.rae.es/srv/search?m=30\&w=sostenible 
Gonçalves, A. y. (2012). El concepto de consumo socialmente responsable y su medición. Una revisión de la literatura. Estudios Gerenciales, 287-300.

Hallama, M., Montllò, M., Rofas Tudela, S., \&Ciutat Vendrell, G. (Septiembre de 2011). El Fenòmeno del Greenwashig y su impacto sobre los consumidores propuesta metodològca para su evaluaciòn. Aposta.

Iguarin, A., \& Cavazos, J. (2015). Mezcla del marketing verde, una perspectiva teórica. Green marketing mix: A theoreticalperspective.

InfoAgro. (2016). Obtenido de InfoAgro:

http://www.lombricultura.cl/lombricultura.cl/userfiles/file/Compostaje.pdf

Justo y bueno: La nueva apuesta de los creadores de D1. (2016). RevistaDinero.

Jones, T. (1980). Corporate social responsibility revisited redefined. California management review, 59.

Kenneth, A. (1971). The concept Corporate Strategy.Homewood: Dow Jones-Irwin.

Marquardt, B. (2006). Histori de la sostenibilidad, un concepro medio ambiental en la historia de Euopa central. Revista cientifica de Ameica Latina y del Caribe , 172-190.

Marquardt, B. (2006). Historia de la sostenibilidad. Un concepto medioambiental en la historia de europaCentral.Bogotà.

Murgado, E. (2016). El consumo socialmente responsable: Un enfoque conceptual. Revista de antropologiainstrumental.

Pereira, Z. (2011). Los diseños de mètodo mixto en la investigaciòn en educaciòn: Una experiencia concreta .Educare, 20.

Pizzinatto, N. K., \&Giuliani, C. A. (2015). Universida metodista de Piracicaba Mezcla del marketing verde, una perspectiva teórica. Universidade Metodista de Piracicaba.

Porter, M. E. (2007). VENTAJA COMPETITIVA. COMPETITIVESTRATEGY, 2.

Quintero, L. F. (2010). El punto de venta, el sector Retail y el comportamiento del consumidor. MKT Mundo del marketing, 12. 
Freeman, R. (1983). Stockholders and stakeholders: A new perspective on corporate governance . California management, 35 .

Hernández, Sampiere R. H. (2010). Metodología de la Investigación. Peru: Mc Graw Hill. Litz, R. (1996). A resource bsed view of the socially responsible firm: Stakeholder interdependenc, ethical awareness and issue responsiveness as strategic assets. Journal of business ethics, 1355.

Marquardt, B. (2006). Marqua Historia de la sostenibilidad. Un concepto medioambiental en la historia de Europa Central.Zürich, Schulthes.

Murray, K., \& Montanari, J. (1986). Strategiz management of the socially responsible firm: Integrating management and marketing theory. Academy of management review, 815.

Nebel, B. J., \& Wright, R. T. (1999). Ecología y desarrollo sostenible. Mexico : Prentice Hall .

Orgánicos de colombia. (2017). Obtenido de Orgánicos de colombia: http://www.organicosdecolombia.com/content/compostaje

Porter, M., \& Kramer, M. (2006). Strategy \& Society: The The Link Between Competitive Advantage and Corporate Social Responsibility. Harvad Business, 4.

Rivera, H., \&Malaver, M. (2011). La organizaciòn: Los stakeholdres y la responsabilidad social. .Bogotà: Universidad del Rosario.

Roberts, J. A. (1993). Sex differences in socially responsible comnsumers .psychological Reports , 449-460.

Silva, H. (2012). Panòrama de negocio minorista en colombia. Pensamiento y gestiòn.

Trujillo, M. M., \& Bedolla, R. (2006). Responsabilidad ambiental como estrategia para la perdurabilidad empresarial. Uiversidad y empresa, 308. 
Wilcox, D. (2005). Responsabilidad social empresarias (RSE) la nueva exigencia global.

Wood, D. (2002). Business Citizenship: From Individuals to Organizations. Business Ethics Quarterly, 59-94.

\section{ANEXO 1}

\section{ANEXOS}

\section{Entrevista semiestructurada:}

La entrevista realizada el día viernes 5 de mayo del 2017 en la ciudad de Bogotá, siendo las 13 horas, se realizó la entrevista al señor Camilo Ramírez quien es en cargado de 1 orientación de operaciones en la empresa mercaderías justo y bueno.

1. ¿Qué entiende por responsabilidad social?

Son acciones que contribuyen a la sociedad, en mercaderías justo y bueno ofrecemos calidad y buenos precios en nuestros productos para satisfacer las necesidades básicas.

2. ¿Su empresatiene acciones en el marco social y ambiental? ¿Cuáles?

$\mathrm{Si}$, en el marco social tenemos dos enfoques interno y externo: a nivel interno se inculca a los trabajadores valores como el respeto, colaboración, justicia autogestión e integridad, para así generar estos mismos valores en la sociedad. En materia de inclusión la empresa da oportunidad laboral a practicantes del Sena, se contrata personas de todas las edades siempre cuando tengan el perfil y las ganas. Promovemos y apoyamos el arte colombiano ya que nuestras instalaciones se encuentran dibujadas por artistas colombianos populares. Ademan ayudamos enviando alimentos de necesidad básica para las personas afectadas por la tragedia en Mocoa. 
No apoyamos ninguna fundación.

3. Si la empresa provee gratuitamente bolsas plásticas a los consumidores. ¿Cree que contribuye al medio ambiente? ¿Por qué?

No, antes del decreto las bolsas plásticas se vendían, este formato surgió debido a que las familias colombianas estaban acostumbradas a recibir los productos empacados en una bolsa plástica gratuita, nosotros vendemos bolsas reutilizables en material de lona y otros. La bolsa es considerada como un producto. Considero que esta acción permite mitigar las emisiones de plástico.

4. ¿Ustedes manejan alguna separación de residuos? ¿tienen algún tipo de tratamiento?

$\mathrm{Si}$, contamos con un proceso de almacenamiento y clasificación de cartón y plástico que posteriormente se vende a una empresa recicladora.

5. ¿Cómo es el proceso de reciclaje? ¿Se reutiliza?

Si, se almacena adecuadamente el cartón y el plástico en las tiendas y los conductores lo trasladan al CEDI, no se reciclan las cajas se organizan y se venden a una empresa de reciclaje se convierten en canastas y estibas, las cajas en buen estado se dejan para los clientes.

6. ¿La compañía realiza algún tipo de publicidad con las acciones que gestiona?

No, somos una empresa muy reservada, no nos gusta está en oídos y boca de todo el mundo, ni que nos vean como grandes y benevolentes. Nos interesa colaborar para que las familias colombianas tengan calidad de vida, nunca nos verán en una valla publicitaria, ni televisión, somos muy discretos y reservados.

7. ¿La empresa adquiere y comercializa productos amigables con el ambiente?

No tengo conocimiento. 
8. ¿Cree que las acciones que contribuyen a la protección del medio ambiente generan una

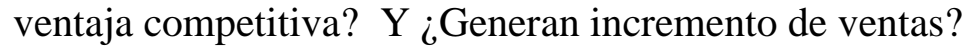

No porque es realmente un proceso interno, mitigan gastos, se puede cubrir algún improvisto, no daría valor agregado, es algo que sabemos que debemos cuidar responsablemente, darle buen manejo, no posiciona, no porque la venta no la hace el reciclaje ellos toman la decisión.

9. ¿Sus proveedores cuentan con certificados de responsabilidad social o ambiental? .Si es así, ¿porque lo eligen?

No tengo conocimiento.

10. ¿Qué porcentaje de sus proveedores son colombianos? ¿Son pymes? De ser así ¿cree que está ayudando al desarrollo económico del país?

Nuestros proveedores son Colombianos $85 \%$ y $15 \%$ extranjeros, no son pymes porque para manejar la frecuencia y el volumen debe ser una empresa muy bien estructura y con una capacidad de producción alta.

Si ayuda al desarrollo económico del país potencializando industrias que han venido declinando, negociamos con proveedores de manera justa logrando que las empresas crezcan con nosotros.

11. ¿Qué cree que le llama la atención a sus clientes para ir a comprar en la empresa que labora?¿Ese posicionamiento porque cree a que se debe? (porque la gente prefiere comprar acá)

Considero que el cliente prefiere comprar en nuestros almacenes debido a nuestra cordialidad en el servicio, excelente atención, consintiendo al cliente. Exponemos la mercancía de manera que se perciba agradable, no botada en el piso ni desarreglada 
haciendo que el cliente se sienta a gusto en una tienda de barrio grande y organizado ofreciendo gran portafolio de producto a un precio económico.

12. ¿Cree que al usar el marketing Green puede tener una diferencia competitiva con otras instituciones? ¿Porque? ¿Por qué no lo harían?

El marketing Green puede generar una diferencia competitiva en el mercado y un impacto positivo a la empresa ayudando al medio ambiente.

13. ¿Cuál es el proceso que manejan con los alimentos que se dañan o se pasan de fecha? Si en poco inventario se vota a la basura pero si es masivo se lleva a una empresa donde se destruye masivamente.

\section{Anexo 2}

Mercaderia J \& B @justoybueno.25 feb.

(717i) Lamentamos su mala experiencia en nuestro establecimiento, trataremos de mejorar el trato de nuestro personal, muy buen dia amiga *

Yeimi Katerin@YeimiKaterin

Si sellama @justoybueno no entiendo por qué su atención es cero buena?

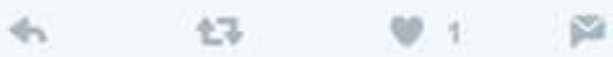

Mercaderia J \& B @justoybueno.25 teb.

Lamentamos su mala experiencia en nuestros establecimientos y tomaremos en cuenta su sugerencia buen dia amiga

Galatea @daligala20

@justoybueno hoy en el local de la caracas con 8 sur, las empleadas muy... no hicieron respetar la fila y muuuuy leeentas 


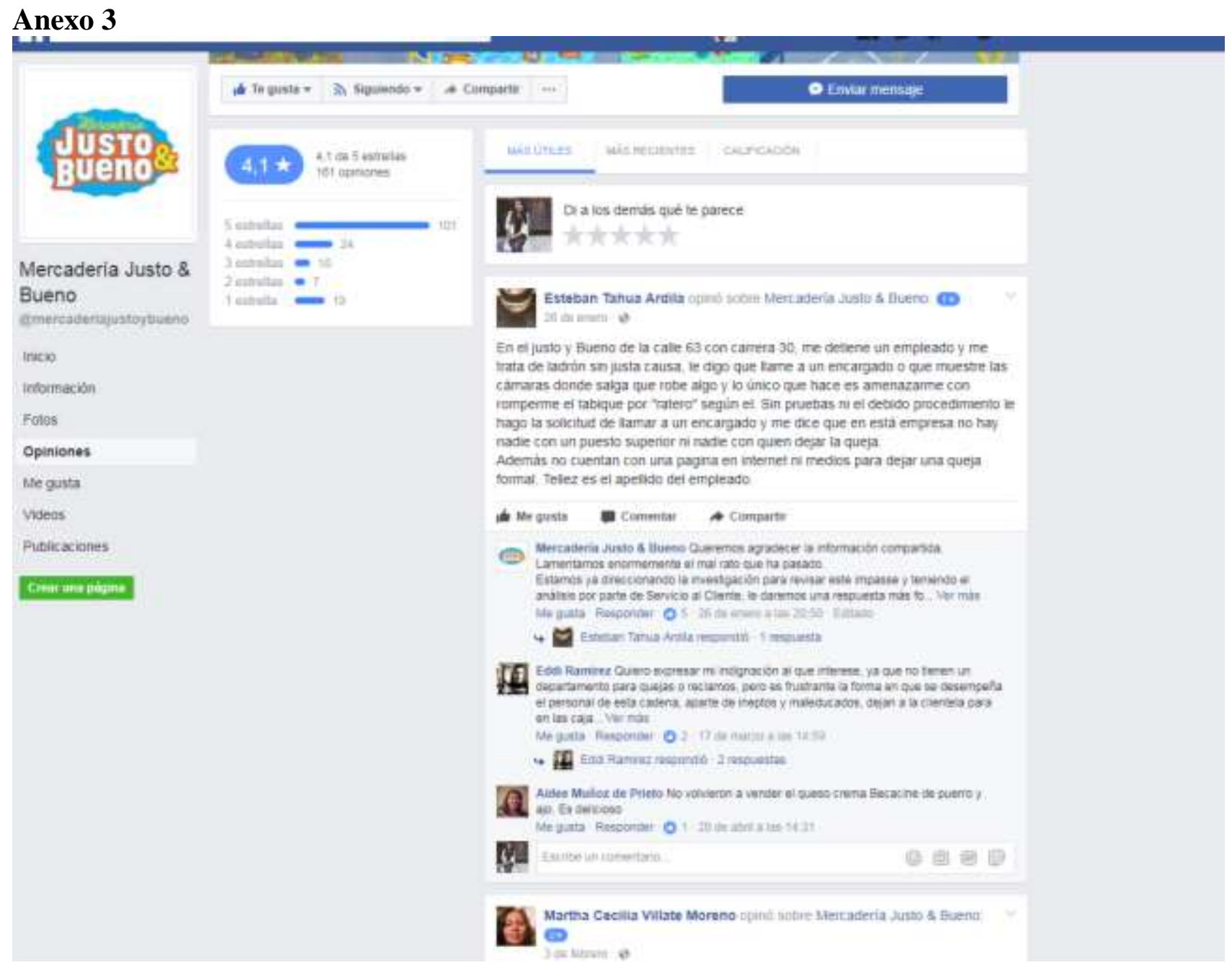

\section{Anexo 4}




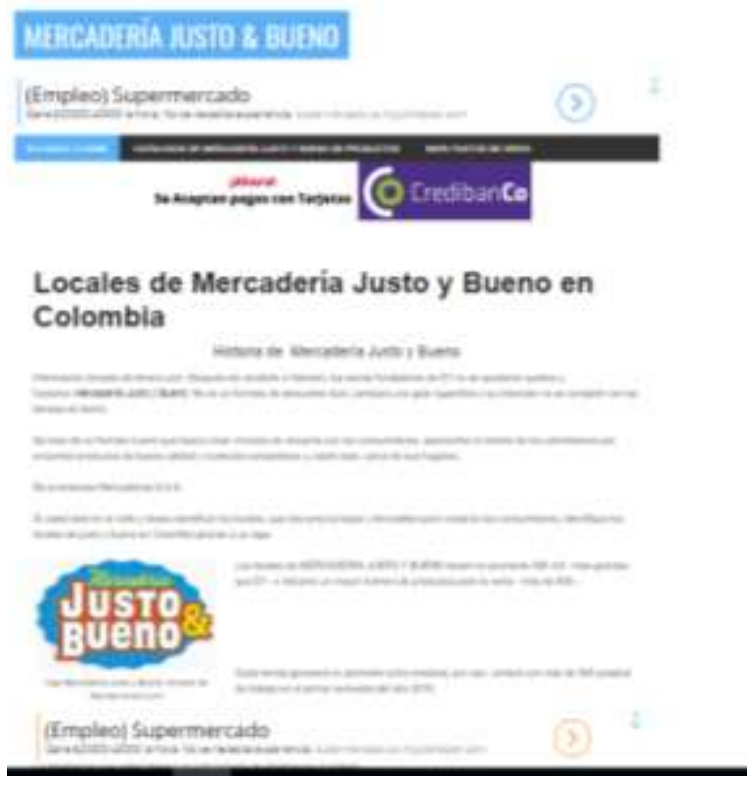

Anexo 5: Encuestas 